\title{
Girls on the Move: Adolescent Girls \& Migration in the Developing World
}

Miriam Temin

Mark R. Montgomery

Population Council

Sarah Engebretsen

Population Council

Kathryn M. Barker

Population Council

Follow this and additional works at: https://knowledgecommons.popcouncil.org/departments_sbsr-pgy

Part of the Demography, Population, and Ecology Commons, Family, Life Course, and Society Commons, Gender and Sexuality Commons, International Public Health Commons, Medicine and Health Commons, and the Migration Studies Commons How does access to this work benefit you? Let us know!

\section{Recommended Citation}

Temin, Miriam, Mark R. Montgomery, Sarah Engebretsen, and Kathryn M. Barker. 2013. "Girls on the Move: Adolescent Girls \& Migration in the Developing World," A Girls Count Report on Adolescent Girls. New York: Population Council. 


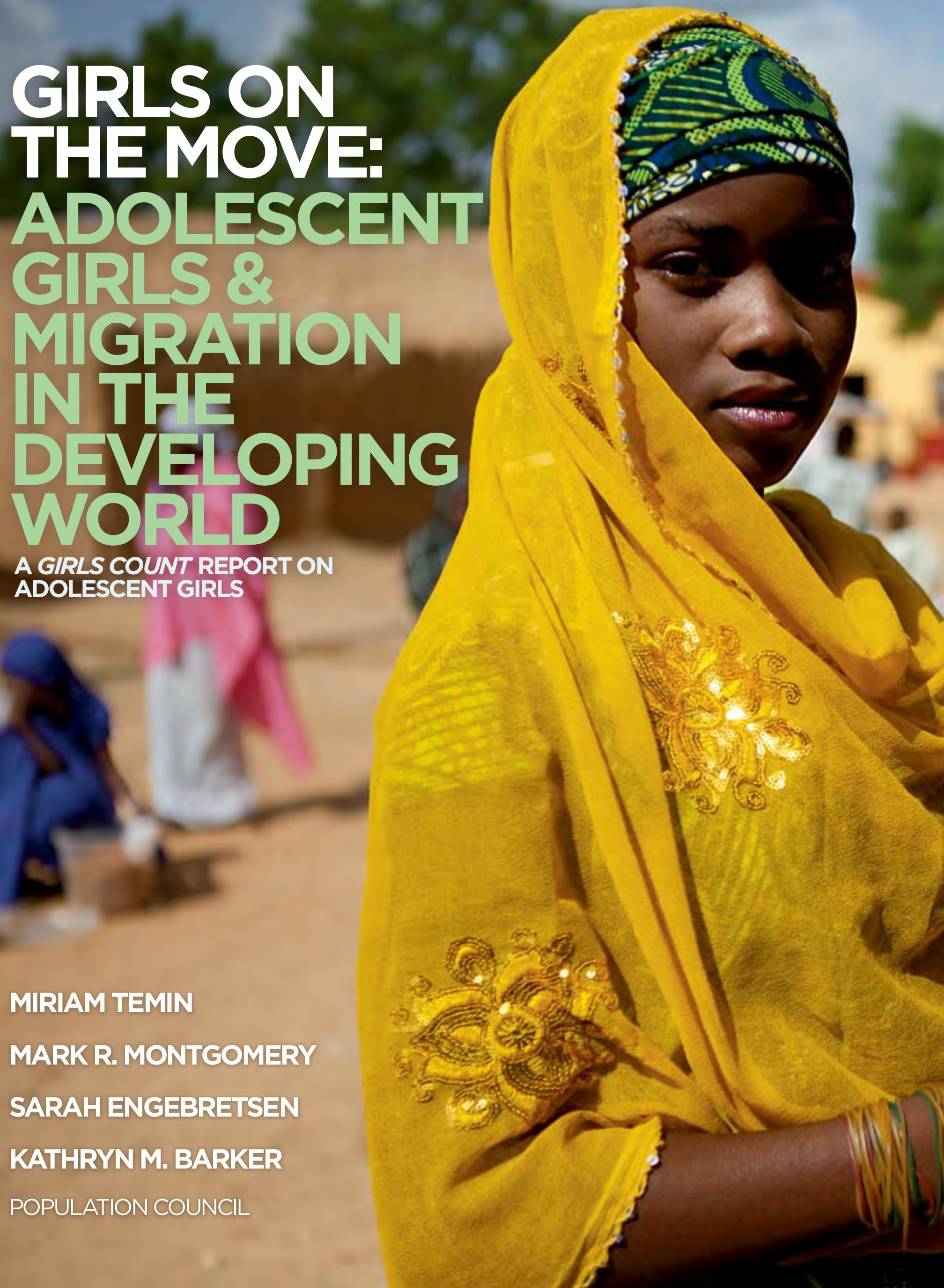


Photo Credit: Jane Hahn 
GIRLS ON

THE MOVE:

ADOLESCENT

GIRL \&

MIGRATION

NTHE

DEVELOPING

WORLD 


\section{TAKEACTION FOR MIGRANT GIRLS}

1

\section{Prepare and equip girls before they migrate}

Migrant girls need education, good health, and life skills before they move so they can navigate risks and opportunities in their new lives. Maximize girls' chances of successful migration by preparing them with education, knowledge of their human rights, life skills training, and information about what they will encounter during the journey and on arrival. Equip girls with personal documentation to facilitate their access to health and education services and social benefits in their new communities.

2

\section{Ensure a smooth landing: a safe place to stay and social connections}

A girl's new environment can be risky without the guarantee of a safe place to stay and a reliable connection to trusted individuals on arrival. Migrant girls may be immediately absorbed into an urban environment when they arrive, essentially hidden from programs and excluded from support services. Develop mechanisms to identify migrant girls immediately on arrival before they fall into harm's way. Then connect them to safe places to stay and services and networks to help them thrivesuch as migrant groups, employee networks, and neighborhood associations of the poor.
3

\section{Create time and space for migrant girls to meet friends and mentors}

Migration disrupts girls' social networks, leaving some isolated and vulnerable to abuse and exploitation. Rebuilding migrant girls' social networks is essential to their safety and well-being. Reduce isolation by connecting migrant girls to dedicated safe spaces ${ }^{1}$ where they can meet peers and female mentors, expand their social networks, and receive training, education, and referrals to health and other services.

\footnotetext{
4

Make services "migrant girl friendly"

A significant number of people in selected groups of international interest - including children in exploitative and dangerous employment, the urban poor, and of course migrants - are migrant adolescent girls. But services for these groups rarely recognize the unique needs of adolescent girls nor of migrants. Adapting initiatives to integrate migrant girls is a relatively low-cost way to improve their access to opportunities. Design programs with age, gender, and migration status in mind so migrant girls can benefit from child protection, education, and economic empowerment activities.
}

1 "Safe space" programs provide girls with a place where provide girls with a place where
they are respected and where they can develop life and livelihood skills, form friendships and gain peer support, enjoy freedom of expression and movement, and receive support and education from trusted female mentors (Brady 2003). 
5

\section{Test innovative ways to prepare migrant girls for success}

Programs for migrant girls tend to be reactive rather than proactive, treating problems instead of preventing them. Implement new programs and research on innovative approaches to develop girls' assets early in the migration process. Test innovative solutions such as providing migrant girls with mobile technology and mobile savings products pre-departure, safe spaces, and personal documentation immediately on arrival, and social capital building opportunities such as connections to associations of the urban poor. Enable migrant girls to shape program design based on their own experiences. Evidence from these experiments will enable policymakers and programmers to determine how best to make girls' migration a positive experience.

\section{6}

\section{Focus on the most isolated and vulnerable}

The most socially isolated and vulnerable sub-groups of migrant adolescent girls-domestic workers, child brides, and sexually exploited girls - are at greatest risk of experiencing the worst outcomes, including trafficking, exploitation, and abuse. Advocacy efforts must consider all migrant adolescent girls, but they should not overlook these girls' unique needs. Carefully design girl-only approaches to reach the most vulnerable, socially isolated migrant girls using targeted, purposeful recruitment to locate and engage them.

\section{7}

\section{Fill critical evidence gaps}

Important evidence gaps on adolescent girls'

migration remain. Research is needed that reflects the diversity of migrant girls' experiences. This would enable funders, policymakers, and programmers to more strategically allocate limited resources. USAID's Demographic and Health Surveys and UNICEF's Multiple Indicator Cluster Surveys should be designed to illuminate age- and sex-disaggregated internal migration rates. Analyze data from these surveys to reveal which sub-populations of migrant girls face the greatest risk, what those risks are, and where the most vulnerable migrant girls reside in the greatest numbers. Conduct longitudinal surveys on the implications of migration for girls' social, economic, and health outcomes. Conduct qualitative research to better understand migrant girls' experiences and needs. Evaluate programs to assess their impact by migrant age, origin, and timing of move, as well as the sustainability of benefits over time.

8

\section{Increase migrant girls' visibility through policy and advocacy}

Migrant adolescent girls barely feature in advocacy and policies on migration, working children, girls' education, and child marriage. The failure to consider migrant girls in policy and advocacy prevents them from maximizing the benefits of migration. Make migrant girls more visible in policy efforts by taking account of age, gender, and migration status. Ensure special consideration of adolescent girls in migration policy and advocacy: reducing barriers to internal population movement, facilitating remittance flows, and improving living conditions in migrant arrival areas. 



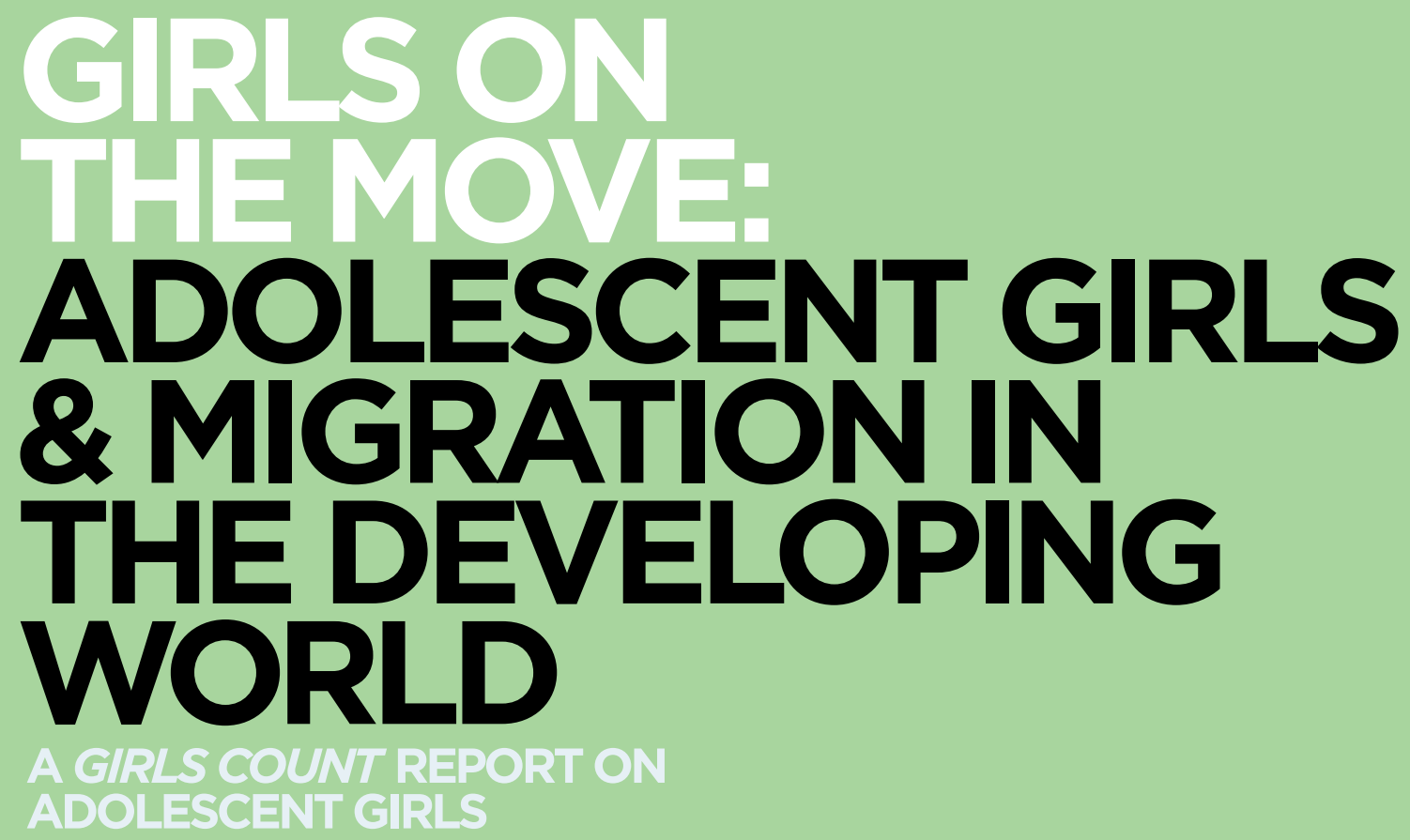

MIRIAM TEMIN

MARK R. MONTGOMERY

SARAH ENGEBRETSEN

KATHRYN M. BARKER

\section{(2) Population Council}

The Population Council confronts critical health and development issues-from stopping the spread of HIV to improving reproductive health and ensuring that young people lead full and productive lives. Through biomedical, social science, and public health research in 50 countries, we work with our partners to deliver solutions that lead to more effective policies, programs, and technologies that improve lives around the world. Established in 1952 and headquartered in New York, the Council is a nongovernmental, nonprofit organization governed by an international board of trustees.

www.popcouncil.org

(C) 2013 The Population Council, Inc.
Support for this project was generously provided by the Nike Foundation and the United Nations Foundation. The views expressed are those of the authors and should not be attributed to the funders of this report. 

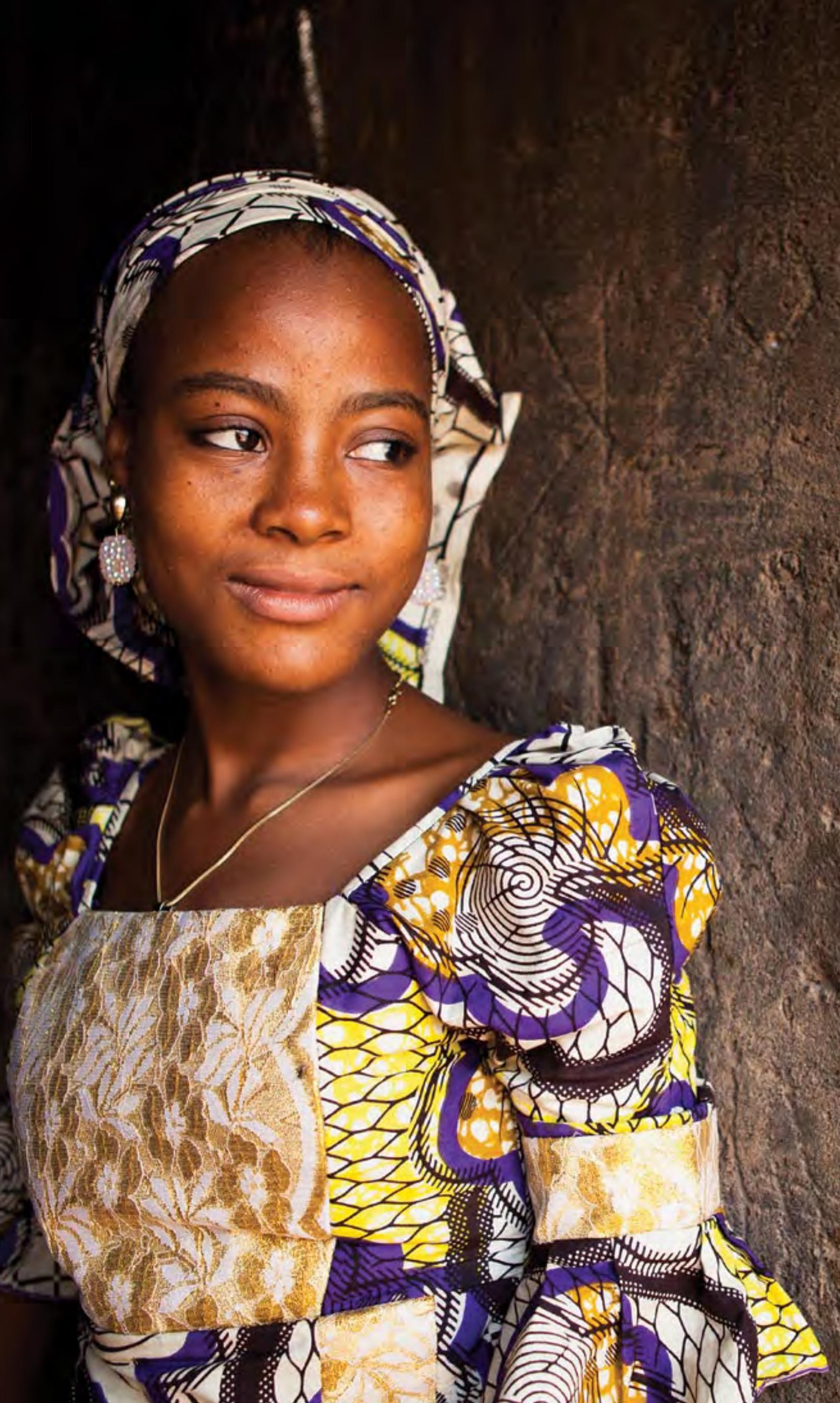


\section{CONTENTS}

Take Action for Migrant Girls

ix Boxes and Figures

x Foreword

xiii Acknowledgements

xv Preface

1 Executive Summary

4 Chapter 1: Migrant Adolescent Girls: An Important Population in a Rapidly Urbanizing World

7 Assessing the Demographic Evidence

12 A Highly Diverse Group

15 Putting Migrant Girls on the Map

18

Chapter 2: Deciding to Leave: Why Girls Migrate

20 Why Girls Migrate

25 Making the Decision to Move

28 Adolescent Girls' Migration and Marriage

32 Chapter 3: On the Move: Migrant Girls in Transit

34 The Characteristics of Migrant Girls' Journeys

37 Most Girls Don't Move Alone, Creating Opportunity and Risk

39 Worst-Case Scenarios

42 Chapter 4: Settling in: Connections and Social Capital

44 Migrant Girls on Arrival

45 Neighborhoods and Social Networks
48 Community Groups to Facilitate Connections

50 Chapter 5: Migrant Girls' Employment

52 Migrant Labor: Limited Options and the "Three Ds"

54 Common Jobs for Migrant Girls

62 Chapter 6: Migrant Girls' Human Capital: Education and Health

64 More Educated than Rural Girls, Less Educated than Urban Girls

67 Migrant Girls' Health

74 Chapter 7: The State of Migrant Adolescent Girl Programming

76 Current Programming Approaches

85 Programs and Policies Often Miss the Mark

86 Chapter 8: Accelerating Action for Girls on the Move

88 The Time Is Right

88 Multiple Actors for Migrant Girls

89 The Action Agenda for Migrant Adolescent Girls

94 Key Definitions

95 Annex

96 References

110 Advisors

114 About the Authors 


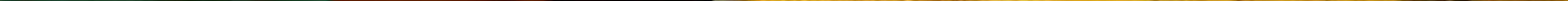




\section{BOXES \& FIGURES}

\section{BOXES}

8

1.1 What about migrant adolescent boys?

$27 \quad 2.1$ Fostering

$36 \quad 3.1$ The value of personal documentation

$38 \quad 3.2$ Social networks ease the way for Haitian girls in the Dominican Republic

474.1 Mobile phones connect and empower migrant girls

4.2 Indigenous identities and adjustment

$54 \quad 5.1$ Remittances

$55 \quad 5.2$ Getting ahead in Bangladesh's garment industry

$57 \quad 5.3$ Recognizing child domestic workers diversity

$58 \quad 5.4$ Sexual exploitation

676.1 For child domestic workers in Peru, benefits of non-formal education extend beyond academics

$79 \quad 7.1$ A targeted approach to build social capital: The Biruh Tesfa (Bright Future) program in urban Ethiopia

82 7.2 The power of collective worker action

\section{FIGURES}

$8 \quad 1.1$ Among urban adolescents, more girls than boys are migrants

$9 \quad 1.2$ More boys than girls migrate for education or employment

$11 \quad 1.3$ Substantial percentages of urban adolescent girls are recent in-migrants
$13 \quad 1.4$ The majority of urban in-migrant girls come not from rural villages but from other cities and towns

$14 \quad 1.5$ The diversity of adolescent girls requires a variety of responses

$17 \quad 1.6$ Programs may need to work in different neighborhoods to reach disadvantaged girls and migrant girls

232.1 School and work opportunities are primary reasons for adolescent migration

292.2 The majority of urban in-migrant girls move before marriage

$37 \quad 3.1$ Adolescent girls may encounter barriers to safe and successful migration, most of which are preventable

393.2 As girls age, they begin to migrate farther away

$46 \quad 4.1$ Migrant girls are significantly less likely to be related to the head of household than their non-migrant peers

$66 \quad 6.1$ Urban migrant girls have higher levels of education than rural non-migrant girls

$66 \quad 6.2$ Urban migrant girls have lower levels of education than urban non-migrant girls

686.3 Local urban girls are more likely than migrants to be enrolled in school

$77 \quad 7.1$ Promising approaches for migrant girls at each stage of their journey

$81 \quad 7.2$ Protective assets for successful migration 


\section{FOREWORD}

If you want to change the world, invest in an adolescent girl.

An adolescent girl stands at the doorway of adulthood. In that moment, much is decided. If she stays in school, remains healthy, and gains real skills, she will marry later, have fewer and healthier children, and earn an income that she'll invest back into her family.

But if she follows the path laid down by poverty, she'll leave school and enter marriage. As a girl mother, an unskilled worker, and an uneducated citizen, she'll miss out on the opportunity to reach her full human potential. And each individual tragedy, multiplied by millions of girls, will contribute to a much larger downward spiral for her nation.

Investing in girls is the right thing to do on moral, ethical, and human rights grounds. Perhaps no other segment of society globally faces as much exploitation and injustice, and we owe girls our support as integral, yet overlooked, members of the human family.

Investing in girls is also the smart thing to do. With over 515 million adolescent girls in the developing world today, the best way to break the cycles of poverty is to keep girls off the path of school dropout, early marriage and early childbirth, and vulnerability to sexual violence and HIV/AIDS. Investments in girls yield large returns: an extra year of primary school boosts girls' eventual wages by 10 to 20 percent, and girls who receive an education marry later, have fewer children, and are less likely to experience violence. Women invest 90 percent of their earnings into their families compared to the 30 percent or 40 percent by men.

Yet today, only a tiny fraction of international aid dollars is spent-and spent effectively-on needs specific to adolescent girls. That underinvestment is the reality the Coalition for Adolescent Girls (www.coalitionforadolescentgirls.org) is trying to change.

The Coalition for Adolescent Girls includes over 40 leading organizations committed to driving new and improving existing programming, policies, and investments that will promote the rights and opportunities of adolescent girls. The Coalition envisions a world where adolescent girls are able to fully realize their rights, navigate challenges, and access opportunities during the transition from childhood to adulthood and beyond. The Coalition is supported by the Nike Foundation and United Nations Foundation.

The Coalition's first step was to uncover adolescent girl-specific data and insights to drive meaningful action. In 2008, Girls Count: A Global Investment and Action Agenda did just that. Authored by Ruth Levine, Cynthia B. Lloyd, Margaret Greene, and Caren Grown, Girls Count laid out the case for investing in girls and outlined actions that policymakers, donors, the private sector, and development professionals can and should take to improve the prospects for girls' well-being in developing countries.

Today, we are pleased that Girls Count has gone into its second printing. More importantly, the authors have continued beyond that groundbreaking work to explore girls' lives further. Together, the results comprise the Girls Count series:

- In New Lessons: The Power of Educating Adolescent Girls, Cynthia B. Lloyd and Juliet Young demonstrate that education for girls during adolescence can be transformative, and they identify a broad array of promising educational approaches which should be evaluated for their impact. 
- In Start with a Girl: A New Agenda for Global Health, Miriam Temin and Ruth Levine describe the positive multiplier effect of including adolescent girls in global health programs and policies - and the risks if they continue to be left out.

- In Girls Speak: A New Voice in Global Development, Margaret Greene, Laura Cardinal, and Eve GoldsteinSiegel reveal that adolescent girls in poverty are acutely aware of the obstacles they face, but are full of ambitious, powerful ideas about how to overcome them.

- Through Girls Discovered: Global Maps of Adolescent Girls, Alyson Warhurst, Eva Molyneux, and Rebecca Jackson at Maplecroft join the ranks of Girls Count authors by using their unique quantitative analysis of girl-specific data to literally put girls on the global map.

- Girls Grow: A Vital Force in Rural Economies offers a critical addition to the Girls Count series by addressing the preponderance of girls who live in rural areas. Catherine Bertini and the Chicago Council on Global Affairs highlight how girls, as the backbone of rural economies, have the powerful potential to be agents of economic and social growth and change in their homes, communities, and nations.

- In Girls on the Move: Adolescent Girls \& Migration in the Developing World, Miriam Temin, Mark R. Montgomery, Sarah Engebretsen, and Kathryn M. Barker illuminate girls' migration to urban areas in pursuit of work, education, and social opportunities unavailable to them in rural areas. Migrant girls who successfully connect to these opportunities can be powerful agents of change, making them an important group warranting greater policy and programmatic attention.

Each report takes us deeper into the lives of adolescent girls and contains an action agenda outlining how the global community can count girls, invest in girls, and advocate for girls. Taken together, the Girls Count series presents a powerful platform for action. Please visit www.coalitionforadolescent girls.org for more information.

The girl effect is the missing and transformative force needed to achieve the Millennium Development Goals, with the unique power to break the intergenerational cycle of poverty. It is about the lives of 515 million adolescent girls, and the millions more lives that are affected by them. Girls do indeed count.

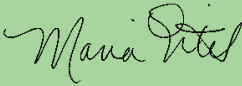

Maria Eitel

President

The Nike Foundation

May 2013
Kaity Buantin Caluin

Kathy Bushkin Calvin

President and CEO

The United Nations

Foundation

May 2013 


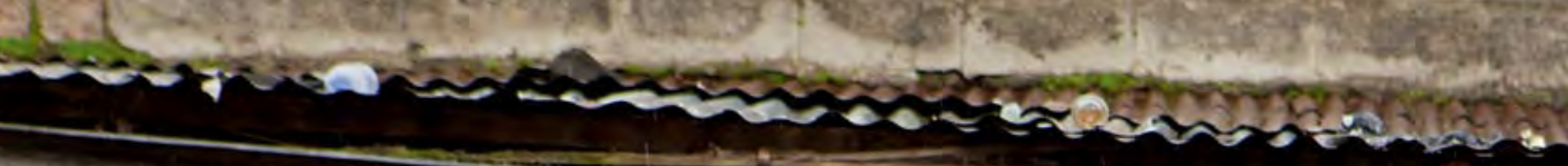

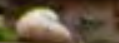

atol

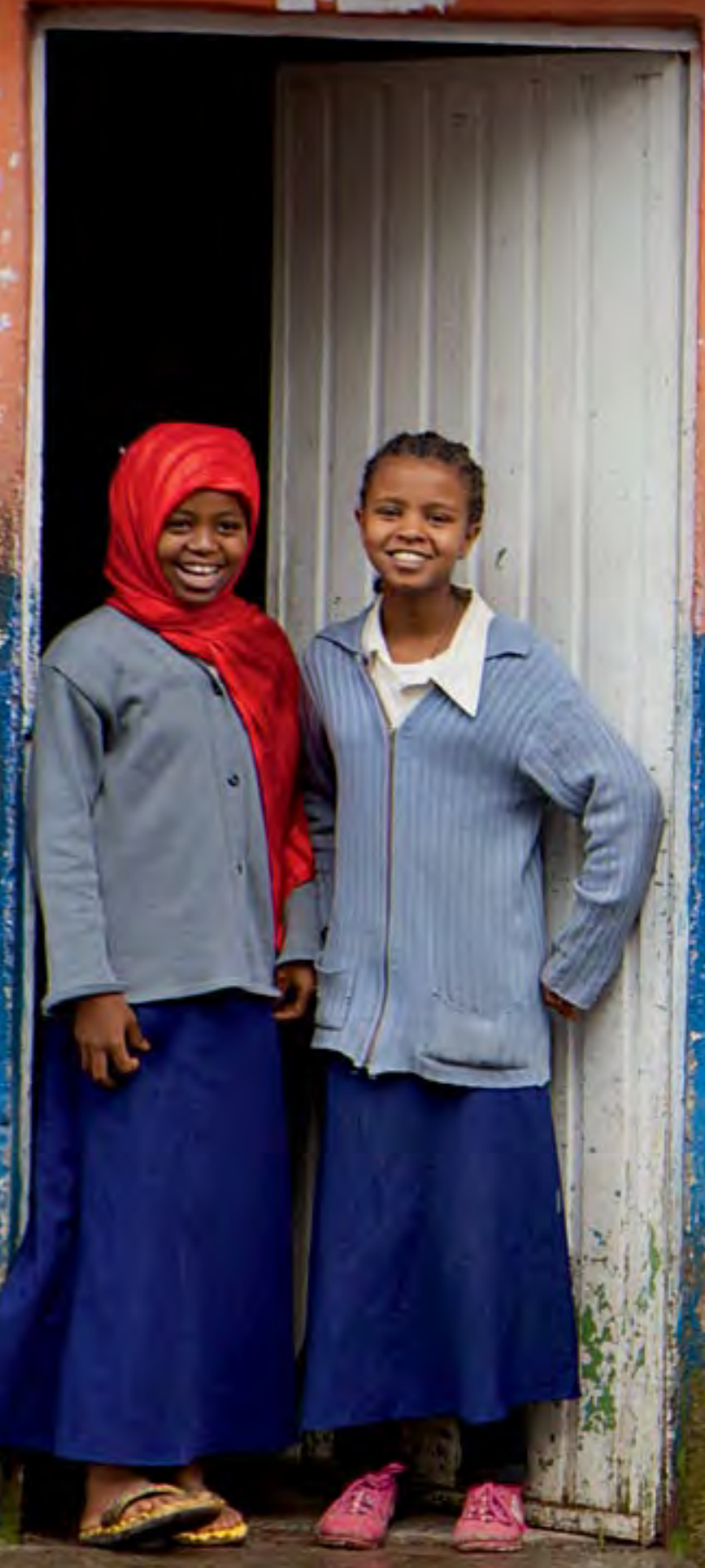

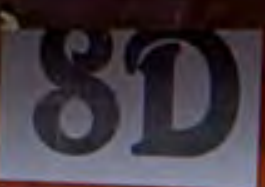

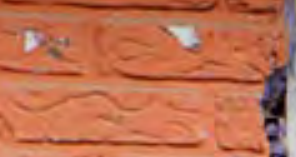

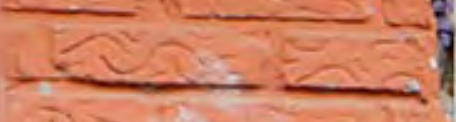

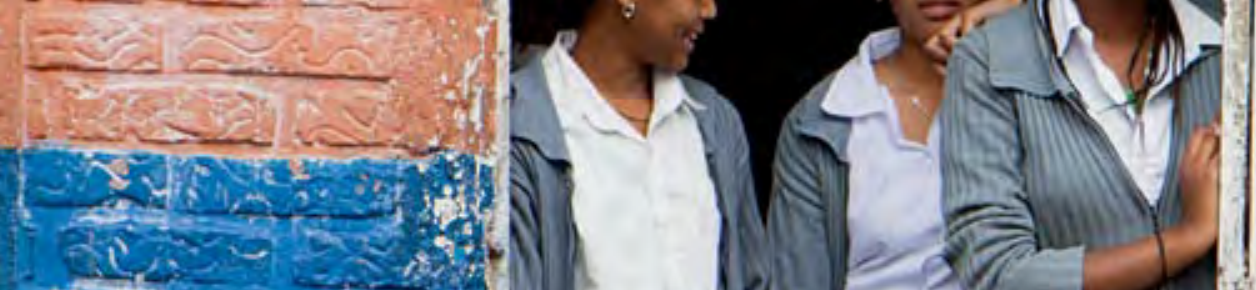

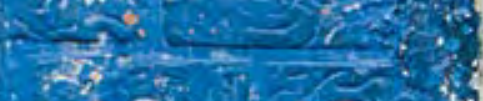

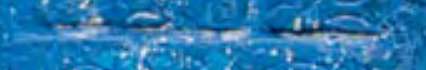

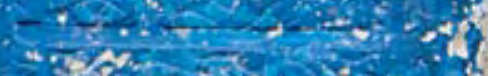

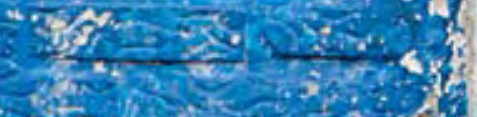

is 30 -

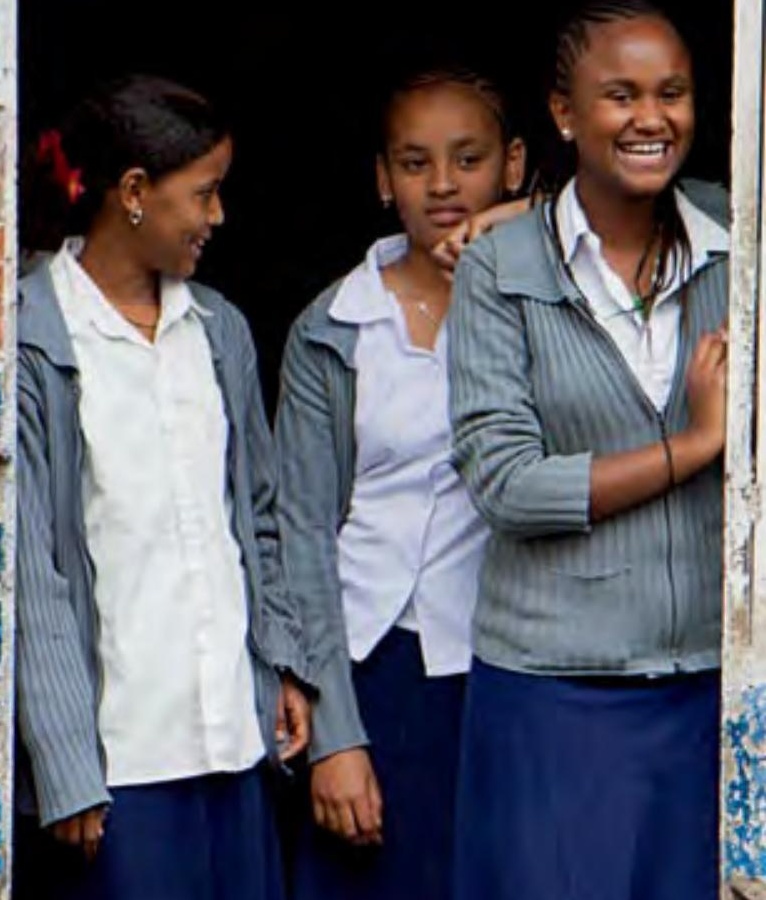

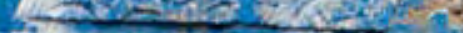

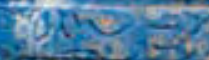

rostos 


\section{ACKNOWLEDGEMENTS}

Girls on the Move benefited from the contributions of many individuals. We are deeply grateful to the members of our expert Advisory Group: Taina Bien-Aimé, Mike Dottridge, Annabel Erulkar, Michael Gibbons, Margaret Greene, Véronique Hertrich, Michele Klein-Solomon, Anju Malhotra, Véronique Mathieu, Ann Whitehead, and Yu Zhu. The Advisors generously shared their time and ideas throughout the report development process. Each member's distinct background, technical expertise, and perspectives were essential to our cross-sectoral examination of migrant adolescent girls.

Particular thanks go to the Commissioned Researchers who provided novel data contributions that enabled us to see more clearly the lives of migrant adolescent girls. They include: Rajib Acharya, Susana Adamo, Siddharth Agarwal, Deborah Balk, Joanna Busza, Satvika Chalasani, Shelley Clark, Cassandra Cotton, Annabel Erulkar, Christophe Guilmoto, Mélanie Jacquemin, Shireen Jejeebhoy, Eleri Jones, Marie Lesclingand, Zhen Liu, Myriam de Loenzien, Richard Mabala, Aracely Martinez, Mandiogou Ndiaye, Allison Petrozziello, Nelly Robin, Slawa Rokicki, Annagrace Rwehumbiza, Marie Stoner, and Francis Zavier. Our deep appreciation also goes to the girls who shared details of their lives for this research. Heartfelt thanks also to Joanna Busza, Annabel Erulkar, Margaret Greene, and Véronique Hertrich, who went beyond their roles as Advisors and Commissioned Researchers to provide additional evidence and comments as the report developed.

We would also like to thank the many researchers and programmers who provided detailed information on aspects of migrant adolescent girls' lives. Without these individuals the report would not be as rich as it is: Dang Anh, Marla Asis, Nipa Bhansali, Michael Bourdillon, Matilda Broni, Julia Broussard, Alejandra Colom, Jean D'Cunha, Jacole Douglas, Adrienne Germain, Lucy Hillier, Sylvia Lopez-Ekra, Brenda
Okumu, Miquel de Paladella, Sok Kim Sroeung, and AKM Ahsan Ullah.

Warm thanks go to colleagues at the Population Council, in particular Judith Bruce and Ann Blanc, who provided specific input to the report and offered critical insights on adolescent girls; Christina Tse, who coordinated all aspects of the design and layout; Gina Duclayan, who provided communications guidance and support; Robert Heidel, who edited the report; Michael Vosika, who provided the graphics; and Olga Tymejczyk, whose language skills allowed us to incorporate literature from Latin America. We are grateful to Cynthia Lloyd for her sage advice and technical review at a formative stage in the report development.

Finally, our deep appreciation goes to the Nike Foundation and the United Nations Foundation for their generous support for this research and their continued energies to improve the lives of adolescent girls around the world. 


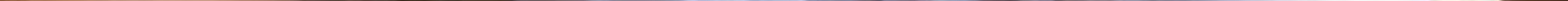




\section{PREFACE}

Migration is transforming our world: by the end of this decade, most developing countries will have more people living in cities than in rural areas. Adolescent girls in developing countries are an overlooked population, but one that is migrating to urban areas in ever greater numbers. Girls are on the move because they lack opportunity in their rural hometowns, and want to work, to learn, and to gain skills and resources. They also move to escape hardship: poverty, war, or early marriage. While migration can carry risks, for many girls moving can unlock opportunity, autonomy, and the chance for prosperity.

Research has shown that to realize the full benefits of migration, girls need support. Before departing, they need a realistic sense of what awaits them at their destinations, to know their rights, and be equipped with marketable skills. They need people along the way and in their destination who can help them find safe places to live and socialize, safe work, and friends. If they do not get this support, girls can fall into risky circumstances.

The world has turned much-needed attention to the dire situation of girls who are trafficked for sex work. But we must also tend to the needs of the vast majority of girls who migrate voluntarily. If these girls arrive at their destinations and settle in safely, their diligence and industriousness can allow them to become productive, contributing members of their community. But without support, girls can find themselves isolated or in circumstances that are dangerous, abusive, or economically exploitative. Preparing girls before they leave, protecting them along the way, and assisting them where they land will help ensure that they thrive. Their success will make greater prosperity possible for their families, communities, and the world.

For decades, the Population Council has been conducting research to shed light on the hidden lives of girls and changing the expectations of policymakers, communities, families, and girls themselves. This report is the first of its kind to examine the social and economic drivers of the internal migration of adolescent girls in developing countries. Using existing evidence as well as research commissioned specifically for this report, our researchers examine the ways in which migration can exacerbate risk, and how it can create opportunity in the lives of adolescent girls.

The authors propose wide-ranging recommendations to help migrant girls become visible, successful, and active community members. Program managers should work to strengthen girls' support networks to combat social isolation. Policymakers need to include adolescent girls in their strategies for improving the lives of all internal migrants. Most importantly, we need to use rigorous research to learn more about the lives and needs of migrant girls and to demonstrate that our policies and programs are working.

Studies by the Population Council and others have shown that when girls are allowed to make choices about their own lives in a supportive environment, they are more likely to go to school, avoid child marriage, avoid unwanted pregnancy, and eventually earn more, which they invest back into their families and communities, helping to break the grip of poverty for all.

Enabling girls' success is our ethical duty. Substantial investments in girls' well-being from governments, donors, and societies will ensure that they get the skills, support, and opportunity to take ownership of their lives and strive for a more promising future. Spanish poet Antonio Machado wrote, "se hace camino al andar," or "you make the way as you go." Girls will make their way, and we must help them build that road as they go.

\section{Peter J. Donaldson}

President, Population Council
Opposite Page Friends Pryanka Garg, 16, and Babalu Garg, 15, read in Dehra Village, Jodhpur District, Rajasthan State. A year ago, Babalu's parents arranged her marriage to a 45 -yearold man who was unemployed and illiterate. With support from a community educator and women's advocate from the local government, Pryanka, and Pryanka's mother, a village health center worker, Babalu's parents agreed to worker, Babalu's parents agreed to attends school. 


\section{EXECUTIVE SUMMARY}

Adolescent girls are on the move. Throughout the developing world, natural disasters, political emergencies, child marriage, and violence force a migration journey many girls do not choose. But for most girls, migration is a choice made in a quest for social and economic advancement. Migration offers adolescent girls the possibility and promise of opportunity. Absent from their parents and the limits of their natal homes, migrant girls can seize new opportunities and fully enjoy their human rights as they enter adulthood. ${ }^{2}$

The ability to navigate a number of critical milestones throughout her journey shapes a migrant girl's success or failure. An unsuccessful transition can have significant consequences. It is those consequences that are portrayed in popular culture: the trafficked Eastern European girl who is sexually exploited; the young Chinese woman hunched over a sewing machine in filthy surroundings; the frightened domestic worker in Central America. These disadvantages are real and deserve attention, but they do not tell the whole story. Girls on the Move brings a fresh image of girls' migration: the uniformed secondary school student in a boarding school in Zimbabwe; the apprentice acquiring tailoring skills in Ghana; and the factory worker in Bangladesh abandoning her traditional role to negotiate higher wages with an employer.

Should a migrant girl successfully navigate her journey, the ability to unlock her potential expands enormously. When she thrives in her new home, a successful migrant girl can be a powerful agent of social and economic change, transforming the prospects of her family and community. She has a unique potential, known as the girl effect, to end poverty for herself and for others.

\section{Where migrant adolescent girls settle matters}

Urbanization, the demographic process through which developing countries are becoming majority urban, is an emerging reality that social and development policies must accommodate. Hence, this report focuses on girls' migration to cities and towns. Girls find a concentration of opportunities in cities: education and health institutions, diverse labor and capital markets, multiple levels of government, and a range of NGOs and community groups. But in cities, migrant girls can also find themselves marginalized, vulnerable, and unable to take advantage of resources that may be within walking distance.

Migration is an essential element in national social and economic growth. Adolescent girls can play an important role in propelling that growth through migration. But to do so, they must be able to connect to urban social networks and institutions that can protect and enhance their well-being.

With a primary focus on internal migration, Girls on the Move presents evidence not only about how and why a girl moves, but ultimately about what factors enable girls to take advantage of new opportunities in employment, education, and health. Building from the evidence, Girls on the Move recommends policies and programs for migrant adolescent girls that take account of their diversity, ensure protection, and cultivate connections, assets, and capital-the main ingredients for migrant girls' success.
The term migrant and other key terms used in this report are defined in Key Definitions. 


\section{Many successful approaches rely on building girls informal assets, including firendship networks and life skills, combined with interventions that link girls to formal assets and institutions, such as identity papers, savings programs, and schools.}

\section{The payoff of unleashing the girl effect}

The current surge of interest in adolescent girls and in urbanization creates an unprecedented opportunity for migrant girls. When a migrant girl's safe passage is assured and she is integrated into her new community, she is positioned to take advantage of resources, institutions, and opportunities unavailable at home, decisively enhancing her life prospects. A successful migrant girl unlocks her potential for personal growth and development, causing a ripple effect with benefits for national economic growth.

Migration can also boost girls' human capital. Adolescent girls who migrate to urban areas have higher education levels than rural non-migrant girls. This is, in part, because they are closer to secondary schools. Migrant adolescent girls doing domestic work in West Africa note the value of skills gained through urban employment, saying this is the only viable strategy for continuing their education. The gains from sustaining adolescent girls' education are well documented for their labor and economic potential and their reduced risk for pregnancy and HIV infection. Benefits also accrue to their future children and families.

In addition to providing human capital, migration can empower adolescent girls economically. Working migrant girls generate savings, which allow them to exercise agency in meeting their basic needs and planning for the future. In addition, many migrant girls describe their strong commitment to fulfilling family responsibilities, caring for aging parents, and paying for siblings' schooling. Rural families are much more likely to receive remittances from internal migrants than from international migrants (Godoy et al. 2012). Across regions, remittances from migrant girls to their natal families are raising the living standards of rural households. 
The collective social impact of migrant girls' increased human capital and their economic empowerment can result in another shift: a change in perception about girls' roles and social position. Many parents report that girls' status in the family increases because of their remittances. This gives girls greater influence over family decisionmaking. Where girls' out-migration is common, this may lead community members to rethink the importance of girls. By distancing girls from their families, independent migration can also loosen the grip of restrictive social control that dictates the terms of many girls' lives following puberty. Migration can lead to new social networks and exposure to different ideas and norms. This can affect marriage practices by reducing parents' and community elders' influence over the timing and choice of a husband. Migrant girls may gain more control over these terms than other girls. Finally, migration can increase girls' autonomy and enable them to retain independence after marriage. This autonomy can lead to fewer child marriages, delayed childbearing, lower fertility rates, and increased schooling for the next generation.

\section{What do migrant girls need?}

The diversity of migrant girls and their experiences necessitates a range of strategies to enable them to secure their human rights and unlock their considerable potential. Broad efforts to expand social service access are priorities for some migrant girls, while targeted interventions such as "safe space" programs are priorities for others. Some approaches will be most effective when targeting migrant girls, while others should focus on all adolescent girls or other disadvantaged population groups rather than migrants alone. Many successful approaches rely on building girls' informal assets, including friendship networks and life skills, combined with interventions that link girls to formal assets and institutions, such as identity papers, savings programs, and schools.
It is essential to design policies and programs with careful input from migrant girls themselves. When they speak in their own voices, many migrant girls in difficult circumstances-ranging from sexual exploitation to low-wage factory work and living on the street-say they prefer what they are doing to the life they left behind. These girls see themselves as taking action to improve their conditions, exercising agency if only to choose between less-than-desirable alternatives.

***

Migrant adolescent girls can be a force for social change. Migration's payoff for girls' human capital, economic status, independence, and social position causes a ripple effect through generations: their families and future children will be better off. And they are role models, motivating younger girls to follow in pursuit of better opportunities.

The barriers to migrant girls' success can be significant: the decision to leave, the journey itself, and establishing stability in a new home present challenges. By outlining motivations, mechanisms, and consequences of migration, Girls on the Move balances a number of perspectives to help policies and programs take account of the mixture of risk and opportunity marking migrant girls' experiences, and concentrate on maximizing the opportunities migration can bring for girls and their families. 


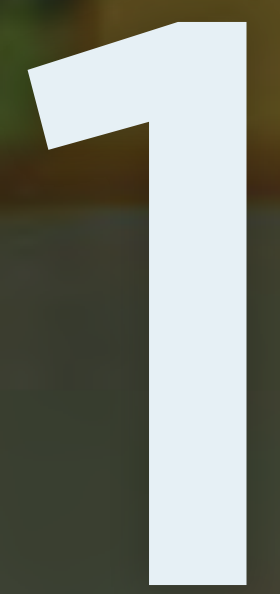

MIGRANT

D. 0

ADOLESCENT

GRLS: AN

IMPORTANT

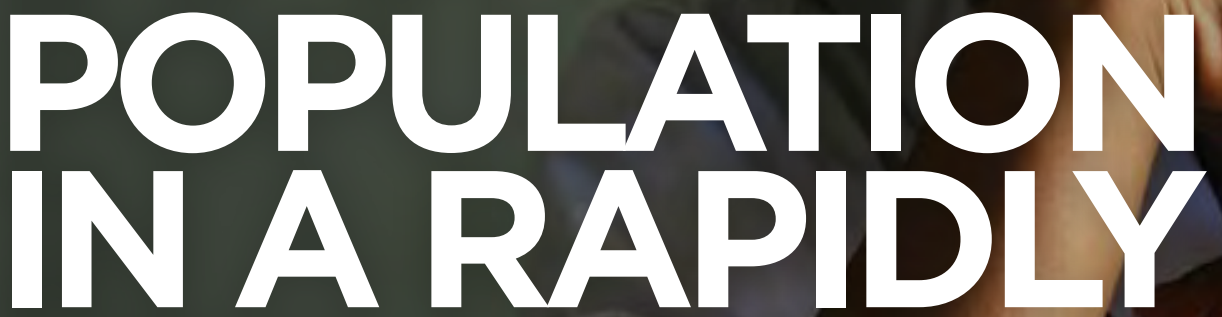

URBANIZIG

WORLD 


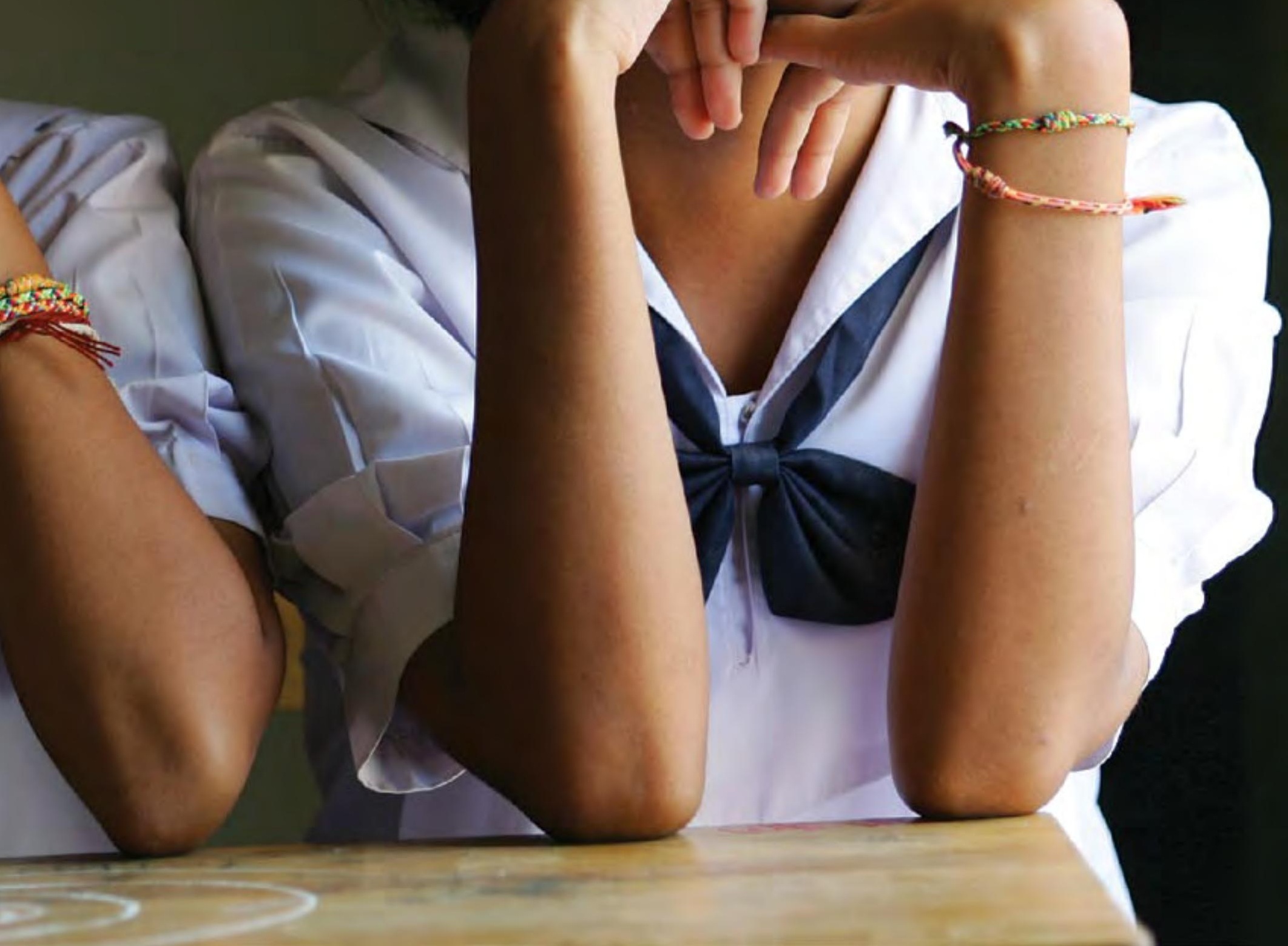




Much as migrant adults do in
this rapidly urbanizing world,
girls move to cities and towns
in search of the educational,
health, social, and labor market
resources that are unavailable in
their original homes. When girls
succeed in connecting to urban
resources, their chances of mar-
rying later, having fewer, healthi-
er, and better-educated children,
and participating more fully in
society increase considerably. In
this way, adolescent girls' migra-
tion to urban areas can have a
transformative effect, benefit-
ing girls as individuals as well as
society at large. For this reason,
migrant adolescent girls in urban
areas of the developing world are
an important population deserv-
ing greater attention.

As with all migrants, a girl who moves is bound to experience social disorientation en route and after arrival. She may encounter unforeseen circumstances and risks as she strives to establish a home and secure education and a livelihood in an unfamiliar environment. Given her age and sex, a migrant girl may be more vulnerable than an adult-or an equally young male-migrant. Indeed, not all girls make the passage safely, and some fail to thrive in their new homes. But as Girls on the Move shows, many migrant girls do make successful transitions. These girls possess the energy and resilience, as well as the social connections, to take full advantage of new opportunities and fulfill their potential.

This chapter outlines the evidence that shapes the arguments in Girls on the Move, highlighting where more research is needed to strengthen the basis for policy and programs. Demographic evidence is limited not only on migrant adolescent girls, but also on migrants in general. The neglect of migration by researchers has led to misconceptions. For example, the migration literature overwhelmingly focuses on rural-to-urban moves, rarely examining the implications of urban-to-urban migration. Yet analysis of demographic surveys conducted for Girls on the Move shows that for adolescent girls and women alike, moves from one urban area to another are already common and are likely to become more so as the developing world continues to urbanize. This new research establishes the numerical importance of urban-origin migration, but it does not shed much light on its social meaning for adolescent girls. Policymakers need information beyond what the demographic data show. To prioritize approaches and target resources, they must know whether adolescent urban-to-urban migrant girls are a distinctly advantaged or disadvantaged group relative to others. This is only one of the many important evidence gaps Girls on the Move identifies as requiring focused qualitative research.

While Girls on the Move is mainly concerned with migration to urban destinations, it considers the social significance of rural-to-rural migration as evidence allows. Rural moves are important for many girls. In rural India, for example, girls who migrate to their husband's village upon marriage can experience profound social isolation in their new homes, much as do Indian girls who migrate to cities for marriage (Santhya, Haberland, and Das 2008). Unfortunately, it is difficult to systematically document migration to rural areas, in part because demographic surveys use vague definitions of rural migration. Circular migration (from rural to urban areas and back), of importance in settings such as West Africa and Southeast Asia, is also poorly measured in surveys and not measured at all in national population censuses.

The first section of this chapter summarizes new quantitative findings on the migration patterns of adolescent girls, based on a study of hundreds of Demographic and Health Surveys (DHS) and population censuses from developing countries. ${ }^{3}$ Although neither censuses nor surveys provide a full picture of migrant girls' lives, both sources are valuable in documenting the scale of migration and in checking preconceptions against the empirical record. The second section places these quantitative findings in the context of the report's broad themes: the wide diversity among migrant adolescent girls; their distinctive advantages and disadvantages relative to non-migrant girls; and the range of policy and 


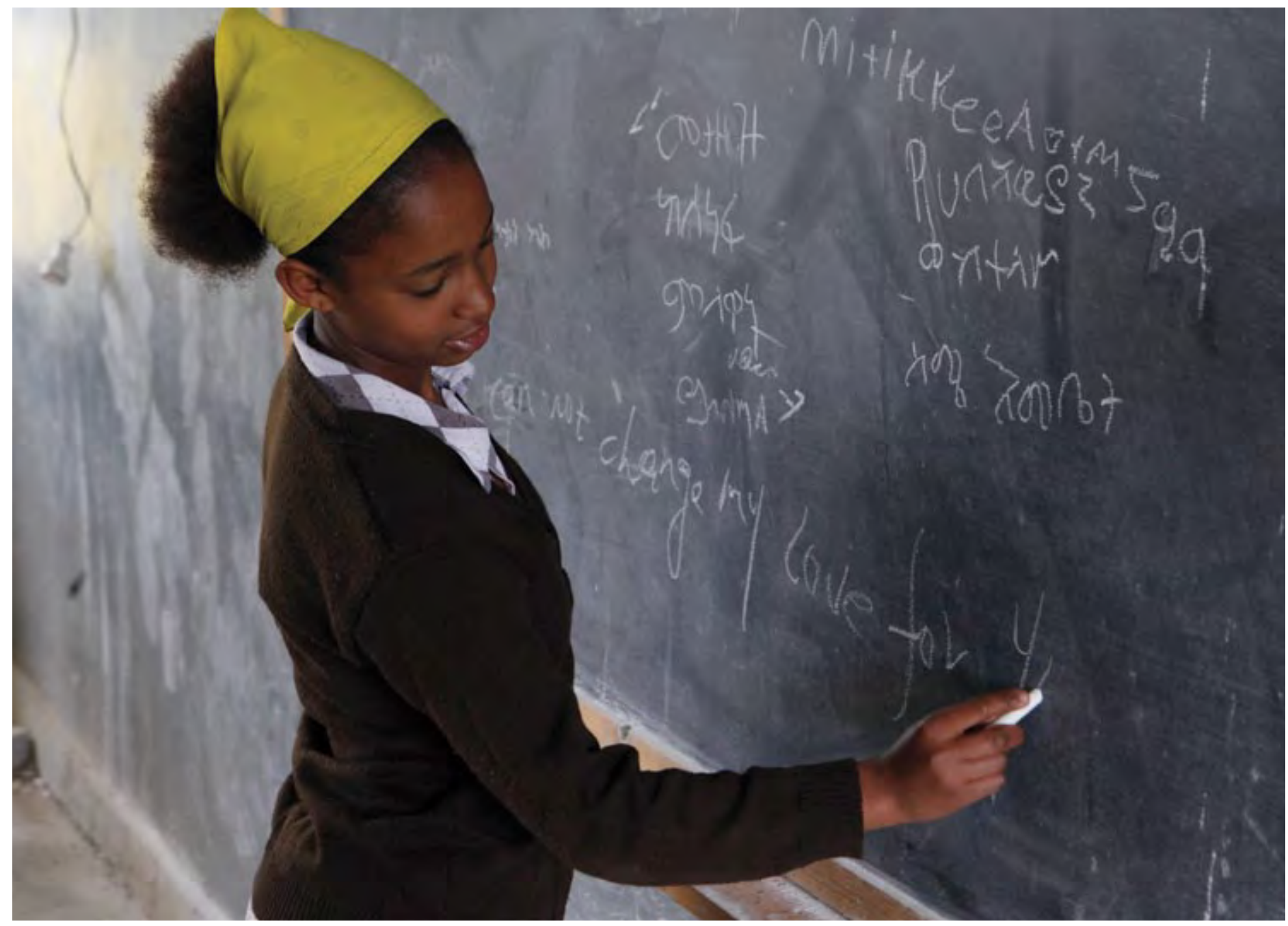

program responses that migrant girls require. The chapter closes by showing how developing-country governments can use information they already have in hand, in the form of population censuses and surveys, to identify girls in need and target program resources appropriately. An example from Ghana demonstrates how neighborhood-level census data can put disadvantaged migrant adolescent girls on the map.

\subsection{Assessing the Demographic Evidence}

Demographers have rarely catalogued the size and direction of internal migration flows by sex and age, despite the availability of data from national population censuses and Demographic and Health Surveys. In particular, adolescent girls' migration patterns have not been systematically quantified. Policymakers concerned with migrant girls have therefore lacked the evidence on which to base pro-girl programs and policies. The demographic findings Girls on the Move presents illustrate two facts: in many poor countries, substantial percentages of urban adolescent girls are recent in-migrants, having arrived in the five years before the census or survey; and of these migrant girls, a large share (though typically not the majority) are rural-origin migrants. The analysis also demonstrates the importance of definitions and measures in shaping estimates of the scale of migration. The DHS surveys use a definition that differs significantly from that adopted by national censuses, and policymakers need to understand these differences to properly interpret the demographic evidence. Importantly, this report's focus on girls should not undermine attention to the distinct concerns of migrant adolescent boys, as Box 1.1 describes. 


\section{What about migrant adolescent boys?}

Adolescent boys' and girls' migration experiences differ in fundamental ways, including the scale, motivations, and outcomes of migration, but migrant boys clearly face some of the same risks and opportunities as migrant girls. Nevertheless, migrant boys get little attention in Girls on the Move outside of a few comparisons where the evidence permits.
In many countries, more adolescent girls move than boys. Figure 1.1 shows results from a number of censuses, indicating that more 15-to-19-year-old urban girls are migrants than urban boys of the same age. As Figure 1.2 illustrates, there are differences between why boys and girls migrate, with more boys than girls migrating for work or schooling.

FIGURE 1.1

\section{Among urban adolescents, more girls than boys are migrants}

Urban in-migration percentages for adolescent girls and boys aged 15-19

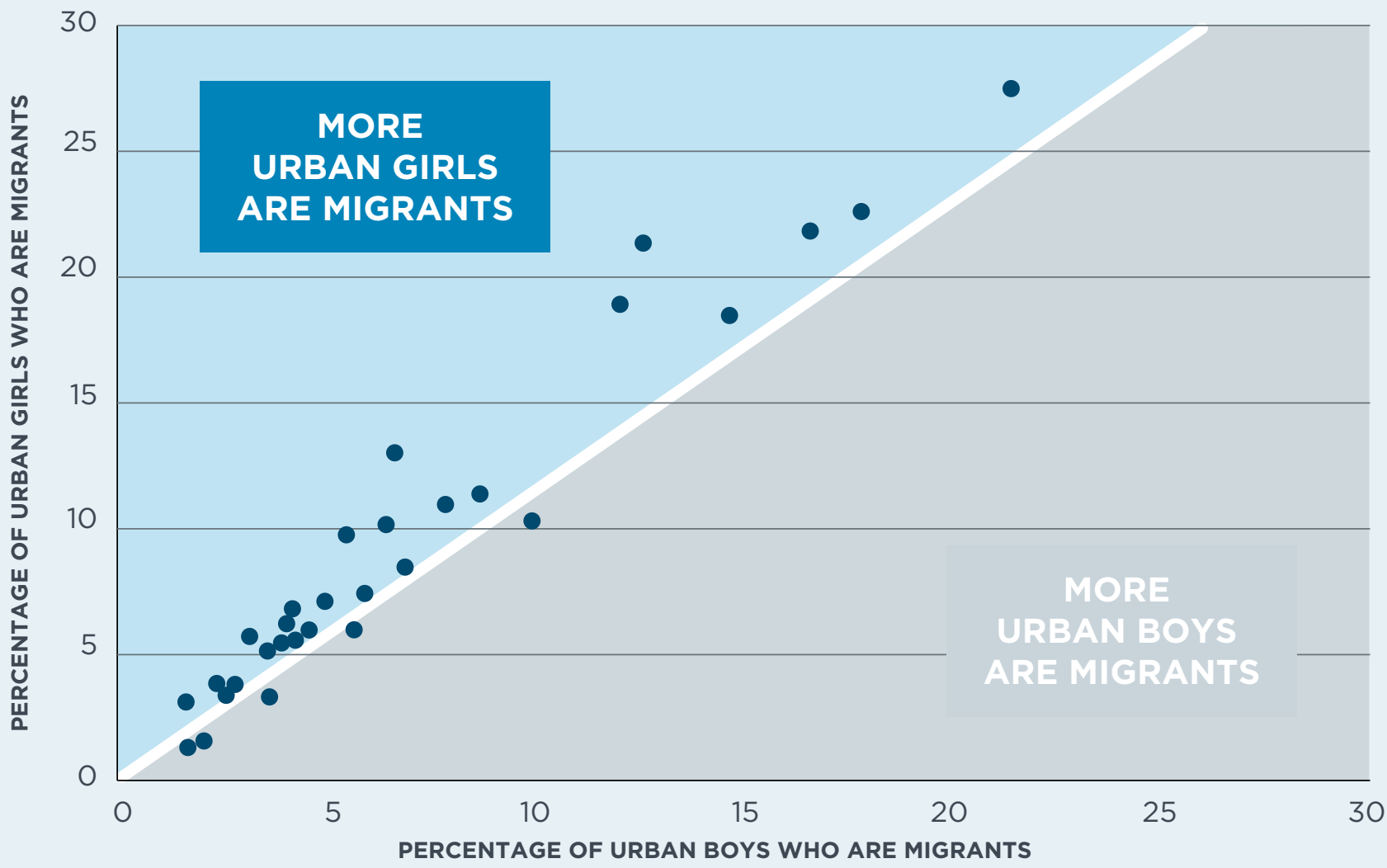


FIGURE 1.2

\section{More boys than girls migrate for education or employment}

Reasons for migration among males and females aged 15-19 in Pakistan

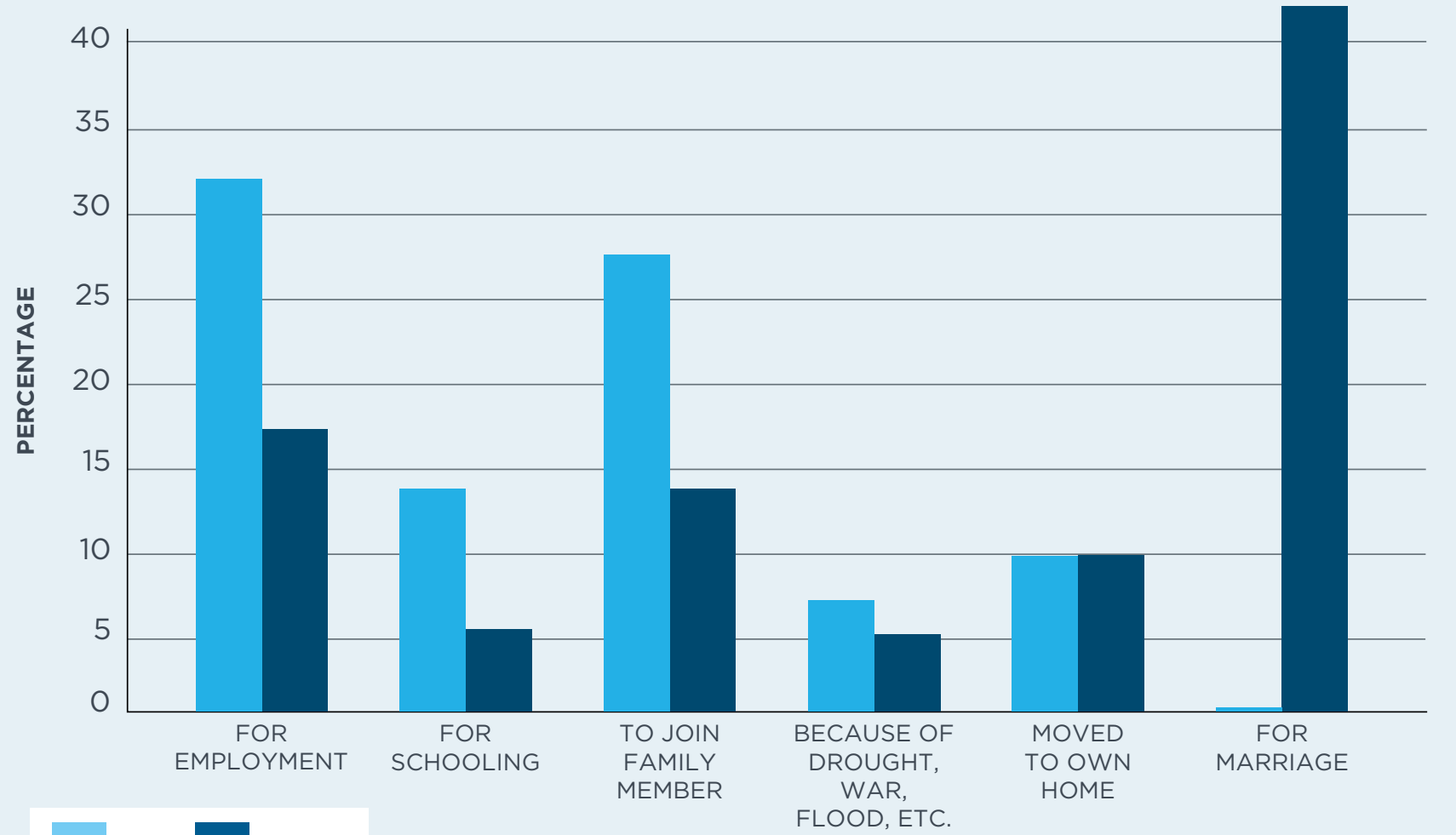

Male

Female

Source: Authors' calculations based on data from Adolescents and Youth in Pakistan (2001-2002) Nationally Representative Survey

Although both migrant boys and girls find work in unregulated industries and often face hazardous conditions, they tend to enter different industries (Edmonds and Shrestha 2009; Heissler 2009). Migrant girls' job options are typically more restricted than boys'. Occupational risks are common in industries that attract migrant boys, such as agriculture and commercial fishing. Working girls earn less than boys and tend to work longer hours, leaving girls less time to rest, attend school, and interact with peers (Liang, Guo, and Duan 2008). These working conditions affect migrant girls' social capital. In Ethiopia, for example, 40 percent of recent migrant girls reported having no friends versus 13 percent of migrant boys (Erulkar 2012). Migrant girls are more likely than boys to become trafficking victims or fall into sexual exploitation because of the gender norms that allow males to undervalue and dominate females of all ages.
The focus of Girls on the Move should not undermine the need for greater attention to migrant boys, especially those who are exploited and face risks similar to those affecting adolescent girls. Indeed some of the recommendations for migrant girls - such as pre-departure preparations, ensuring a safe landing immediately on arrival, and making services "migrant friendly" - apply equally to boys. However, these recommendations must be implemented with gender differences in mind. Boys typically have larger social networks, garner more support from friends and family for their migration projects, and have a wider range of opportunities in their new homes. Gender-sensitive solutions will take account of this variation and specifically address the ways migrant girls are disadvantaged. 


\section{The majority of urban in-migrant girls come from other cities and towns rather than from rural villages. The literature on migrants has not recognized these apparent demographic realities, instead concentrating on rural-to-urban migration.}

The term chain migration and

other key terms used in this report

are defined in Key Definitions.

\subsubsection{The scale of migration}

In national censuses, migration is recorded in terms of moves across either major or minor administrative unit boundaries, with major units being akin to provinces or states. In the DHS surveys, however, migration is recorded less precisely, in terms of changes of locality. For example, a girl who moved from one city to the next-closest city would not generally be counted as a migrant in a census, but would be counted as a migrant in a DHS survey.

Census data presented in Figure 1.3 show that in many countries, substantial percentages of urban adolescent girls aged 15 to 19 arrived at their current home in the five years before the census. In the 2008 census of Malawi, for example, more than one urban girl in four is a recent migrant. There is a great deal of diversity across countries, however: less than 5 percent of urban adolescent girls are migrants in Argentina, Egypt, and Mexico.

Using a different definition of migration, DHS survey estimates (not shown) are much higher, with estimates from some countries showing that nearly 80 percent of urban adolescent girls are recent migrants. The higher estimate doubtless stems from the different definition of migration used in these surveys, which allows moves across localities to count as migration. In general, the DHS surveys are likely to record more short-distance moves than a census detects. Both the DHS and the census estimates are meaningful, but clearly they mean different things.

Should the typically higher survey estimate be used to guide programs and policies, or should policies be guided by the lower census estimate? This question cannot be answered on the basis of demographic data alone. Local judgment is needed on the validity of using distance moved as an indicator of social disruption. That is, are girls who undertake long-distance moves more likely to face adjustment difficulties in their destination than short-distance movers? Certainly the long-distance migrants are further removed from their families of origin and sources of support in their home communities. However, a girl might not have considered such a long-distance move unless there were other relatives and comparable sources of support already present in the destination community. The process of chain migration ${ }^{4}$ - by which earlier waves of migrants from an origin community ease the process 


\section{FIGURE 1.3}

\section{Substantial percentages of urban adolescent girls are recent in-migrants}

Percentage of urban girls aged 15-19 who are recent in-migrants

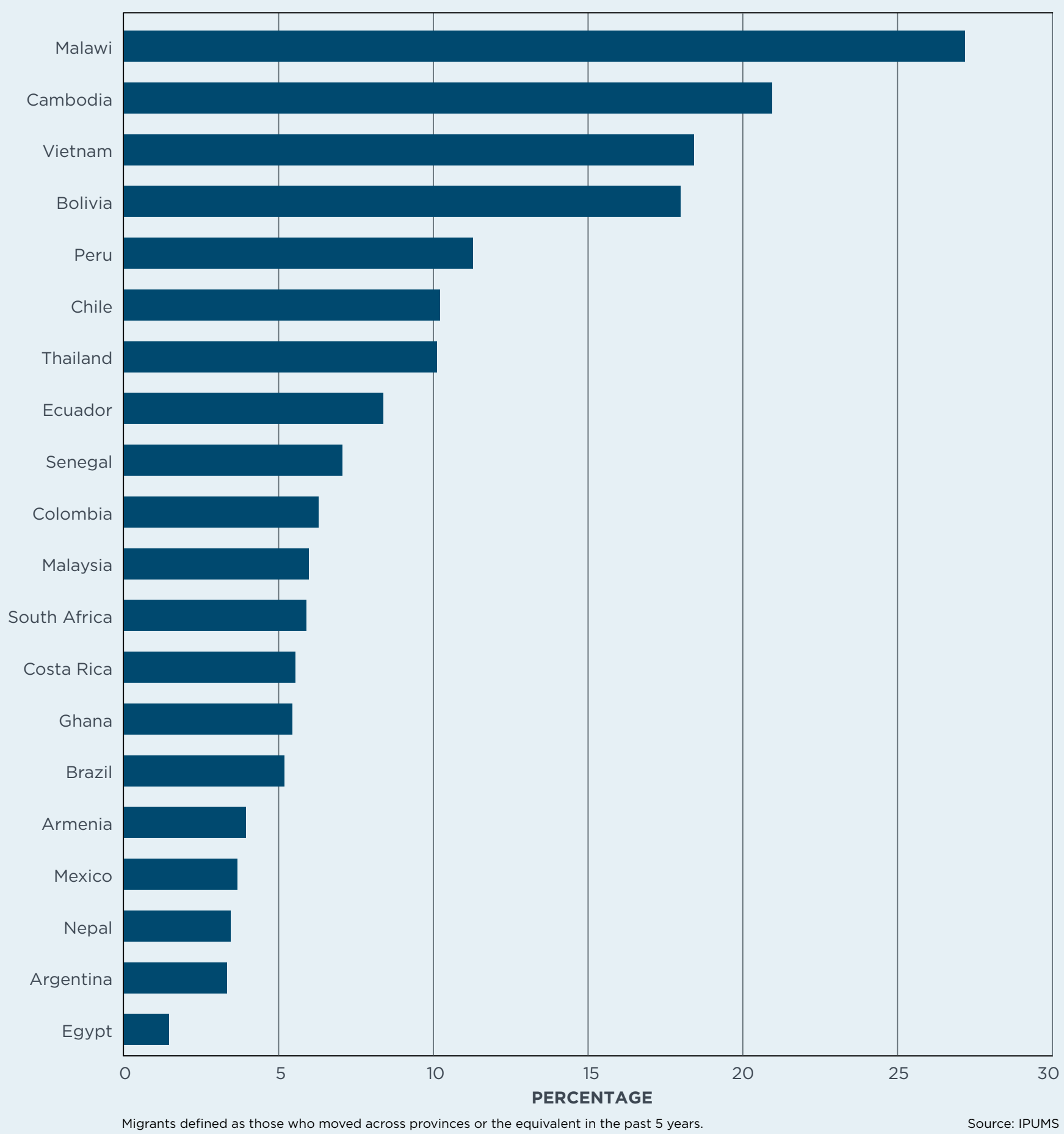


of adjustment faced by later migrants from the same area-might also reduce the risks of long-distance migration. The recency of a girl's move, her age, her degree of agency in the decision to move, and whether she moves alone or with someone else all affect how much social disruption she experiences.

1.1.2 Origins and destinations: urban and rural As Figure 1.4 shows, the majority of urban in-migrant girls come from other cities and towns rather than from rural villages. ${ }^{5}$ This is evident not only in Latin American and other highly urbanized countries, but also in a number of countries with relatively low levels of urbanization. Yet, as mentioned above, the literature on migrants in general has not yet recognized these apparent demographic realities, instead concentrating on rural-to-urban migration. It is reasonable to think that girls who move from rural villages to cities and towns are likely to experience greater social disruption and adjustment difficulties than urban-to-urban movers, but nothing definitive can be said without more evidence. Whether a girl migrates near or far, to a rural or an urban area, maintaining and building social networks remains a crucial factor shaping her ability to successfully interact with her new community.

\subsection{A Highly Diverse Group}

With the quantitative background in place, the chapter now examines the diversity of migrant girls. Gradations of risk, vulnerability, and fortune mark migrant adolescent girls' experiences. Some girls arrive in their new urban homes already disadvantaged for reasons such as curtailed schooling or poverty. Some of them are able to marshal their meager resources and do better in their new communities than they would have done had they not moved. Others fall victim to risks in transit and fail to connect to the resources in their new neighborhoods, becoming socially marginalized. Some risks and disadvantages stem from the move itself or its immediate aftermath, whereas the difficulties of poverty and social marginalization can be experienced by non-migrants as well as migrants.

Clearly, not all migrant adolescent girls are vulnerable. To illustrate this, Figure 1.5 puts the demographic features of urban migration in a larger context. The figure gives a stylized indication of the size of the migrant adolescent girl population relative to other adolescent girls, as Figure 1.3 described. All highly vulnerable adolescent girls are depicted in the figure, with the overlap between the groups suggesting the percentage of migrant girls who are highly vulnerable. The figure also gives an indication of the types of policy and program responses girls' diversity requires: broadly based social policies and systems such as those for child protection, education, social protection, and health, which benefit both migrant and nonmigrant girls, and service delivery targeting migrant adolescent girls or other population groups.

The section below considers a number of important dimensions along which migrant girls differ: the recency of the move; the girl's age at which it took place; and whether the move was voluntary or resulted from crisis, conflict, or trafficking.

\section{The timing of the move matters}

Demographic snapshots from surveys and censuses show that many recently arrived migrant girls are disadvantaged relative to others in their destination communities. Although a number of careful studies of migrant adults find that migrant disadvantage is largely confined to an adjustment period of two or three years, the literature on adolescent migrants does not shed light on the duration of move-related risks. Migrant girls may be particularly vulnerable during the first few years following their arrival. Even temporarily heightened risks can have lifelong consequences for adolescent girls because of the critical formative nature of this period of their development. For example, if an unplanned pregnancy occurs while a migrant girl is seeking to adjust to her new circumstances, her plans to continue her schooling or secure a productive livelihood are likely to be disrupted. Large-scale longitudinal studies need to be designed to follow migrant girls throughout their life course. The results of such studies will make it possible to understand and respond to the long-term implications of migration for adolescent girls and the women they become.

Age at migration may also influence a migrant girl's ability to adjust to her new circumstances. However, little is known about the experiences of girls who migrated as young adolescents aged 10 to 14 . Most demographic surveys do not interview females under age 15, leaving a gap in knowledge about the risks and benefits facing young migrants. It is reasonable to assume that girls aged 10 to 14 who migrate alone 


\title{
FIGURE 1.4
}

\section{The majority of urban in-migrant girls come not from rural villages but from other cities and towns}

\author{
Percentage of urban in-migrants who come from rural villages, girls aged 15-19
}

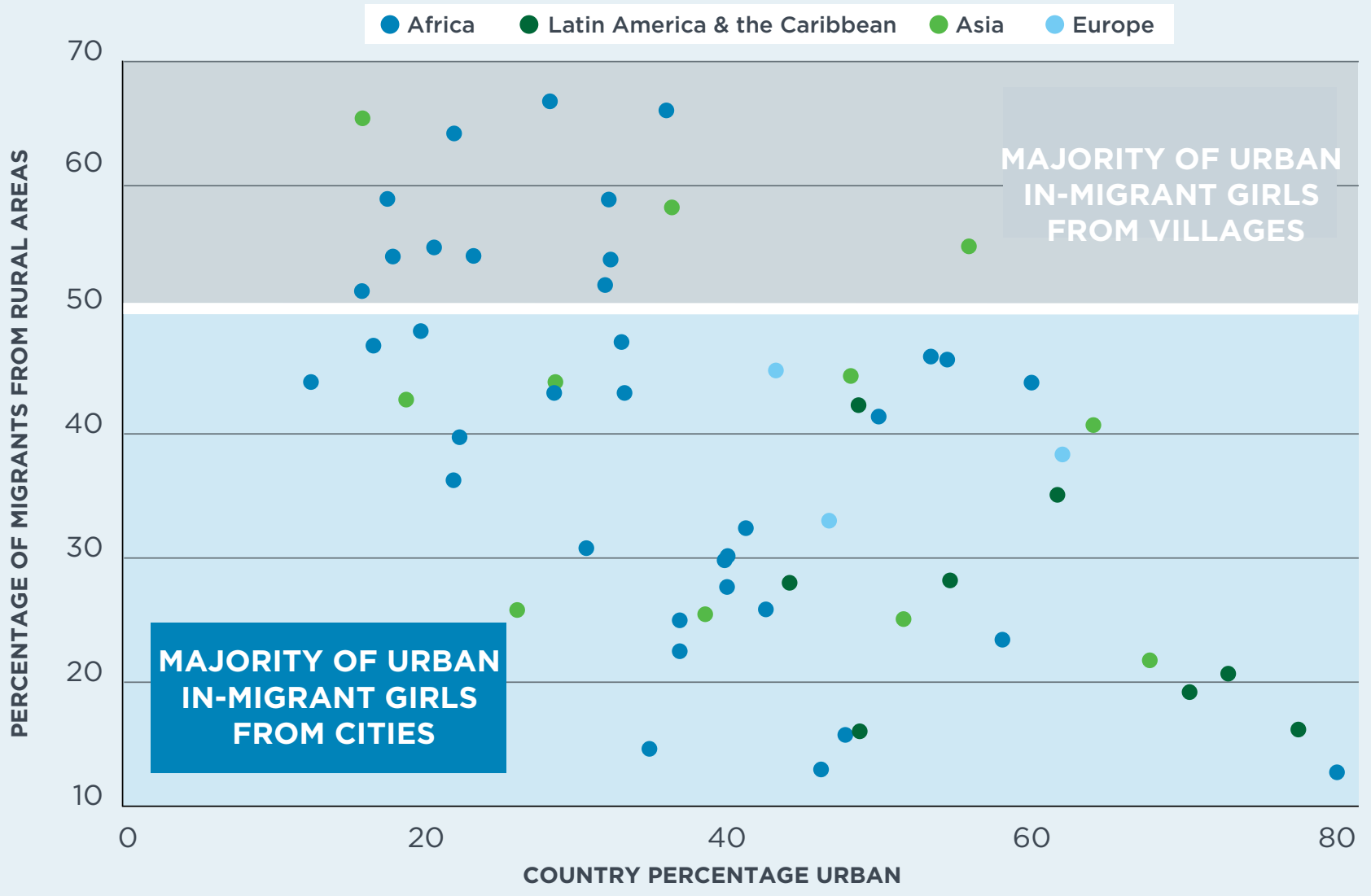

Migration defined as a change in locality.

Source: DHS surveys

to work face much higher risks of falling into abusive and exploitative circumstances than older adolescent labor migrants. This is an evidence gap in need of urgent attention. A few studies find that girls who moved as young children (under age 10) appear to be on par with urban-born girls as they develop, possibly because they are more likely than older migrant girls to have moved with their parents (McDonald et al. 2010).

\section{Migrants fleeing crises}

In many cities, groups of migrant girls include some who were forced to move by humanitarian emergencies. Urban internally displaced persons (IDPs) - people who have migrated within their country's borders to a city as a result of conflict or natural disaster - are of increasing interest to national governments and international agencies (Davies and Jacobsen 2010). Estimates of the total number of urban IDPs are uncertain, and no credible estimate of the number of displaced adolescent girls is available. ${ }^{6}$ Internally displaced adolescent girls have much in common with girls who move in response to personal or family crises such as the death of a family member, since these girls tend to change
According to Skeels and Sandvik-Nylund (2012:9), "Based on the information currently available, some 47 percent of UNHCR's global caseload is thought to be children and adolescents under the age of 18." 


\section{The diversity of adolescent girls requires a variety of responses}

\section{Policy Changes to Social Systems}

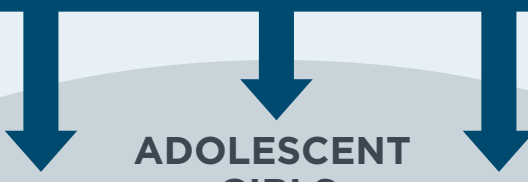

GIRLS

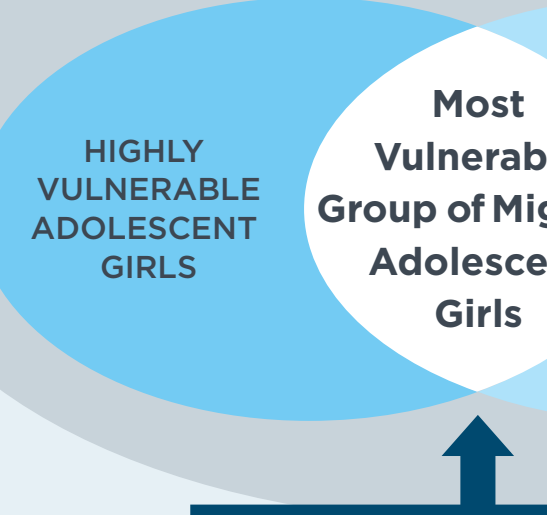

Direct Service Delivery

residence frequently and experience numerous social and health problems (Haour-Knipe 2009; Van Blerk and Ansell 2006). But not even qualitative studies or the accounts of humanitarian agencies are available for more than a few settings, such as post-earthquake Haiti. This absence of quantitative evidence on displaced adolescent girls highlights another research priority (Guterres 2010; Albuja and Ceballos 2010; Siddiqi 2012).

\section{Migrant girls and human trafficking}

Determining the proportion of migrant girls who are trafficked is exceedingly difficult because of the clandestine nature of the practice, although estimates suggest it is low. One estimate holds that 2.3 percent of female migrants are involved in trafficking (Murison 2005). The gross violation of human rights that victims of trafficking experience has stimulated international action; indeed, trafficking is one of the few types of girls' migration that have received such attention. As such, it provides a compelling example of how the international community tends to overlook migrant girls as a group until they fall into the worst situations.

Some systems developed to stop trafficking can unintentionally increase the vulnerability of migrant girls. For example, in West Africa, there are indications that Village Vigilance Committees set up to prevent trafficking end up preventing all movement of young people, whether legal or not, driving would-be migrants to less visible, and therefore riskier, forms of movement (Dottridge and Feneyrol 2007). To combat trafficking, some advocates call for a shift from punitive and legalistic approaches to human rights-based approaches. These include immediate assistance and alternative livelihood training for trafficked girls, along with efforts to address the root causes of 
trafficking: poverty, marginalization of ethnic minorities, and gender inequality (UNICEF 2006a).

\subsection{Putting Migrant Girls on the Map}

Empirical evidence on the location of migrant girls in need should guide decisions about the scale of resources required and where those resources should go. Governments routinely collect evidence that could be used in this way, but they often overlook the value of what has been collected. A case study from Ghana shows how better analysis of existing data could improve decisionmaking for resource allocation. To illustrate the potential of available evidence, consider the case of Accra, Ghana at the time of the country's 2000 national census. The Greater Metropolitan Area of Accra was divided into small neighborhoods, allowing the locations of different groups of adolescent girls to be mapped in great detail. ${ }^{7}$ The census records contain information on migration in the last five years from areas outside the Accra district and indicators of social and economic disadvantage for both migrants and non-migrants.

To bring quantitative content to the stylized representations of Figure 1.5, one such indicator is defined for all Accra adolescent girls aged 15 to 19, marking as potentially disadvantaged all girls who are not in school, not employed, and not living in a household whose head is a close relative. Some 12 percent of Accra adolescent girls are disadvantaged according to this definition, and for recent in-migrant girls, the percentage is nearly double that, at 23 percent. In other words, migrant girls are nearly twice as likely as non-migrants to be disadvantaged according to this composite measure of disadvantage. A difference this large would seem to suggest that girl-focused programs should make special efforts to focus on migrant girls. Yet if the data are viewed from a different angle, the rationale for focusing on migrants becomes less clear: of all disadvantaged adolescent girls in Accra, only 12 percent are recent in-migrants. It seems the great majority of disadvantaged girls in Accra are non-migrants. In directing their resources and efforts, program managers would need to think carefully about the costs of identifying migrant girls and consider the balance of costs and benefits entailed by a program focus on migrants alone.
The gross violation of human rights that victims of trafficking experience has stimulated international action, providing a compelling example of how the international community tends to overlook migrant girls as a group until they fall into the worst situations. 


\section{Many governments collect critical evidence that could be marshaled to benefit adolescent girls, census data being a leading example.}

Similar considerations come into play in identifying priority neighborhoods for program attention. The top panel of Figure 1.6 depicts the number of recent adolescent in-migrant girls by neighborhood; the bottom panel depicts the number of disadvantaged girls in total, whether recent migrant or not. A number of neighborhoods rank high in the totals of in-migrants and disadvantaged girls alike, but a comparison of these maps also reveals neighborhoods with substantial numbers of one group but not the other. In this example, groups of disadvantaged adolescent girls are found in a variety of neighborhoods across the metropolitan region, whereas the migrant girls are more concentrated in specific neighborhoods.

One lesson from this illustration is that many governments collect critical evidence that could be marshaled to benefit adolescent girls, census data being a leading example. Most countries regularly conduct national censuses and have the capacity to map the results along the lines seen in the Accra case. These data can, and should, be disaggregated to the finest possible levels, mapped, and made available to municipal authorities and program managers so they can ascertain where disadvantaged girls live and identify their levels of deprivation.

Migrant adolescent girls are a significant population in many urban areas of the developing world.

The diversity of their experiences and needs will be explored in the following chapters. Chapter 2 starts with the pre-migration phase, using qualitative accounts to illuminate girls' perceptions of risk and reward. As will become clear, girls take a more active role in migration decisions than is widely believed. Chapter 3 follows girls through the transit experience. Chapter 4 explores migrant girls' early stages of arrival, how they settle into their new neighborhoods, or how they fail to integrate, paying special attention to social capital. Chapter 5 summarizes the evidence on the jobs migrant girls typically take. Chapter 6 examines migrant girls' access to education and health services in the place of destination. Chapter 7 describes the state of policies and programs for migrant girls. Chapter 8 concludes with recommendations for policymakers, donors, and program managers to minimize the risks migrant girls face and provide opportunities for them to express their full potential. 


\section{Programs may need to work in different neighborhoods to reach disadvantaged girls and migrant girls}

Total number of girls in particular neighborhoods in Accra

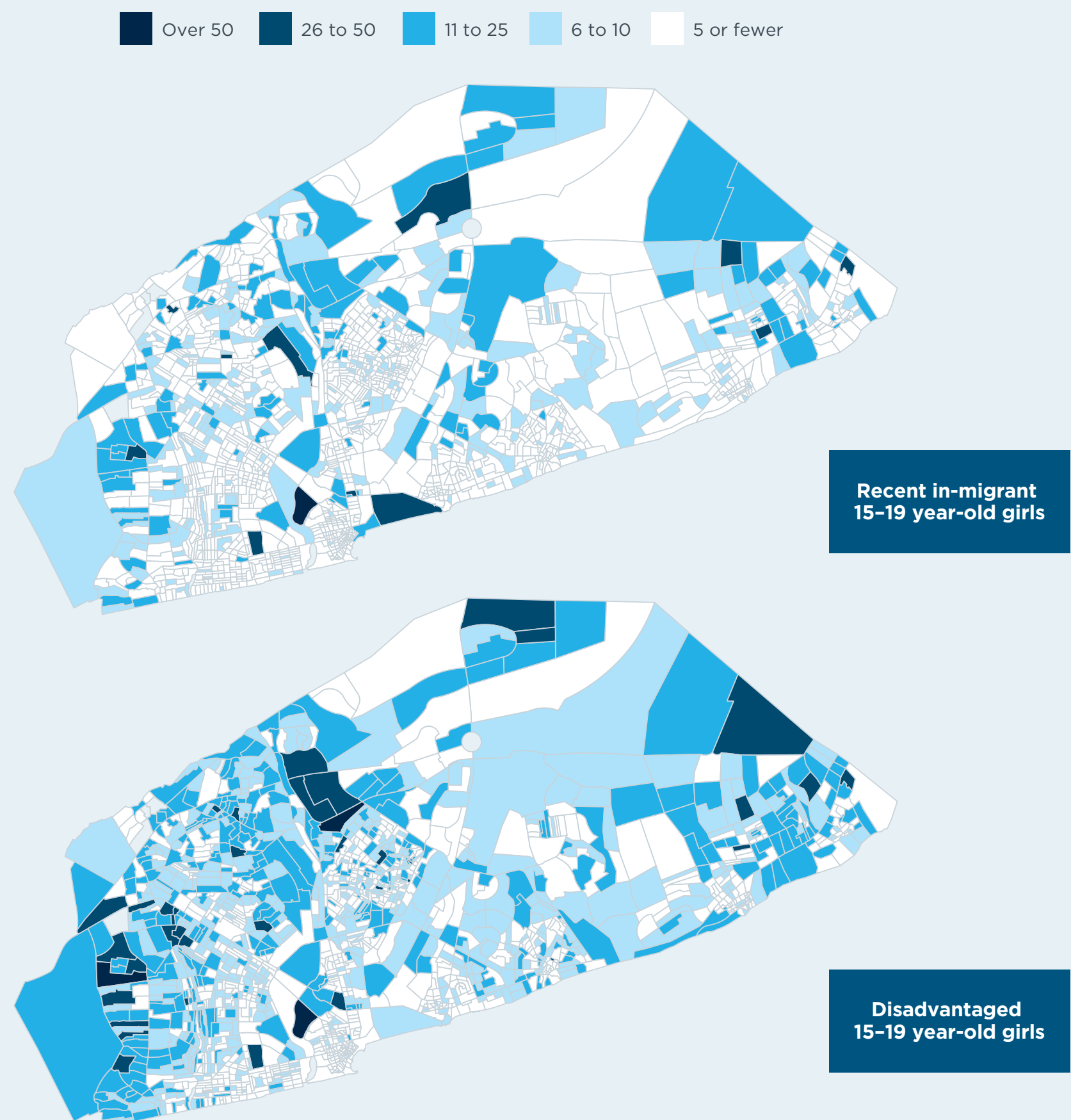

Source: These data were collected under a National Institute of Child Health and Human Development Project entitled "Health, Poverty and Place in Accra, Ghana," John R. Weeks, Project Director/Principal Investigator 


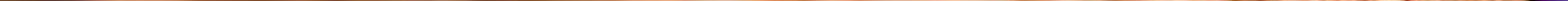




A girl's decision to migrate
reflects individual and family
concerns and broad social and
economic circumstances. In
some communities, migration
is a long-standing adult tradi-
tion, and girls' migration is no
exception. In others, girls cast
off community norms and leave
home as pioneers. Girls' migra-
tion can cause a ripple effect. A
few girls move, which influences
others to join them. The early ar-
rivals, if successful, can provide
social support for new migrants
and ease adjustment. This cycle
can stimulate further migration
(Hertrich and Lesclingand 2012 ).
Chain migration is as important
to national as it is to international
migration, rapidly bringing about
social change.

This chapter examines reasons why girls migrate, including the quest for education, employment, and personal development; family obligations; and the need to escape difficult circumstances. Many girls also migrate for marriage, a type of migration with unique considerations because child marriage is a human rights violation. Child marriage is featured in a special section in this chapter. The chapter ends with a discussion of how girls' agency - the ability to act to further their own interests - and access to information influence family decisionmaking. Whatever her motivation, a migrant girl's access to information, assets, and social support influences the chance that migration will help her fulfill her objectives and realize her full potential.

Most quantitative research fails to explore migration decisionmaking in adequate depth. Surveys tend to ask migrants about only one reason for a move, compelling respondents to simplify a complex decisionmaking process. Gender-specific factors also hinder understanding. In India, for example, "it is in- appropriate for a woman to emphasize her economic role especially if the interviewer is a stranger and a male" (Shanthi 2006). This could lead a migrant girl to report that she moved for marriage when the real reason was to advance economically. Furthermore, a girl may be reluctant to admit that she sought escape from abuse, violence, child marriage, and other forms of mistreatment. For these reasons, quantitative summaries of migration motivations are inadequate. Uncovering the real motivations for migration requires in-depth qualitative studies that are sensitive to girls' cultural and social position.

\subsection{Why Girls Migrate}

Adolescent girls migrate to cities from both urban and rural homes, motivated by similar aspirations and needs. Limited prospects in rural areas have a particularly strong influence on rural-to-urban migration of young people of both sexes. In qualitative accounts, 16 to 24 year-old migrants cited the "boredom" of village life (in Thailand, Mills 2005) and the tedium of agricultural work ("boring work in the rice field" in Laos, Yoddumnern-Attig et al. 2007) as factors prompting their departure. These perspectives reflect the effects of globalization, which increasingly exposes young people to other ways of life. Girls and women especially note the drudgery of their work in the rural domestic sphere (Balakrishnan 2005). Achieving a productive livelihood is also a challenge for rural girls. The few jobs available to them, such as piece-work and farming, can be temporary, unpredictable, and badly paid (Agarwal and Jones 2012). It is not surprising that migration from rural regions to cities and towns offers the most desirable route forward for so many girls.

\subsubsection{Seeking education}

Many girls migrate to further their education in the city. Girls may move to be physically closer to school. The quality and relevance of schooling are also a consideration: in Bangladesh and Burkina Faso, children reported they migrated because they felt the rural school curriculum lacked relevance to modern lives (Giani 2006; Terre des Hommes 2003). Some girls migrate for informal education such as apprenticeships, a popular option for young migrants in West Africa (Hashim 2007). Figure 2.1 shows that school and work aspirations and marriage were the dominant reasons for adolescent migration in a survey in 


\section{CASE STUDY $1^{8}$}

\section{Sakana, Cambodia, Age 14}

My father works as a rice farmer in our village in Cambodia, and my mother sells coconuts and snacks at a roadside stand. When I was 12 , the rice harvest was particularly bad and we earned very little money, so I had to help my mother at the stand. I missed a lot of class and eventually the headmaster told my father I would need to repeat a grade if I wished to continue. I decided not to go back since paying the fees was difficult for my family and it was more important for my brother to stay in school.

One day I was at the market and saw my auntie's daughter who had left to work in a factory in Phnom Penh. She was wearing beautiful clothes and her hair was styled like the girls in magazines. When she saw me, her greeting was, "My dear! How did you get so run-down looking? You should come work with me in the city. There's nothing for you to do out here besides sell coconuts." That night, all I could think about was going to the city. I could work hard, save money to help my family, and buy new clothes like my cousin's. Early the next morning, I mentioned the idea to my mother. At first, she was worried and thought I should wait a few years until I was older. But because I could stay with my cousin and earn almost five times more than we earned each month at the stand, she decided to let me go. She told me not to worry about my father - she would find the right time to tell him. I rushed to find my cousin to tell her the good news. Later that week I got my clothes ready and said goodbye to my mother. She gave me a hug, some food and a little money for the journey, and then my cousin and I walked out to the road to wait for the bus to Phnom Penh.
Ethiopia. Age and sex differences are apparent: more boys than girls reported moving to the city for school, a difference that significantly increases among older adolescents (Erulkar 2012).

Many migrants combine educational aspirations with plans to work. Migrant girls may find jobs to cover fees for part-time schooling or future educational expenses (West 2008). Some anticipate that domestic work will lead to opportunities for formal education. A study in Ghana found that 20 percent of girls entered domestic work because the employer promised to support vocational training either during or after their service (Tsikata 2009). Other labor migrants find that the informal education they receive by acquiring skills through their jobs meets their needs. Many poor rural girls say that doing domestic work in cities is the only way to further their education. Of course, migrant girls' educational experiences do not always meet their expectations, and their enrollment rates fall short of those among native urban girls, as Chapter 6 describes.

\subsubsection{Expanding economic opportunities}

Working for pay is a goal for many migrant girls. Earnings from urban jobs - which cluster in specific industries - enable them to build savings and gain economic independence and empowerment. Migrant employment is a path to upward mobility for many girls. Some are even willing to court social disapproval to obtain economic independence. A young woman from Ghana explained:

In the past when an unmarried woman travelled to the south, she was automatically branded a prostitute. But now who cares? If they call me a prostitute and I know that I am not one, why should I be worried?... Once I am able to work and get money to buy the things that I need, I don't care about what people might say.

Abena, 22, waitress in a bar, Ghana (Abdul-Korah 2006:87) The case studies that open Chapters 2 through 6 are fictitious, but based on migrant girls' actual accounts. 


\section{Migrant girls often cherish the relative freedom they obtain by living at a distance, escaping onerous gender restrictions and parental supervision.}

Personal communication with Ann Whitehead, March 2011.
Girls may use labor migration to gain access to material goods that are either unaffordable or unavailable in rural markets (Murphy 2008; Khair 2005). As a migrant in Guatemala described:

I was hoping to do better for myself because...sometimes we want things that our parents cannot afford. I wanted to have things, maybe simple things, and the only solution is to go to work.

Claudia, 21, Guatemala

(Rodas 2012:11)

Girls migrate to start jobs they have secured formally (e.g., through employment agencies) or informally through relatives or members of their social networks (Panel on Urban Population Dynamics 2003). A study of young labor migrants in Vietnam illustrated how frequently social networks facilitate labor migration: 82 percent of boys and 91 percent of girls used relatives and friends to find employment (Anh 2006). Some migrate with the hope of finding a job, trusting they will be able to support themselves in the short term while searching for better work. This is a safer decision for girls with social connections at their destination than for those who face city life alone.

\subsubsection{A transition to adulthood}

Keeping up with peers is a powerful incentive to migrate where it is common practice for young people. In much of rural West Africa, youth migration is seen as a rite of passage for both boys and girls. Parents and children describe how migration helps children mature by removing them from familiar surroundings and families, exposing them to different environments and lifestyles, and teaching them about work. Residents of rural Mali noted that returned migrant girls have broadened minds and opened eyes (Hertrich and Lesclingand 2012).

The relatively liberating features of urban life are evident in many settings. Migrant girls often cherish the relative freedom they obtain by living at a distance, escaping onerous gender restrictions and parental supervision. Migrant girls from a village in Thailand reported "reveling" in the autonomy only boys enjoy at home (Curran and Saguy 2001). Migrant girls who return to rural areas to visit or live after a period of time away may criticize restrictive community customs and social arrangements, especially those that constrain female voice and choice (Murphy 2008). The experience of a young circular migrant girl in Thailand illustrates how each subsequent migration increased her sense of freedom: "Each time Goy sojourned in Bangkok, the spatial distance from parental authority and the lack of family supervision further intensified the autonomy and economic independence by which she made her own decisions regarding where she would work and live and how she would manage her own income" (Esara 2004:200).

\subsubsection{Migrating for family reasons}

Individual migration is generally seen as part of a broad family strategy to maximize income and minimize overall risk (Stark and Bloom 1985; Waddington and Sabates-Wheeler 2003). For girls who have internalized a strong sense of family responsibility by adolescence, migration is a route to meeting family obligations, establishing themselves as contributors to the wider family, and retaining family relationships as they age. ${ }^{9}$ Yet migration theories recognize that family members have unequal power and that inequitable gender norms place girls at a disadvantage in 


\section{FIGURE 2.1}

\section{School and work opportunities are primary reasons for adolescent migration}

Reasons for migration among Ethiopian males and females aged 10-19

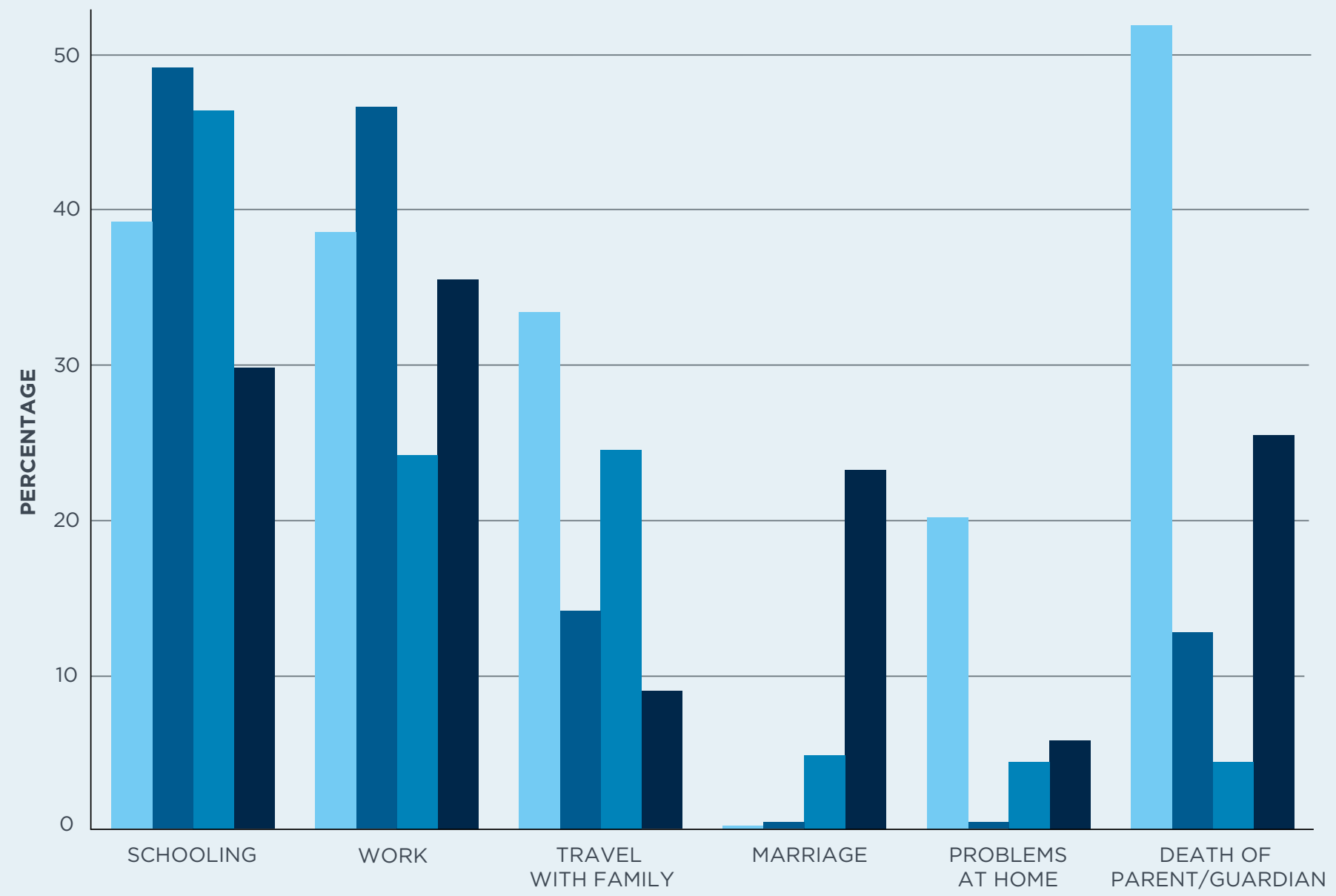

the family migration calculus (Elmhirst 2002; Heissler 2008). Some girls' decision to migrate for their families means risking exploitative circumstances. As a young woman in Vietnam's sex trade explained:
I decided myself to leave and come here because I want to help my family because they are poor.

Phuong, 18, Vietnam

(Rushing 2006:479) 


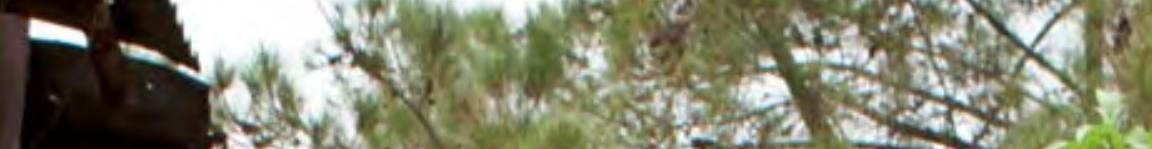
M $=5 x$

$-1 \times x+\frac{1}{3}$

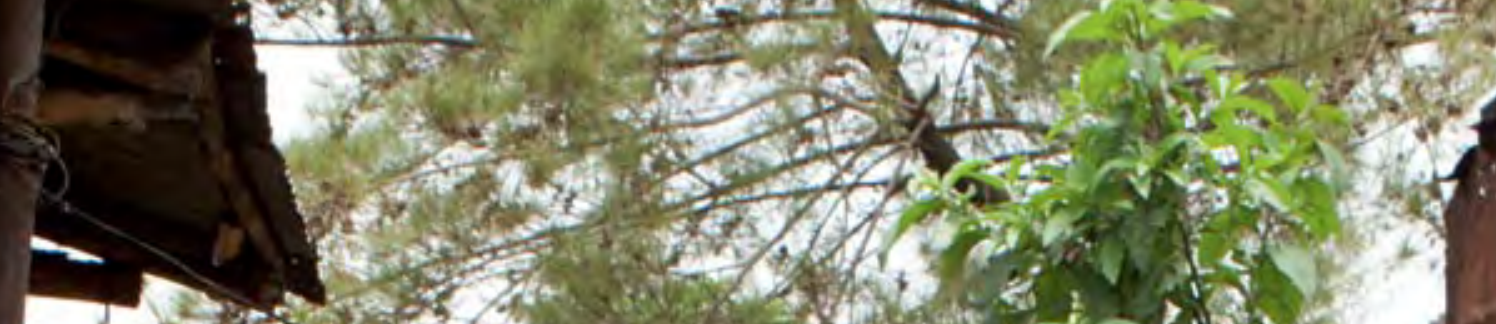
-

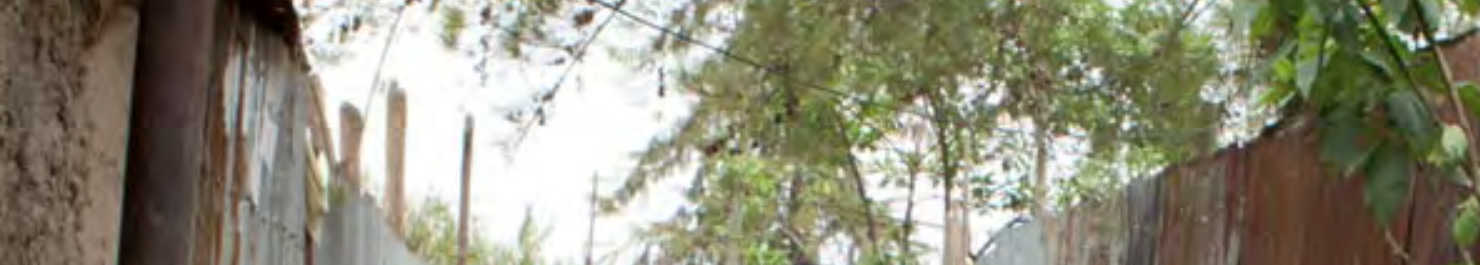
(1)

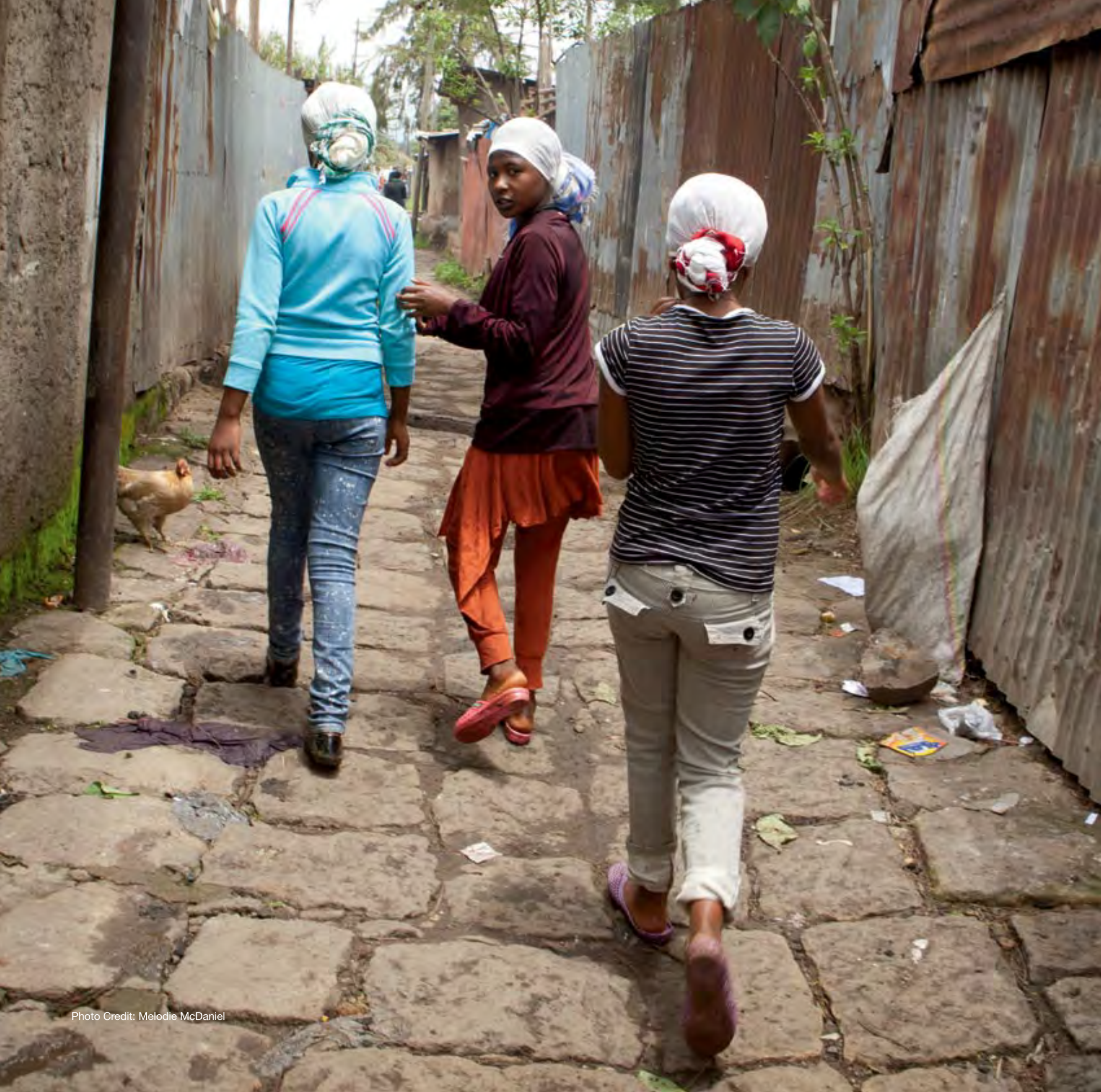


Other family-related objectives also come into play, as when girls migrate to help relatives or relatives' friends as domestic laborers or to care for sick kin (Hashim 2005). This is common in Southern Africa, where-in the context of high rates of HIV-families send girls to care for the ill much more often than they send boys (Ford and Hosegood 2005). Intrafamily migration can strengthen allegiances between extended family members and diversify sources of support in the face of risk, which are goals of child fostering as discussed in Box 2.1.

Changes in family structure, such as a parent's death, can also precipitate girls' migration. In Zambia, property-grabbing following the head of household's death often forces girls to move away (Oyaide 2000). Interestingly, adult death appears to have a different effect on boys' and girls' migration, reflecting differing expectations of their household roles. In a Bangladesh study, girls were 17 times more likely than boys to leave households where a woman died, presumably to be married off at a young age (Roy, Kane, and Khuda 2001). In Lesotho and Malawi, girls were more likely than boys to move following an adult AIDSrelated death in the household, possibly to care for distant relatives (Hosegood and Ford 2003).

\subsubsection{Migration as an escape route}

Some migrant girls move to escape untenable situations. Poverty caused or exacerbated by an acute crisis or chronic deprivation, such as when parents cannot care for their children, prompts many girls to move. A study in Addis Ababa described how poverty frequently drives girls into domestic work. The poorest girls viewed migration for domestic labor as a way to access the bare minimum of food and lodging their parents could not provide (Kifle 2002). In areas where agriculture dominates rural life, problems such as crop failure, flooding, and inadequate land access can lead to livelihood failures that force children to migrate (Khair 2005).

Abuse and violence also precede girls' migration. Children in highly vulnerable sub-groups such as those who live on the street or are sexually exploited often cite abuse or violence as reasons they migrated (Hatløy and Huser 2005; Orme and Seipel 2007). While abuse and violence are factors for both boy and girl migrants, the types and prevalence of violence they experience differ. More girls than boys report moving to escape sexual abuse, often by members of their households (e.g., Conticini and Hulme 2006). A parent's remarriage can prompt girls' migration, and abuse at the hands of a stepfather is another reason for leaving home (Beauchemin 1999).

Girls also migrate to escape harmful traditional practices and dangerous cultural norms. For example, girls may move to prevent child marriage or female genital cutting (Van Blerk 2011). A premarital sexual encounter, whether consensual or forced, may give girls a reason to escape into the relative anonymity of the city. Some migrant girls report moving to avoid the harsh consequences that would follow if anyone discovered their secret (Van Blerk 2008).

\subsection{Making the Decision to Move}

\subsubsection{Information-essential but unreliable}

Girls' access to information about the process of migration and the circumstances of urban life has a demonstrable effect on their migration experience. Those who lack information, as well as family support and assets, may be extremely vulnerable from the start of their journey, a handicap that shapes their adjustment to their new setting. Some girls have a measure of "urban literacy" and a realistic sense of what can be gained or lost by moving to a larger place, while others living in remote rural villages may have an idealized view of city life (Blomster 2004; UNFPA 2006). Would-be migrants who are prepared with adequate information are more likely to succeed than those who are uninformed about city life.

It is reasonable to assume that many rural adolescents learn about cities from social and family networks and the mass media. Returning girls or older sisters have a strong influence on girls' perceptions of urban areas (Hertrich and Lesclingand 2012; Djobokou 2008). In a Burkina Faso village, "the return of the [migrant] girls for the winter is a veritable celebration. 'You know when they return, the whole village mobilizes to welcome them, that's what inspires others to go,' recognizes a village chief. ... Items a girl brings back are set out in her mother's courtyard so that all the village women can admire the new belongings" (Terre des Hommes 2003). Girls' perceptions of the way migration changed their peers also influence their intentions. A migrant in Tanzania recalled: 


\section{Child migrants are frequently active participants in the decision to move.}

When [a girl who used to live in the city] came back, she was very beautiful and she had money and everything, so I knew no matter how difficult life might be in the cities, still you can't compare with the village life...so I was waiting for an opportunity to come [to the city].

Sabina, 17, Tanzania

(Rwehumbiza and Mabala 2011:9)

Returned migrants may describe their urban experiences in glowing terms, given their desire to appear successful, leaving out details about hardships, stress, and episodes of failure (Hertrich and Lesclingand 2012).

Employers and employment agencies are another source of information for potential migrants, although this information may be unreliable. The story of a young migrant worker in a Buenos Aires textile workshop illustrates the way some recruiters lure migrants with lies: "[The recruiter said she would] pay us cash - that she was going to bring us back after one year, that if we wanted to come back, she would bring us back. ... [That] she would treat us really well, that the work wasn't hard, all that. But it was exactly the opposite" (Bastia 2005:72). Even relatives may not give girls and parents the full picture. Relatives may deceive parents by promising to send a daughter to school in the city, only to put the girl to work in their household instead.

\subsubsection{Parents and girls typically share decisionmaking}

Migration researchers increasingly recognize that child migrants are active participants in the decision- making process (Baek 2008). Nearly three-quarters of urban migrant domestic workers in a Zambia study reported they were involved in the decision to migrate, many initiating the idea themselves (Oyaide 2000). Given how girls' and families' aspirations intertwine, some researchers characterize the decision about children's independent migration as "negotiated inter-dependence," whereby children meet family needs at the same time as they assert agency over their migration decision (Whitehead, Hashim, and Iversen 2005; Punch 2002).

Girls in poverty and with limited schooling and livelihood options may migrate knowing only of pressing family needs, with a vague idea that new and better opportunities await them. At the same time, they may acutely feel familial responsibilities. In this context, girls' scope to act independently, assess situations from their own perspective, and make genuine choices is constrained. Age can further constrain girls' agency: the younger the migrant girl, the less involved she may be in the decision to move (AGTR 2004).

Parental approval is important for migrant girls who want to gain access to their families' financial support and social networks. Social norms about girls' independent movement and migration's frequency affect the likelihood that parents will support daughters' migration plans. Where girls' labor migration expands rapidly, it tends to gain reluctant parents' acceptance (Murphy 2008). In Indonesia, a number of factors eroded parental opposition as girls' migration rates rose. Parents noted the protective benefits of young migrant women's informal peer networks, which tend to crop up where chain migration is common. Parents' perception that factory work was "clean, light, and modern" (compared with farm work) and that living away from the village would enhance girls' value on the marriage market also reduced their opposition. Finally, parents recognized that girls' peer pressure to migrate was far more powerful than their pleas to stay home (Elmhirst 2002).

Economic forces influence parents' views of girls' migration, including the expectation that they will gain from girls' current and future earnings. In situations where poverty prevents parents from providing for their children, studies find little parental opposition to their daughters' migration plans. They may regret letting their daughters go, particularly when they are 
young or moving far away, but at the same time they believe they are doing what is best for their children given their own constraints (Hashim 2005).

\subsubsection{Gender matters}

Gender norms about girls' contribution to their families and their independent movement affect migration decisionmaking. Norms also influence parental involvement: migrant girls often describe mothers as confidantes, assistants, funders, and even collaborators when fathers oppose their plans. This may be a way in which mothers help their daughters overcome gender-related constraints that limited their own life prospects (e.g., Kwankye et al. 2009).

Parents react differently to children's migration plans depending on prevailing norms about their sons' and daughters' long-term contribution to their natal families. In the Philippines, many parents prefer sending daughters away for secondary schooling because they anticipate greater long-term financial support from migrant daughters than from sons (DeGraff and Bilsborrow 2003, cited in Lundberg and Wuermli 2012). In other places, girls have a harder time gaining parental approval because parents think girls have lower earning potential than boys, and are more vulnerable. In a South African study, parents accepted sons' migration plans because they anticipated their future financial support, while they worried migrant daughters would return home pregnant, adding to financial woes (Porter 2010). The degree of parental support for the move is important because it can dictate how much assistance families provide in times of need.

\section{***}

The reasons migrant girls leave home are varied and the circumstances surrounding their departure differ. Ideally, they are migrating for positive reasons, were involved in the decision to leave, and their departure takes place in a supportive environment. Yet some migrant girls set out relatively disadvantaged. Factors like a girl's inherent characteristics, her access to social and financial support and information, and gender norms related to her independent migration are all important determinants of the likelihood that she will achieve her migration goals and reach her full potential. Similar factors influence migrant girls' experiences in transit, which are the topic of the next chapter.

\section{BOX 2.1}

\section{Fostering}

Sending children to live with relatives is a practice commonly documented in West Africa and also prevalent elsewhere. Fostering is a strategy to reduce the number of mouths to feed in the sending family, strengthen family ties, redistribute labor, and, in some cases, provide opportunities for fostered children to attend school (Serra 2009). In regions of Ethiopia, families traditionally send children, especially girls, to relatives' homes to help with domestic chores (Ezra and Kiros 2001). In South America's Andean region, where some residents see solitude and loneliness as fates worse than death, childless relatives might request a child for companionship (Leinaweaver 2007).

The balance between benefits and risks for the fostered child varies. Factors such as the child's age and sex and the motivations of sending and receiving households shape their experience. Fostered children are likely to fare better when the arrangement is based on mutual agreement rather than an acute need, such as poverty brought on by a parent's death (Serra 2009). Children in Southern Africa who are fostered following an AIDS death-especially those moving from urban to rural areas-grapple with new, heavier labor expectations than at home, exacerbating their sense of dislocation (Ansell and van Blerk 2004). Although the opportunity to attend school improves for rural children fostered for educational reasons, girls have different experiences from boys (Madhavan 2004). In Ghana, 76 percent of fostered boys aged 12 to 17 attended school, while only 45 percent of their female counterparts did so (Gage 2005). This is largely explained by different expectations about boys' and girls' roles: fostered girls often help out at home and their domestic duties often crowd out their schooling (Pilon 2003).

Although some fostered girls report feeling disadvantaged compared to their hosts' own children, they also may value the new opportunities fostering provides (Whitehead, Hashim, and Iversen 2005; Leinaweaver 2007). A study of Haitian girls living in a Dominican border town found that the fostered girls believed their circumstances had substantially improved. After living with an abusive employer, one girl was taken in by her cousin's family. Although she was still expected to do household chores and was not enrolled in school, she described her new home as a positive and welcoming environment. "They treat me well. They have bought me clothing, shoes, everything I need. They don't insult me or hit me. I sleep in a room with a bed just for me" Tamara, 10, Dominican Republic (Petrozziello 2012:14).

Because fostering is seen as a private arrangement within families, monitoring fostered children's situation is a delicate matter. In tightly knit communities, community members may be well placed to monitor the situation of fostered girls and ensure their hosts are not exploiting them. 


\section{ADOLESCENT GIRLS MIGRATION AND MARRIAGE}

Marriage is frequently cited as a reason for adolescent girls' migration (Lloyd et al. 2002; Das and Murmu 2010; Heissler 2009). Movement for marriage has much in common with migration for other reasons, but it also differs in fundamental ways. Whether in connection with migration or not, marriage during adolescencechild marriage-is a violation of human rights. This section considers the implications of child marriage and how it relates to girls' migration for marriage.

\section{The importance of adolescent girls' migration for marriage}

In some settings, migrating to join a husband is common. A study in Ethiopia found that marriage motivated the migration of 10 to 29 year-olds more than any other reason: 79 percent of females and 64 percent of males (Ezra and Kiros 2001). In some settings, figures like these could be over-estimates if young women are reluctant to reveal that their real motivation for moving is economic (Shanthi 2006; Khatana 2010). Notwithstanding this bias, girls' migration for marriage is so common that in some child marriage "hot spots," it may not even be seen as migration (Fan and Li 2002).

While it is likely that marriage motivates many girls' rural-to-rural movement, the situation differs in urban areas. Demographic and Health Survey results show that the vast majority of migrant girls moving to urban areas are unmarried. Figure 2.2 illustrates the marital status of 15 to 19 year-old urban in-migrant girls in selected countries. Although the picture in rural areas may well look different, the DHS defines rural migration too vaguely to permit rural comparisons.

\section{How do young marriage migrants fare?}

Child marriage remains a serious problem in certain parts of the world such as South Asia, where in some countries up to half of all girls are married by age 18 (UNICEF 2010). Girls whose rights are violated by child marriage are disadvantaged in multiple ways. They typically have lower levels of educational and civic participation, less mass media access, restricted mobility, and higher risk of maternal mortality and domestic violence (Brady, Saloucou, and Chong 2007; Santhya and Erulkar 2011). Given their social and economic disadvantage, it is likely that girls who migrate to marry have fundamentally different migration experiences from those who migrate for work or education.

Marriage migration might appear to surround brides with protective figures such as in-laws and other relatives, but on closer inspection this type of move exposes migrant girls to social risks. Whether young brides' new lives unfold near or far from their original home, many experience dislocation and loss upon moving, with limited or even nonexistent peer networks compared to unmarried girls and married adult women (Haberland, Chong, and Bracken 2004). They often have difficulty recreating the social networks they had. Less than 20 percent of young married girls in a study in rural India reported having friends in their marital village, compared with a majority who had friends in their natal village (Santhya, Haberland, and Das 2008). 


\section{FIGURE 2.2}

\section{The majority of urban in-migrant girls move before marriage}

Approximate timing of migration in relation to marriage, urban girls aged 15-19

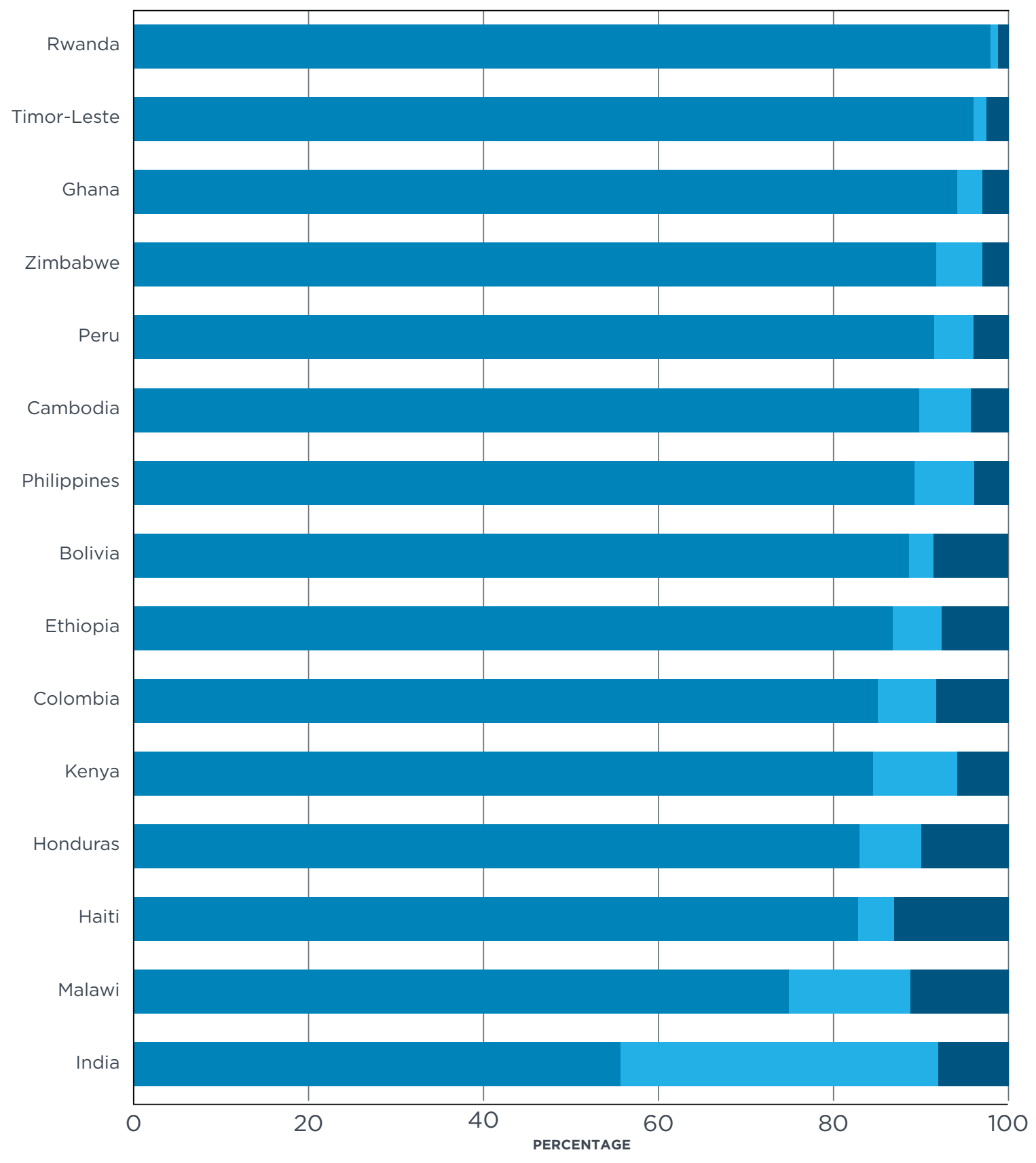




\section{While migration for marriage can put girls at risk, girls' migration also has the potential to change marriage markets for the better by delaying marriage until girls have completed school or gained practical skills.}

Social norms in their new family may deny married girls the autonomy to move around their neighborhoods, compounding their sense of social isolation. In Indore, India, married migrant girls were vulnerable to loneliness and feeling they did not belong. Married migrant girls may be particularly vulnerable if they have poor relationships with their in-laws or have restricted autonomy and access to resources in their marital home (Agarwal and Jones 2012).

These factors may increase married migrant girls' susceptibility to gender-based violence, with little chance of protection from nearby family and friends. A study in India found that married rural-to-urban migrant girls aged 17 to 19 were more likely than urban non-migrant peers to have experienced physical or sexual violence by their husbands (Zavier, Jejeebhoy, and Acharya 2012). Given these findings, it should be a priority to invest in programs to reach married migrant girls with information, assets, and support.

\section{Girls' migration influences the timing of marriage}

Migrant girls who move for reasons other than marriage tend to marry later than their peers who stay at home. This is because girls' migration for school or work may be seen as a socially acceptable alternative to marriage in many settings, leading some parents to support girls' efforts to postpone marriage by migrating. As an Ethiopian girl described:

I was requested for marriage and since my parents didn't want me to get married, they sent me here to my brother so that I could go to school in the city.

Age 15, migrated from rural Amhara to

Addis Ababa at age eight, in school

(Erulkar, Mekbib, and Tegene 2006:369)

Similarly, in rural Bangladesh, where many young women migrate temporarily to work in the garment industry, migration is a viable strategy for prolonging girls' unmarried status while maintaining respectability in the community and enhancing their marriage prospects (Heissler 2008). 
Parents who depend on remittances from their migrant daughters may be less likely to initiate marriage arrangements, knowing that daughters will cease contributing to household budgets when they wed. A mother of two girls in garment work explained: "I will not arrange the marriage of my daughters. They have only one brother. If they leave without establishing him, then they will not be able to help him anymore. They have to help other people" (Naved, Newby, and Amin 2001:98).

Migration can increase girls' ability to determine when and whether they marry. In Mali, young labor migrants reportedly stayed in town until they felt ready to wed. These girls signaled their availability to marry by returning to their village for more than a few weeks. Indeed, within six months of returning to their rural villages, 60 percent of migrant girls had married (Hertrich and Lesclingand 2012). In several countries in Southern Africa, marriage rates are actually lower among female than male migrants, suggesting that young women migrate instead of marrying as their "means of support" (Dodson et al. 2008:16).

Migrant girls may encounter new ways of thinking about marriage, causing them to reconsider what they desire in a spouse and in married life. A study in Thailand found that girls who had migrated for work prioritized career advancement and waited for marriage until they found a desirable spouse. Researchers attributed this to the personal satisfaction and sense of independence associated with gainful employment (Jampaklay 2006). Rather than marrying spouses chosen by families, some migrant factory workers in Bangladesh opt for "love marriages" with other workers they meet in Dhaka. These marriages often take place at older ages than traditionally arranged marriages in rural areas (Naved, Newby, and Amin 2001).

Adolescent girls' migration can be a force for social change vis-à-vis marriage traditions. In rural Mali, fewer marriages involve long-standing traditional rituals. Researchers attribute this to the widespread loss of social control by family heads and community elders resulting from the frequency of adolescents' labor migration (Hertrich and Lesclingand 2012). Following their independent working lives in Jakarta, many young returned migrants in rural Java were unwilling to marry in the village according to local customs (Koning 2005).

Social isolation and separation from families of origin can exacerbate the underlying risks all child brides face. While migration for marriage can put girls at risk, it also has the potential to change marriage markets for the better by delaying marriage until girls have completed school or gained practical skills. These changes are important both for individual girls and for the next generation of girls. Whatever the circumstances, it is clear that migration plays an important role in influencing the transition to adulthood for many girls at risk of child marriage. 


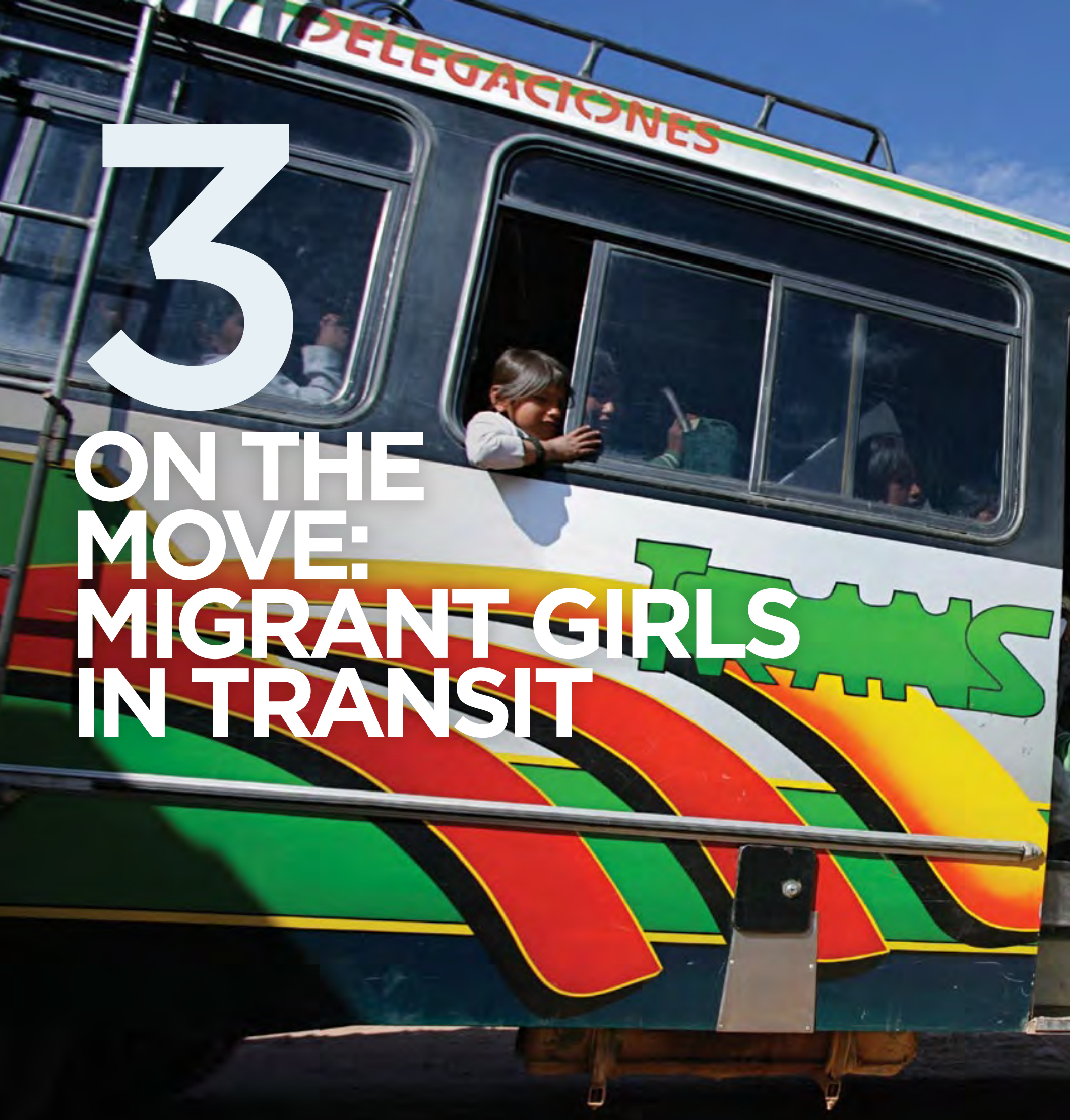


Some experts consider the transit journey the most dangerous phase of child migration because of the many roadblocks along the way. The time in transit is poorly understood because research tends to focus on the riskiest journeys. Most research studies migrants who move independently rather than with families, and "when children migrate on their own...a preoccupation with trafficking blinds research to other forms of children's unaccompanied movement" (Anderson and O'Connell Davidson 2005, cited in Heissler 2008:2). This chapter describes what is known about the migration journey: the circumstances of departure, distance traveled, transport, accompaniment, and factors that shape girls' experiences along the way.

Increasing understanding of girls' transit experiences will allow policy and program planners to determine when, where, and how migrant adolescent girls may be vulnerable during this phase and to respond accordingly. Providing would-be migrants with key assets can help them migrate safely. These include money for the trip, information about the destination and how to get help along the way, a plan for what to do if things go wrong, and personal documentation such as an ID or birth certificate, discussed in Box 3.1.

\subsection{The Characteristics of Migrant Girls' Journeys}

A study of migrant Tanzanian girls found that those who knew more about their journey were likelier than others to have transport fare, a relative to meet them on arrival, and a place to spend the first few nights at their destination (Rwehumbiza and Mabala 2011). Others faced risks because they lacked information about the journey, despite having some travel funds. A young informant in Dar es Salaam described a distressing trip:

My uncle promised to send me to school, since my parents could not do so. After I stayed with him for three days he put me on a bus to come to the city. It was very difficult for me, since I did not have enough money for the bus fare. I had to sit on the floor in the bus, for two days. I only had one dress, they only gave me 2000 [shillings] [USD\$1.20], I was so scared, hungry and I used to cry now and then. I didn't know where I was going. Only the conductor knew...

Neema, 12, domestic worker, Tanzania

(Rwehumbiza and Mabala 2011:14)

Girls who migrate to escape difficult circumstances often lack material and family support, exposing them to treacherous journeys. Girls from Zimbabwe who migrate to South Africa to escape poverty and family disintegration often travel without money or documents (Save the Children, UK 2006). Without the support of their families, they are forced to rely on strangers during their trip. Lacking alternatives, some turn to prostitution to get money to pay their way. Here and elsewhere, reports are common of truck drivers and border officials exploiting girls by allowing them to cross without papers and fees in exchange for sex (Palmary 2007; Busza 2011).

\subsubsection{Traveling near, traveling far}

A number of factors influence the distance migrant girls travel, although this has not been the topic of systematic study. Male migrants tend to travel farther than females (Chalasani 2012). In India, the majority of female migrants of all ages (60 percent) moved within their district, and males comprised an increasing proportion of migrants as the distance of migration increased. This may be because male and female migrants' motivations differ-for example, females move for marriage while males move for work-but evidence is too limited to draw this conclusion (Mitra and Murayama 2009). Some parents try to keep their adolescent daughters close because of concerns 


\section{CASE STUDY 2}

\section{Gifty, Tanzania, Age 11}

When I was nine, my father returned from his job as a trucker because he was sick. My mother soon became sick, too, and I had to leave school because we could no longer pay school fees and I had to take care of them. After my parents died, my grandma told me, "Go and live with your brother," because she could no longer afford to take care of me. My brother had moved to the market town, and a man from our village agreed to take me in the back of his truck when he went to the market. I liked living with my brother and his wife, and I helped my sisterin-law cook and clean. Even though I helped her, she always complained to my brother that I ate too much, and after about six months she told my brother I had to go.

Rather than return to my grandma's house in the village, I decided to go to Dar es Salaam to live with my older sister who moved there some years before. The bus ticket was 35,000 shillings (USD \$22), about half of my brother's monthly earnings. He wasn't happy about it but agreed to buy it for me since he knew his wife would be mad if I stayed any longer. Early the next morning, we went to the bus station and my brother asked a woman he knew to help me out on the ride to Dar. Mid-day, we stopped at a town for lunch and to pick up more passengers. It got so crowded on the bus that I had to sit on the woman's lap. We rode for many more hours, and eventually stopped at another town for the night. We had no money for a hotel, so the woman and I slept in front of the bus station. In the middle of the night, two men in a car stopped by the station and offered to give us a ride to Dar. The bus driver, who was sleeping in the bus, heard the men harassing us and yelled at them to leave us alone, telling us they were bad.

The next day, we traveled for many more hours to the capital. When we finally arrived, the woman's son picked her up and they helped me call a man named Joseph who my brother told me about. Joseph used to live in our village and helped many people when they first arrived in the capital. He told me how to find him and I used my last shillings to take a taxi to his house. His wife gave me dinner and they let me stay the night. The next day Joseph took me to see my sister and ask if her mistress needed help. She didn't, but had a friend who did. I've been working for that woman for over a year now. about their safety and threats to the family's reputation if they "get out of hand" in a distant location (Porter 2010). While some girls who migrate farther from their families are more vulnerable than those nearby, this is not always the case. For example, where chain migration is established, girls may travel far to join relatives and friends who are ready to support and protect them in their new home.

Age also influences the distance girls move: younger migrant girls tend to remain closer to home while older ones move farther away (Hertrich, Lesclingand, and Jacquemin 2012; Adamo 2012). An analysis of Vietnamese census data illustrates this, as shown in
Figure 3.2. Before age 15, girls tend to move infrequently, and those who do move go to nearby destinations within districts or provinces. At age 18, however, more girls begin to travel between provinces. This coincides with the end of compulsory education as well as with the legal age of marriage and employment (Guilmoto and De Loenzien 2011).

Indigenous rural Guatemalan girls explained that older girls migrate to destinations farther away when they are more responsible and have the minimum required level of schooling, identification, and/or letters of recommendation: 


\section{BOX 3.1}

\section{The value of personal documentation}

In many developing countries, adolescent girls lack personal identification such as birth certificates, national identity cards, or other forms of documentation that show their age, birth date, identity of biological parents, legal surname, or health records. These official forms of identity affirm that a girl is a valued member of society and enable girls to be counted in official records. Migrant girls can take personal documentation with them, facilitating their access to services and entitlements such as health, education, and social grants. A study in urban Ethiopia found that girls working in domestic labor, many of whom were migrants, lacked identity cards from the local government (kebele). These girls were not only denied rights because of their lack of registration, but were also denied access to subsidized or free medical care provided to registered kebele residents who could prove sufficient need (Erulkar, Mekbib, and Tegegne 2008).

Migrant girls' limited knowledge, resources, and social networks can hinder their ability to access services and entitlements during the transit phase and in urban settings. The absence of parents or trusted adults to help them navigate the requirements for accessing services is a particular problem. Providing migrant girls with personal documentation is a step toward reducing barriers to resources and affording migrant girls the same access to entitlements as their urban peers. They also need education about available services and their rights to them.

Maybe girls go out but only close to home, because they would not be given work elsewhere...because they are young and cannot go to the City, where they always ask for a middle school diploma.

Catalina, 19, domestic worker, Guatemala

(Rodas 2012:7)

One reason for the variation in the distance migrant girls travel is that migration is not necessarily a onetime event. Migrant girls may start with a temporary move to a nearby regional center to gain work experience-and perhaps parental acceptance-before setting out to a larger city (Richter et al. 2006; Young 2004; Matsuo and Blagbrough 2006). Step migration is seen in Mali, for instance, where the proportion of rural adolescent girls who head to the capital city rises with each successive move. Half of the girls go to Bamako for their first migration, compared with 70 percent for subsequent moves (Hertrich, Lesclingand, and Jacquemin 2012). As shown by the analysis of DHS data in Chapter 1, the majority of urban in-migrant adolescent girls come from other cities and towns. This finding hints at just how many girls undertake step migration. It is possible that many urban-to-urban migrant girls originated in rural areas, moving first to a medium-sized urban setting before traveling to a larger city.

\subsubsection{Transport}

How migrant girls reach their destination depends on transport availability and affordability. A study of migrant child domestic workers in Burkina Faso found that 50 percent of them paid for transport themselves, using the cheapest mode available (Terre des Hommes 2003). Some migrant girls walk to their destination or to the nearest town to catch a bus or train. Other girls hitch rides on motorcycles or trucks. Girls recruited by an intermediary or employer might travel by bus, private car, or other more expensive mode of transportation (Groupe Développement 2006; Djobokou 2008; Rodas 2012).

Some migrant adolescent girls are less likely than their male peers to receive help with travel costs. A study of rural adolescent migrants in urban Ghana found that extended family members more often contributed to boys' travel costs than to girls', probably reflecting greater acceptance of boys' migration (Kwankye et al. 2009). Girls who pay for their travel may take on extra work in already over-burdened days, for example, earning from menial agricultural, hauling, or other jobs. In a Tanzania study, rural girls performed additional farm labor, washed clothes, and fetched water to cover travel expenses (Rwehumbiza and Mabala 2011). While poorly documented, without doubt some girls borrow money for the trip. For those who start their migration projects in debt, financial obligations may limit job options and increase vulnerability to exploitative labor. This lack of financial support and other obstacles that may hinder girls' successful transit are depicted in Figure 3.1. 
FIGURE 3.1

\title{
Adolescent girls may encounter barriers to safe and successful migration, most of which are preventable
}

\author{
Possible roadblocks to girls' safe and successful migration
}

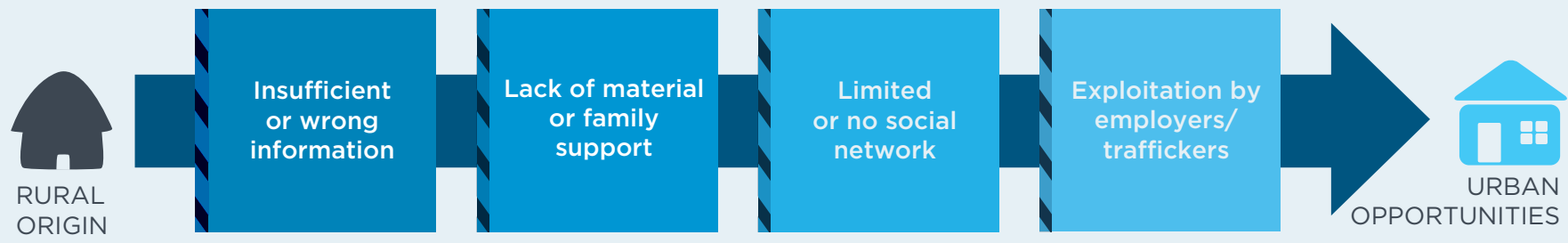

\subsection{Most Girls Don't Move Alone, Creating Opportunity and Risk}

The majority of migrant girls do not travel alone (Hashim 2006). Migrant girls typically know their escorts, who might be parents, aunts, spouses, or friends (Rokicki 2011). In a Cambodia study, over three-quarters of girls migrating for urban domestic work knew the person they traveled with before leaving the village (Brown 2007). A study in India described how seasoned migrants escorted groups of girls from tribal areas to cities by train, where the new arrivals followed the experienced workers into domestic labor (Deshingkar 2010). Alternatively, some girls migrate with recruiting intermediaries or employers whom they do not know. Young labor migrants in Argentina recounted how an unfamiliar woman came to their neighborhood in Bolivia seeking workers for her distant textile workshop, gathering together 12 teenage girls who migrated as a group (Bastia 2005). Accompaniment during transit does not necessarily translate to living with others at the destination, underlining the importance of considering each stage of the migration process separately (Yaqub 2009).

The type of person who accompanies a migrant girl can have a bearing on her social standing and that of her family. Retaining "respectability" in their home communities may be especially significant for girls who plan to return home. A study of young female migrants in Bangladesh's garment industry revealed that parents only accepted daughters' migration when a sibling, relative, or fictive kin (e.g., a close friend or neighbor) accompanied them on the journey and a relative waited at the receiving end. As a migrant girl in a Dhaka factory put it: "No one comes [to the city] on their own. Behind them are some known village persons who stay here [in the city]. For example, I came with other people. It is not possible to come on your own..." (Heissler 2009:7). According to this Bangladesh study, boys were free to migrate alone or with different types of people, but strict expectations control girls' accompaniment. For the girls, the escort had to be an older female, typically of the same socioeconomic status as the girl's family. Were a girl to migrate alone or with a male, the move would place her and her family's reputation in question. Patterns of migrants' accompaniment are an extension of the gender norms tightly controlling girls in highly conservative settings.

Young men often migrate alone, whereas many young women migrate with one or more friends from their village (Hertrich, Lesclingand, and Jacquemin 2012). Other girls travel without an escort under the watch of a transport operator who receives money from the girl's parents to take her to a specific destination. In this scenario, many migrants are ignorant about where they are going, even though bus or taxi drivers have an address. This arrangement has obvious risks for girls, though it can work well as this girl describes: 


\section{BOX 3.2}

\section{Social networks ease the way for Haitian girls in the Dominican Republic}

A study of Haitian adolescent girls living in the Dominican Republic's (DR) border town of Elías Piña reveals how migration histories and social networks affected girls' journeys (Petrozziello 2012).

Mobility was a way of life for these girls before they moved to the DR, and several recounted earlier moves from rural to urban Haiti and sometimes back again. One girl explained: "I used to come [to the DR] before when I was little because my mother was in the capital. Later I returned to Haiti and came back because of the earthquake" (Kathia, 19). They migrated with their mothers as young children and remained mobile in their adolescence. These stories hint at an overlooked aspect of female migration-its inter-generational nature-suggesting it may contribute to the inter-generational transfer of poverty and instability, and also of opportunity.

For these girls, whose poverty was exacerbated by the 2010 earthquake in Haiti, social capital generated through female networks was critical to facilitate their migration. Many girls described how female kin or pseudo-kin ("cousins") brought them to the DR following a disaster (predominantly the earthquake) and/or helped them escape extreme poverty ("misery"). As a young former domestic worker explained, following her parents' death: " $A$ cousin brought me here because I was going through misery where I was living, and she ... bought me clothes and shoes" (Tamara, 10). Without the critical assistance female kinship networks provide in the form of information, fare money, phone calls, and housing, many more new arrivals would face insurmountable hurdles while settling in.

One day my relative from Arusha came and told my parents that someone needs a house girl. They asked the bus driver to take care of me. On the way the bus got some problems but that man took care of me until we arrived in the city. I didn't get any problem until I met my employer.

Zamda, 16, Tanzania

(Rwehumbiza and Mabala 2011:13)

\subsubsection{Intermediaries}

Intermediaries, who have come under scrutiny in the context of trafficking, deserve special mention here. "Intermediary" is distinct from "escort." It typically refers to someone the migrant and her family do not know, but also includes recruiters who represent family decisionmakers (Edmonds and Shrestha 2009). The label covers a broad range of operators, including those working on behalf of an employer or agency and those operating independently. Intermediaries such as recruiters or brokers help connect girls with employment, visiting villages and neighborhoods to collect interested migrants and escort them to their destination, gaining income and social status along the way (Hashim and Thorsen 2011).

Some intermediaries extend their role beyond recruitment and accompaniment to actually help girls. Rural girls from Togo doing domestic work in Accra described how most intermediaries are former housemaids who regularly visit employers' homes to check on girls' treatment and living conditions, and to facilitate communication between girls and their families (Djobokou 2008). Intermediaries undertook similar roles for young migrants from the Mekong region working in Thailand. In addition to job placement, sending remittances, and arranging communication with families, some recruiters advocated for better wages and working conditions or helped extricate migrants from exploitative situations and found them other jobs (Pearson 2006). Concern for children's well-being may motivate these actions; intermediaries may also see intervention on migrants' behalf as a savvy move that will enhance their reputation and expand their business. Regardless of their motivation, capitalizing on intermediaries' potentially protective functions would be a way to increase migrant girls' safety.

Parents and children place considerable trust in intermediaries, often with good reason. In West Africa, children traveling without an intermediary were more likely to be harmed or exploited than those traveling with one (Whitehead and Hashim 2005). Children may rely on intermediaries during the transit phase because they need help, especially where movement is tightly controlled (O'Connell Davidson and Farrow 2007). The closer the relationship between the intermediary and the sending family, the greater the chance that they will fulfill their commitment to ensure that girls arrive safely at their destination, knowing the family will find out and their reputation will suffer if they fail (Heissler 2009). However, not all intermediaries help girls. Some, abusing their trusted position, lead girls into worst-case situations. 
FIGURE 3.2

\section{As girls age, they begin to migrate farther away}

\section{Destination of female Vietnamese migrants aged 10-19}

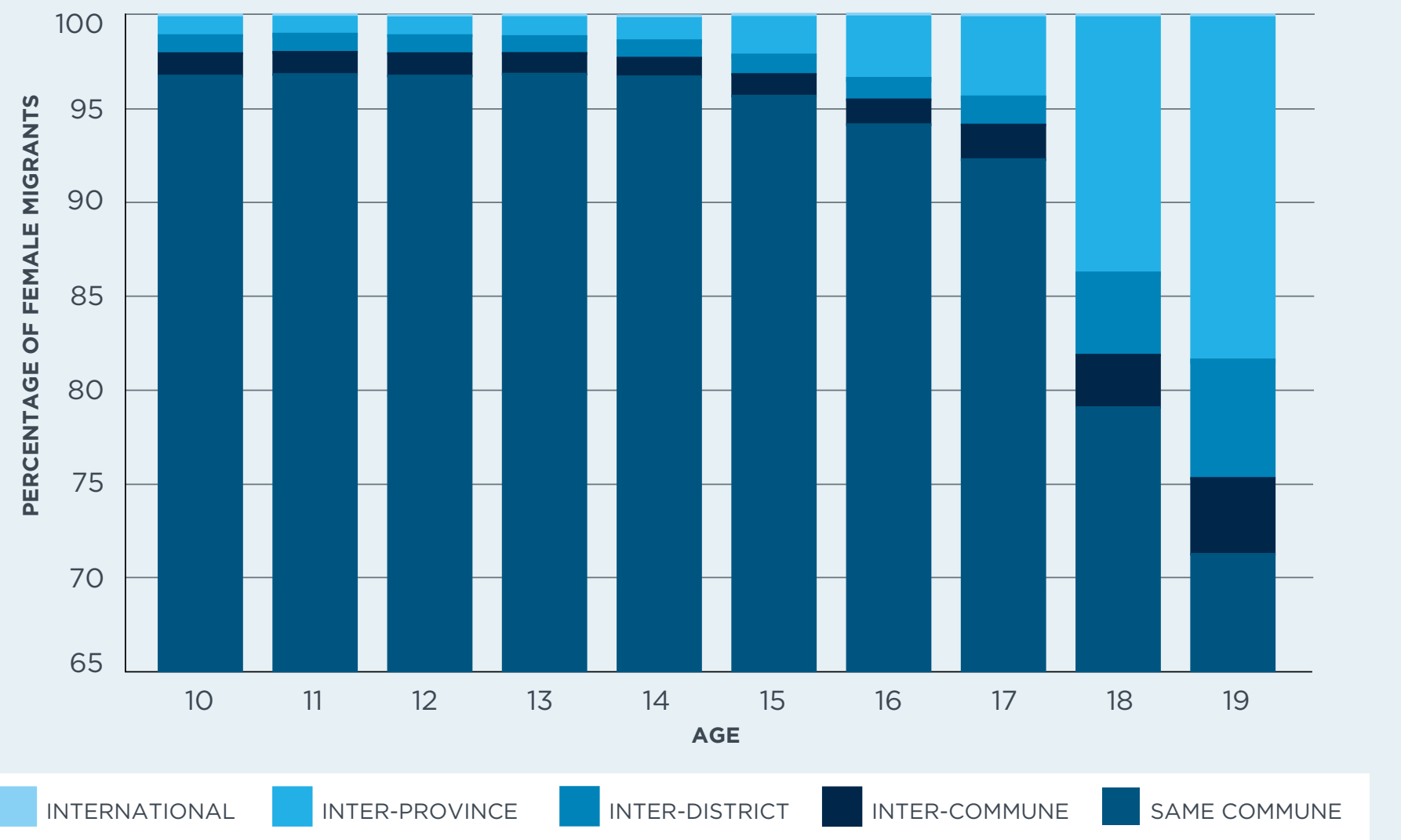

\subsection{Worst-Case Scenarios}

Migrant girls who travel with peers or alone are vulnerable to robbery, injury, rape, or trafficking. Traveling with an intermediary can protect girls en route. However, some intermediaries, both familiar and unfamiliar, use misinformation to allay parents' concerns and attract girls, exposing them to the possibility of being trafficked.

\subsubsection{Migrant girls and trafficking}

Some migrant girls start out as victims of trafficking or fall into the hands of traffickers along the way-a fate more likely for girls than for boys. One estimate places the proportion of all female migrants who are trafficked at approximately 2.3 percent (Murison 2005). It is difficult to specify how many girls are actually trafficked, where, and into what industries because of the clandestine nature of trafficking and the fact that few countries provide detailed data (UNICEF 2006b; UNODC 2009). Another obstacle is the broad definition. The widely accepted definition of child trafficking - the recruitment, transportation, transfer, harboring, or receipt of children (as old as 18) for the purpose of exploitation (UNICEF 2011) - is criticized for being open to interpretation (Huijsmans 2008). 


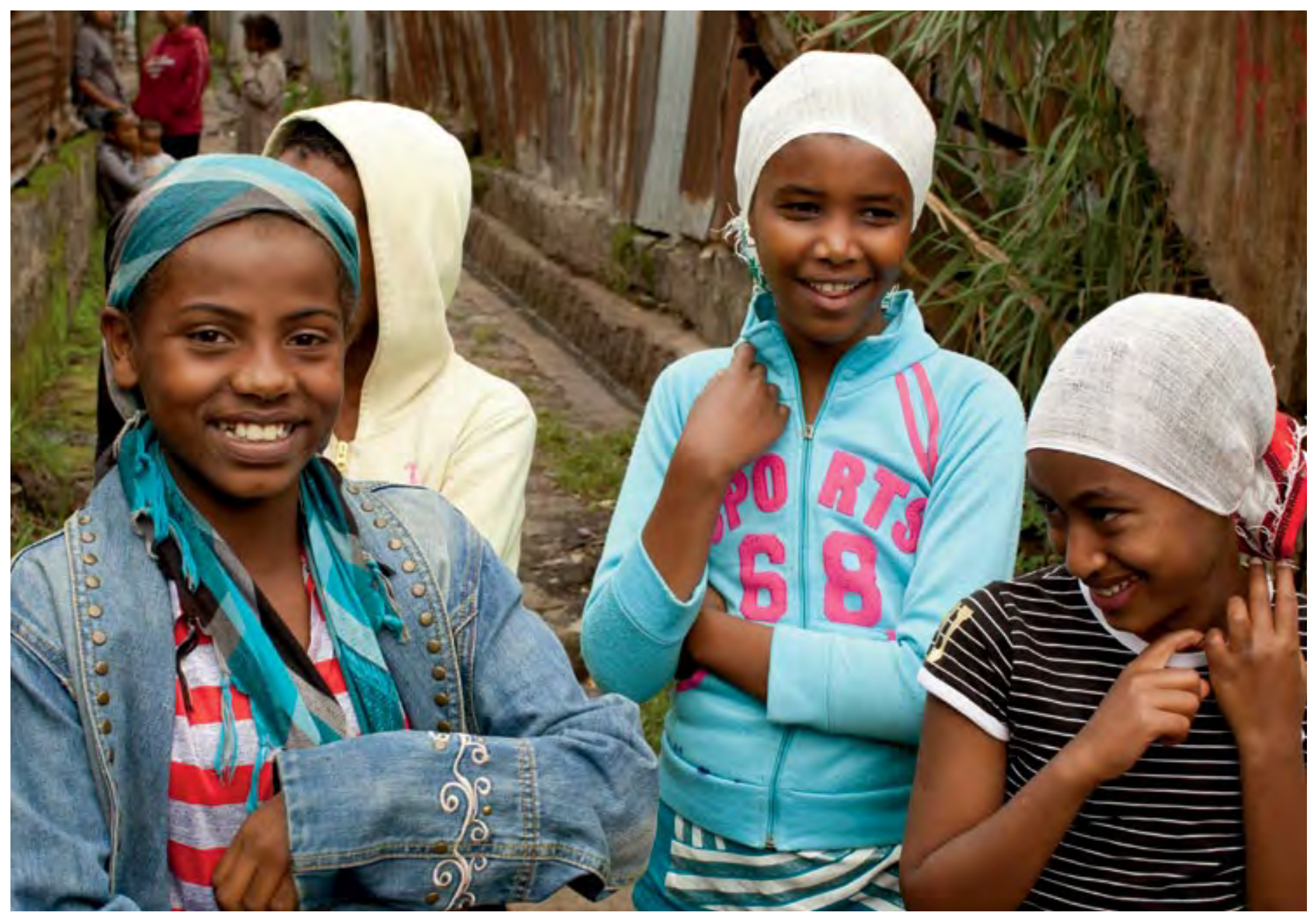

In particular, some note "a considerable grey area in which it is hard to distinguish certain forms of labor migration from certain forms of human trafficking" (Huijsmans 2008:339-40). This is especially pertinent to child labor, given widely varying views about its acceptability.

\section{When trafficking occurs}

Girls who embark on migration independently may land in the hands of traffickers. By taking advantage of migrating girls' unsettled status, some traffickers divert them into exploitative circumstances. In Ethiopia, brokers were observed loitering at bus stations waiting for new arrivals en route to Addis Ababa. Under the guise of offering to help, they took advantage of girls' fear and poverty to recruit them into sex exploitation (Van Blerk 2008). Trafficking also may occur later in the migration process, after a girl

is settled. A migrant girl in Nepal described how she was trafficked into sexual exploitation after working independently in a factory:

...one day I heard there was another factory nearby, paying higher wages... I went to the other factory to ask them if they had a job for me. "You're in luck" said the manager, "I need someone to accompany me and my wife to Hetauda, to collect wool for weaving. It will pay very well." I immediately agreed.... I did not think anything strange about it, especially since I would be traveling with his young wife. After a long journey I found myself in Mumbai where I was sold for Rs 40,000 [US \$725] by the manager.

$\sim$ Sabitri, 18, Nepal

(Simkhada 2008:239)

Girls leaving extremely difficult situations - abject poverty, social marginalization due to ethnic minority status, and abuse or neglect at home-may be more 
willing to accept offers from traffickers (Dottridge 2008a). The majority of trafficked girls are willingly recruited by trusted members of their communities or social networks. With hope for a better life, girls and their families may accept offers from members of their kinship networks or communities, only to learn they were misled by false promises of jobs, schooling, or marriage (Dottridge 2008a; Busza, Castle, and Diarra 2004).

\section{Girls' trafficking experiences}

Trafficked girls' stories are documented in depth elsewhere (Dottridge and Jordan 2012; Crawford 2010; Kara 2009). Typically, their journeys are lengthy and involve several modes of transportation, unlawful treatment, and misinformation. Most such girls are ignorant about where they are going and often travel in groups, which may grow larger as traffickers pick up new girls along the way. Another common characteristic is the involvement of several adults, with money changing hands throughout the journey (Workneh 2008; Groupe Développement 2006). When a border is crossed, girls report that police and other officials were involved and often bribed. Drugging and rape are not uncommon.

\section{Responses to trafficking}

Victims of trafficking may escape or be released from their indentured situations. Some may return home while others choose to stay within their trade. Girls who have been trafficked into sexual exploitation may be more likely than others to remain in the sex trade, fearing rejection at home (Simkhada 2008). Strategies to assist victims of trafficking frequently adhere to the "raid, rescue, and rehabilitate" model, including efforts to "reintegrate" girls into their families of origin (Bandyopadhyay et al. 2008). Some criticize these strategies as failing to recognize what children want, in particular their agency in migration and employment decisions (Ennew, Myers, and Plateau 2005, cited in Huijsmans 2008). The proliferation of anti-trafficking measures has had some success, and in certain countries trafficking rates have dropped (Limanowska 2005). It is worth noting, however, that anti-trafficking measures may increase the vulnerability of people embarking on voluntary migration (Dottridge 2008b). Tight controls on movement may force voluntary migrants to rely on multiple intermediaries to help them circumvent barriers erected to prevent trafficking, increasing the risk of abuse at the hands of malevolent individuals. These observations illustrate how critical it is to include girls who have been trafficked in the design of programs to assist them. While girls in trafficking situations are likely to face greater risks than others, more sophisticated responses to trafficking are needed that tackle the root causes of trafficking and diversify responses to different forms of girls' migration. Finally, it is essential not to conflate girls' migration and trafficking.

Evidence on migrant girls' transit experiences is biased toward the worst-case scenarios, reflecting the fact that adolescent girls often become visible to policymakers only when something goes wrong. Research is needed on the weak points in girls' routine migration journeys, providing pointers for program planners to prevent transit problems before they occur. In particular, it makes sense to re-visit strategies that penalize intermediaries regardless of their potentially protective role. It is also important to strengthen informal systems that are in place to assist migrant children, increasing the chances of a soft landing on arrival. Chapter 4 now turns to how girls' social capital before and during migration shapes their experience as they arrive and settle into their new location. 


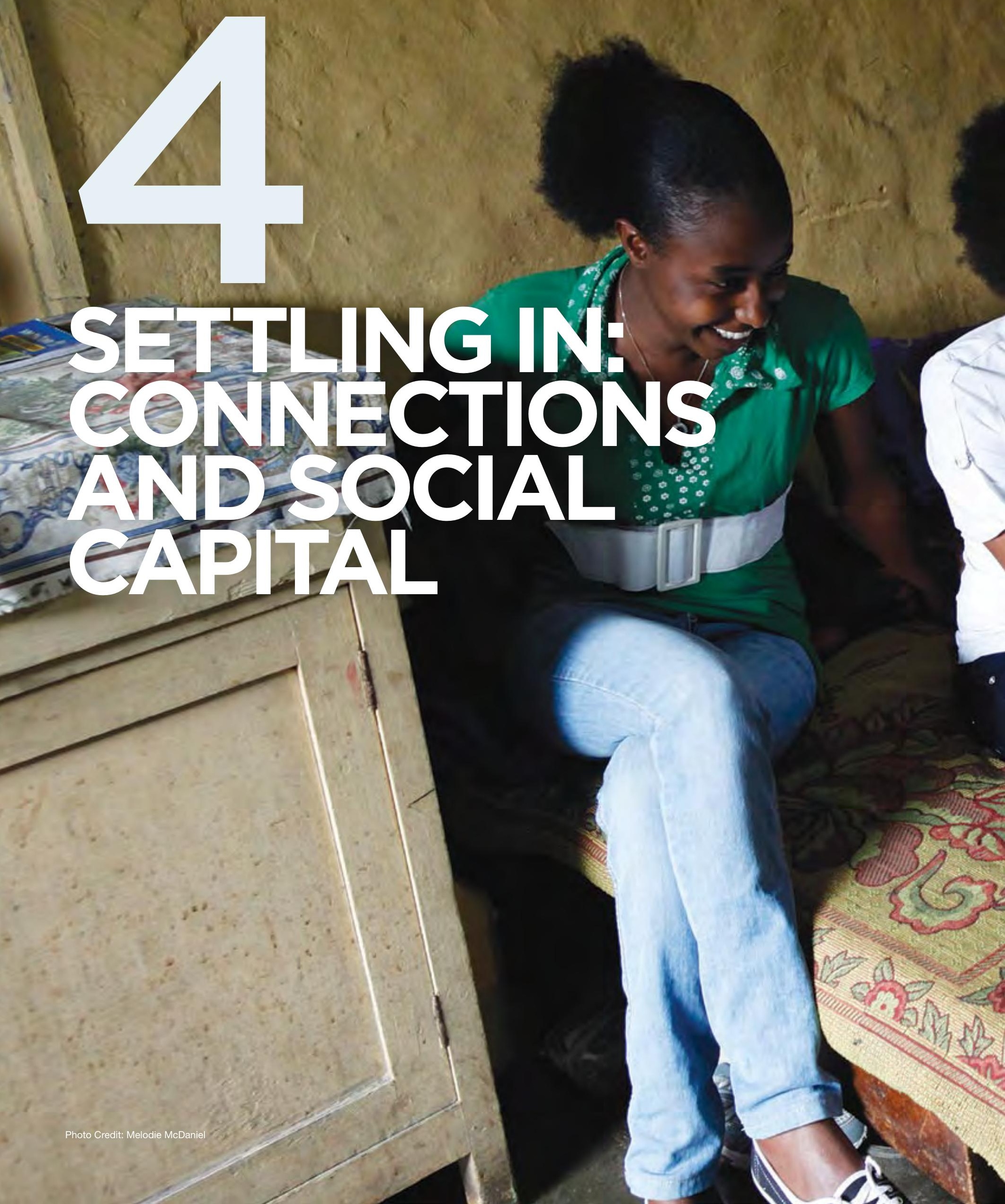


The ability of migrant girls to avoid risks and take advantage of opportunities depends on the assets available to them in daily life and in times of need. Assets include human and financial capital, but also the social resources that provide girls an identity and connections in their new surroundings. Contact with relatives, friends, and coworkers, combined with links to neighborhood groups and services, can help girls succeed. Taken as a whole, these personal networks, groups, and institutions constitute social capital (Moser 2006). The amount of social capital new arrivals have varies. Migrant girls often face a double challenge: understanding the available resources and constructing new social networks to help them access those resources. To surmount these challenges, adolescent girl migrants need access to safe spaces on arrival, measures to prevent or reduce isolation, and services that are sensitive to their needs.

This chapter describes the social resources of urban neighborhoods and wider city environments, framed through the eyes of adolescent girls on arrival. It considers the types of urban neighborhoods where new migrants find housing. Neighborhoods determine the resources available nearby, although migrants' social networks can extend across urban spaces, reaching many neighborhoods. The chapter closes with a discussion of the potential of women's groups and associations of the urban poor to include migrant girls in their networks. These groups, while increasingly influential, rarely view adolescent girls as potential members who need help to integrate into the neighborhood.

\subsection{Migrant Girls on Arrival}

By some measures, new migrants are worse off than more established migrants, having a relatively fragile status on arrival (Panel on Urban Population Dynamics 2003). For girls, the first night in their new location can be a pivotal moment that marks the beginning of a positive venture or a downward spiral. Some recent arrivals have the benefit of help from family members, friends, or intermediaries, while others must make their own way. Those lacking immediate assistance are especially vulnerable to crime and abuse. A Tanzanian girl's experience highlights the potential risks:

The difficulty I got was where to spend the night for the first nights, since I didn't know anyone and I really didn't know where I was going. So I stopped in a small town before we reached the real town. Bad boys stole my bag, but fortunately... [ [had] kept the money in my underpants.

Zamda, 16, domestic worker, Tanzania

(Rwehumbiza and Mabala 2011:14)

Even travel with an escort and plans to meet relatives do not guarantee migrant girls' protection. Another migrant from Tanzania was relying on relatives to help during the arrival phase, but she was not adequately prepared with a back-up plan:

I knew I had a relative here in Arusha, though on the day I arrived she didn't come to pick me up. That day it was after election disturbances. There was tear gas in town. So I didn't know where to go.

Prisca, 18, bar worker, Tanzania (Rwehumbiza and Mabala 2011:14)

Having an address or familiar destination in a new environment can facilitate settling in following arrival. Such circumstances are more likely for girls who migrate with the knowledge and assistance of parents or a known escort. Relatives, former villagers residing in the city, or members of the same ethnic group may provide newcomers with an initial place to stay and information about the city and employment options (Agarwal and Jones 2012). 


\section{CASE STUDY 3}

\section{Ida, Burkina Faso, Age 13}

My auntie recently had a baby and my uncle called my father to ask if I could come and help them in their home in Ouagadougou. I had just finished grade six so my father asked my uncle if he would also help me study for my middle school entrance exams while I was helping them out. My uncle agreed, and my father arranged for me to travel by car with a woman from our village who was going to the city for trade. She dropped me off at the train station and we found my uncle who was waiting there for me. I'm so happy he was there to pick me up-the station was so busy!

I've been in Ouaga for two months now, helping my aunt with some of the cooking and cleaning and waking up at night with the baby. In the evenings after dinner, my uncle helps me study for my exams.
For the first month I was here, I didn't want to leave the house without my uncle because I was worried l'd get lost. But I'm starting to understand the neighborhood better and yesterday I went by myself to the boutique [neighborhood store] near our house to buy bread. While I was there, I met a girl my age who asked me who I was. I told her I was there visiting for a while to help my aunt and uncle, and she invited me to come shopping with her the next day at the main market. My uncle said I could go for a few hours and asked me to pick up some things for the baby. I was so amazed by all the things there! The girl also took me to get some sweets and tea. She said that she would be starting middle school soon, too. If I do well on my exams, I am going to ask my aunt and uncle if I can stay and help longer so I can go to school in Ouaga, too.

\subsection{Neighborhoods and Social Networks}

Much remains to be learned about migrant girls' neighborhoods, which are their main source of social contacts, services, and other resources. Migrants of all ages often find homes in slums. A large study of two Nairobi slums found that some 80 percent of inhabitants are migrants, most of whom moved there between ages 17 and 23 (Béguy, Bocquier, and Zulu 2009). However, empirical evidence suggests that migrant girls live in a variety of neighborhoods, yet non-slum neighborhoods are rarely the focus of the migration literature. An analysis of survey data from over 40 countries shows that recent in-migrant girls live in households with the same general access to improved drinking water and sanitation as those of non-migrant girls (Montgomery et al. 2012).

\subsubsection{Less connected in their new households}

Migrant girls may experience greater social isolation than other urban residents. As Figure 4.1 shows, migrant girls are significantly less likely to be related to the head of household than their non-migrant peers, although quantitative data cannot describe the full extent of their social isolation. Differences between migrant and non-migrant girls' degree of connectedness can be quite large.

For migrant girls who have no option but to live far from their families, members of their urban household can help them communicate with parents. In Dakar, Sereer migrants gather in living quarters according to their origin. They often join forces to rent a room under the responsibility of an older woman who is more experienced and integrated into urban networks. The link with the landlady is known to family members in the village, who may instruct her to keep an eye on the girls (Delaunay and Enel 2009). In Bangladesh, where gender norms are more restrictive, members of the migrant's city household may assume an oversight role to closely monitor girls' behavior and actions. This permits girls' parents in the village to feel they are behaving "honorably" in the city. As Box 4.1 describes, mobile phones can be another way parents and girls stay in touch. 


\section{FIGURE 4.1}

\section{Migrant girls are significantly less likely to be related to the head of household than their non-migrant peers}

Percentages of urban girls aged 15-19 unrelated or distantly related to household head, by migrant status

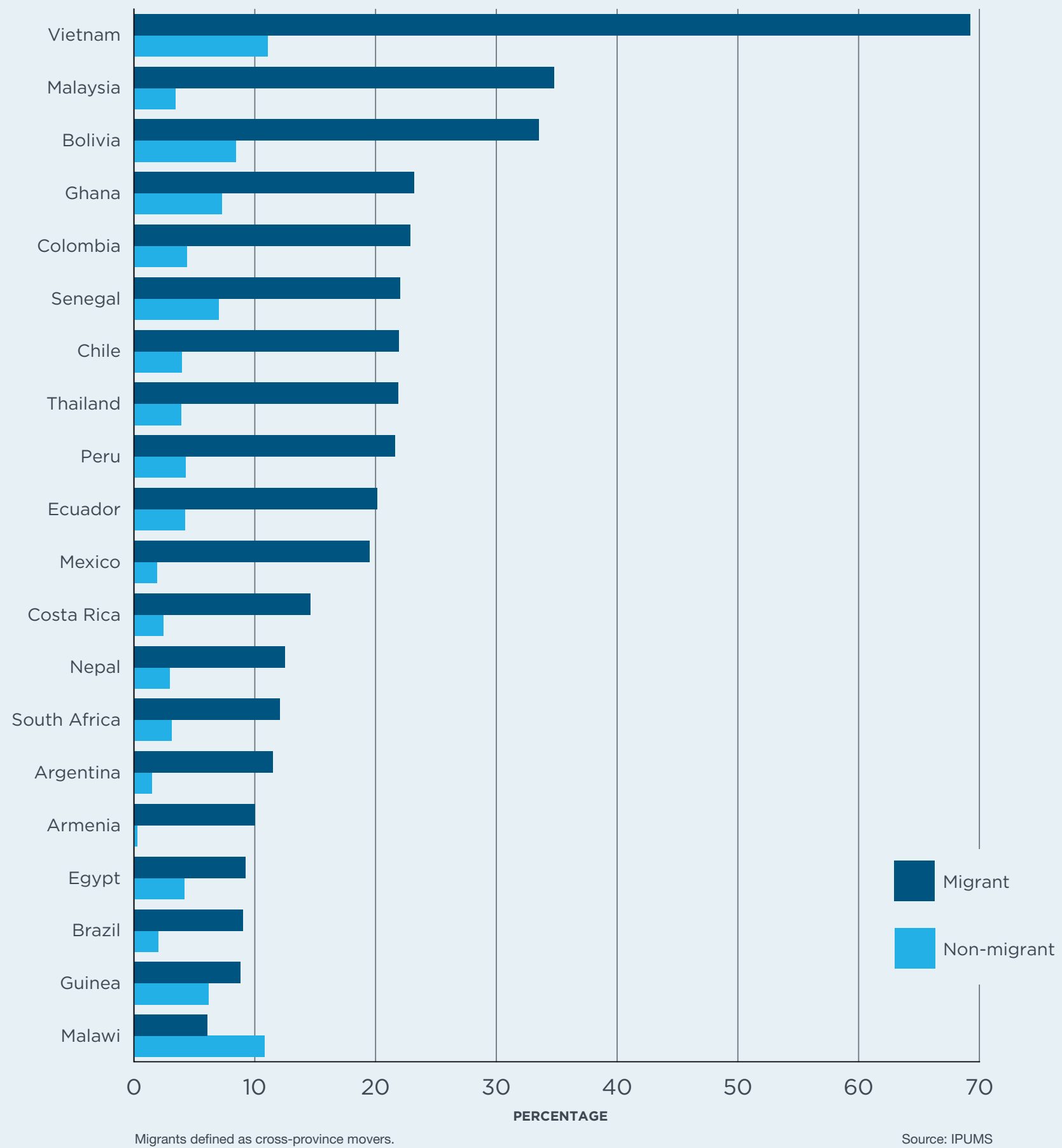




\subsubsection{Forging connections outside their new households}

For some migrant girls, the early period following arrival can be a difficult and lonely time. Those restricted to home may be effectively locked into a circumscribed world inside a vibrant metropolis. In a study in Indore, India, recent migrant girls initially hesitated to build relationships in their new neighborhoods. They felt they did not belong and were concerned about how others saw them. As a migrant girl described:

People think they don't know who we are, where we're from, and what we're doing so they're reluctant to get to know us.

Jyoti, 14, India

(Agarwal and Jones 2012:11)

For long-distance migrants, adjustment can be difficult if they are unfamiliar with the local language and culture:

When I came [to the city] I did not even know Hindi. I spoke the village language ... I felt odd as I did not understand what they were saying. Gradually I started understanding ... [It took] 5 to 6 months.

$\sim$ Priti, 15, India

(Agarwal and Jones 2012:18)

The disconnected feeling gradually subsided for girls who became involved in local activities such as going to markets or temples, or meeting with other girls and women in the neighborhood. Migrant girls with the autonomy and social confidence to spend time outside their homes may eventually build a new network of city contacts and friends. Box 4.2 describes how indigenous migrant girls benefit from socializing with other migrants of similar origin.

Even domestic workers, many of whom are extremely socially isolated, may enjoy the possibility of seeing family and friends. A study of domestic workers in Ghana found that most received visits from friends in their employer's home, although their ability to go out on visits was more restricted. A significant proportion (over 40 percent) reported that their parents visited, and many were given time off to see parents and family on holidays or other special occasions (Apt 2005).

\section{BOX 4.1}

\section{Mobile phones connect and empower migrant girls}

For migrants, mobile phones are an important and low-cost means to stay in touch with families at home, build social networks, and exchange job information. Access to mobile phones is increasing globally: three-quarters of the world's inhabitants now have access to a mobile phone (World Bank 2012). Quantitative data on global access to mobile phones are not disaggregated by sex or age, so information specific to migrant adolescent girls' access to mobile phones is limited.

An emerging literature based on small-scale studies in China and Southeast Asian countries suggests that mobile phones are central to the lives of some migrant girls. Girls in these regions actively create personal networks through text messaging (Bunmak 2012; Lin and Tong 2008; Yang 2008). The phenomenon is especially marked among migrant "factory girls" who work long hours in tedious jobs and have few opportunities to spend time with friends and family. For them, text messaging becomes a form of social life that allows them to communicate with parents and family and sustain friendships from afar. It also creates space for girls to express their feelings and take more initiative in romantic relationships, which may not be possible in rural communities (Lin and Tong 2008).

The use of SMS messaging also provides young Chinese migrant women in factory work opportunities to acquire and practice literacy skills in their everyday lives (Lin and Tong 2008:77). Because factory work does not require literacy, SMS messaging may be the only chance for these migrant girls to retain their existing levels of literacy.

Evidence on girls' phone access in South Asia, Africa, and Latin America is limited. In patriarchal societies with restrictive gender norms, it would not be surprising if adolescent girls had limited phone access. Migrant girls stand to benefit greatly from applications of mobile technology, such as mobile healthcare, mobile banking and remittances, and access to news and information. Additional research on girls' mobile phone ownership and use, and on how mobile technology affects the cultural and social practices of migrant adolescent girls, could be used to guide innovative programs in this promising area. 
BOX 4.2

\section{Indigenous identities and adjustment}

Some migrants move to cities from culturally isolated communities where indigenous practices dominate. Cultural differences between the communities of origin and arrival can erode long-standing cultural traditions and contribute to migrant girls' sense of dislocation. It can also be a source of discrimination above and beyond what migrant girls experience because of their age and sex, increasing their vulnerability to exploitation and other forms of mistreatment.

Indigenous migrant girls often describe how they abandon their customs to avoid discrimination and appear modern. They often express these changes through their choice of clothing. Indigenous Peruvian girls who migrate to Lima for domestic work reported abandoning traditional costumes of ponchos and skirts, learning "with difficulty" to wear pants instead (AGTR 2004; Leinaweaver 2007). Indigenous migrant agricultural workers in Mexico also reported wearing shorts and pants to blend in (Cos-Montiel 2000). Tribal girls in India revealed a similar adjustment: in a large survey, 78 percent of the girls who moved from tribal areas to work in cities reported that they changed clothing habits; over half also changed food and traditional cultural norms to blend into the new setting (Tirpude College 2004).

Native language is another expression of culture that many migrant girls abandon in an effort to fit in. The migrant girls in Lima reported feeling embarrassed to speak their native tongue when working as urban domestic laborers. Girls who migrated when young and only spoke Spanish in their employers' homes tended to lose touch with their native Quechuan language (AGTR 2004).

Native identity also offers a connection with other migrants in new urban settings, which can be a source of social support and assistance for girls. Migrant girls in Lima who had the opportunity for Sunday visits to relatives in areas populated with migrants benefited from socializing in their native language with those in similar situations. This reportedly restored their selfconfidence and pride in their heritage (AGTR 2004). The benefits of such opportunities can be considerable for girls working in socially isolating circumstances, separated from those around them by language and culture. Strengthening informal indigenous networks is a promising approach for helping migrant adolescent girls, explored further in Chapter 7.

\subsection{Community Groups to Facilitate Connections}

Community groups and associations are important resources for helping recent arrivals and developing migrant girls' social capital. Neighborhoods where migrant girls live vary in the presence and authority of these groups, but in a number of countries, community groups such as associations of the urban poor and women's groups have effectively advocated on behalf of their members with both municipal and national governments. ${ }^{10}$ The groups do not generally provide services, but rather negotiate with local governments to extend existing services and infrastructure to their communities. ${ }^{11}$ These groups are critical because, on their own, adolescent girls are unlikely to be able to influence local government programs and services. They could only hope to do so if associations of the poor, women's groups, and NGOs speak on their behalf.

These community groups confront two challenges in reaching migrant girls. First, many girls are unaware that such groups exist in their neighborhoods. Second, although associations of the urban poor have started to recognize that migrants and adolescents warrant attention, they are founded on the concept of community solidarity and collective action. As such, they may be wary of recent arrivals who have yet to demonstrate their long-term community commitment. In India, women's group members noted that people in the community tended not to invite recent migrants to social activities and groups until they became acquainted and were certain that the migrants intended to stay on a more permanent basis (Agarwal and Jones 2012).

The risks facing adolescent migrant girls are likely to be greatest at and soon after their arrival, just the time when groups of urban poor are likely to be in a "wait and see" mode. This gap warrants attention. Creative programs are needed to welcome and rapidly incorporate migrant girls into community groups and thereby link them to available services. Associations such as groups for children of the street and domestic workers ${ }^{12}$ may be a more readily recognizable resource for adolescent girls in some settings. In this urbanizing era, there is every reason to design programs to respond to the needs of urban in-migrants and to ensure that existing efforts allow 


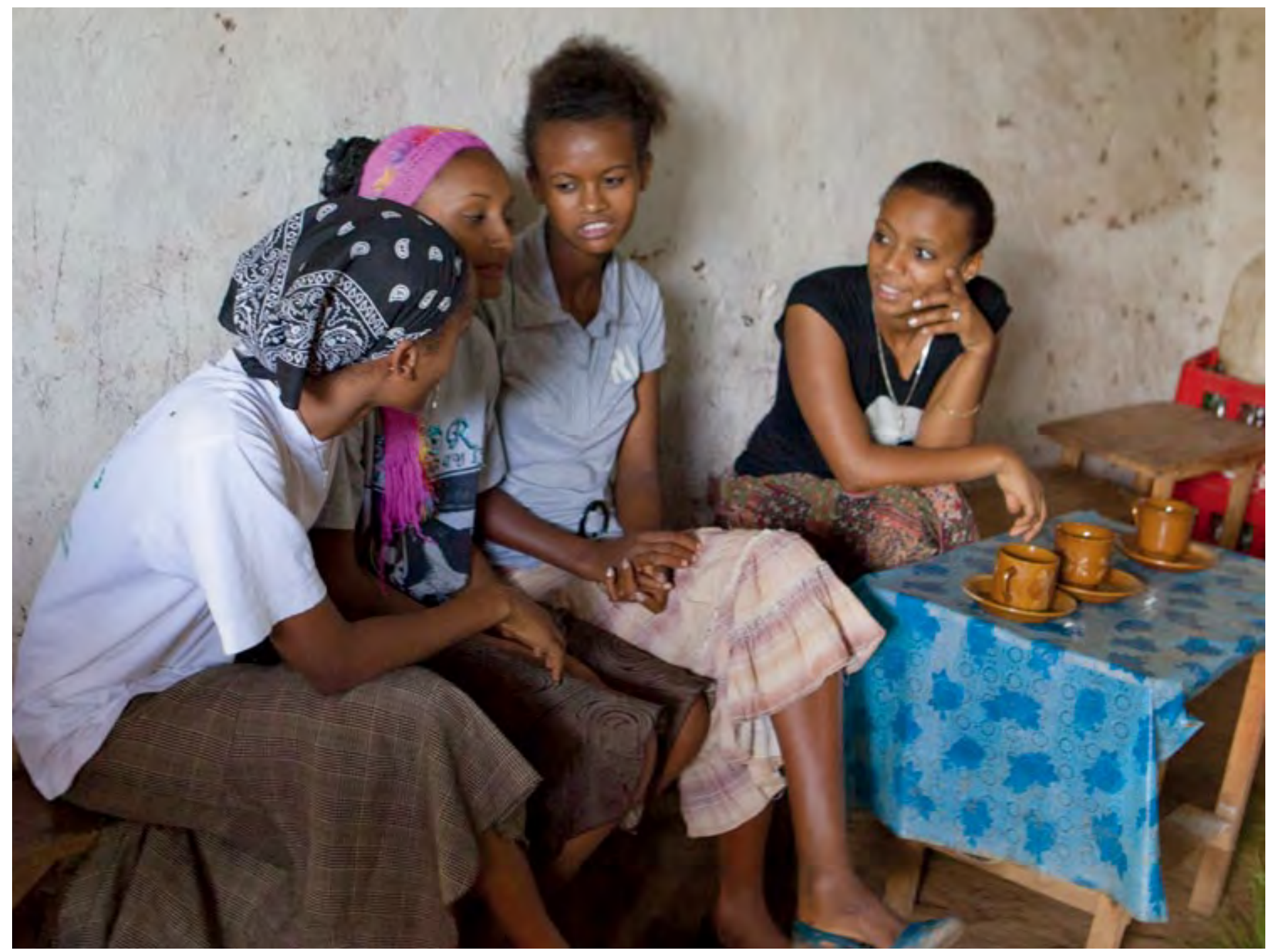

migrant girls to take full advantage of the social resources available in their new communities.

Whether migrant girls in urban areas are isolated or are able to take advantage of opportunities to enhance their human capital depends on their ability to access services and social capital. Some are fortunate enough to have support from relatives or others at each stage of their migration, providing protection, advice, and information about the potential benefits of urban living. Others find support by building new networks. Linking vulnerable adolescent girls to formal and informal urban associations and expanding their access to mobile technology are promising strategies that allow them to develop social capital. Social capital plays a critical role in facilitating migrant girls' employment, a topic that is explored in the next chapter.

Photo Credit: Melodie McDanie

These and similar groups are linked internationally through an umbrella organization known as Slum/Shack Dwellers International (SDI). For further information, visit SDl's website: www.sdinet.org

Their main concerns have been in the areas of safe housing, sanitation, and drinking water.

For example, the Consortium for Street Children (http://www.streetchildren.org.uk/) or the International Domestic Workers' Network (www. idwn.info). 


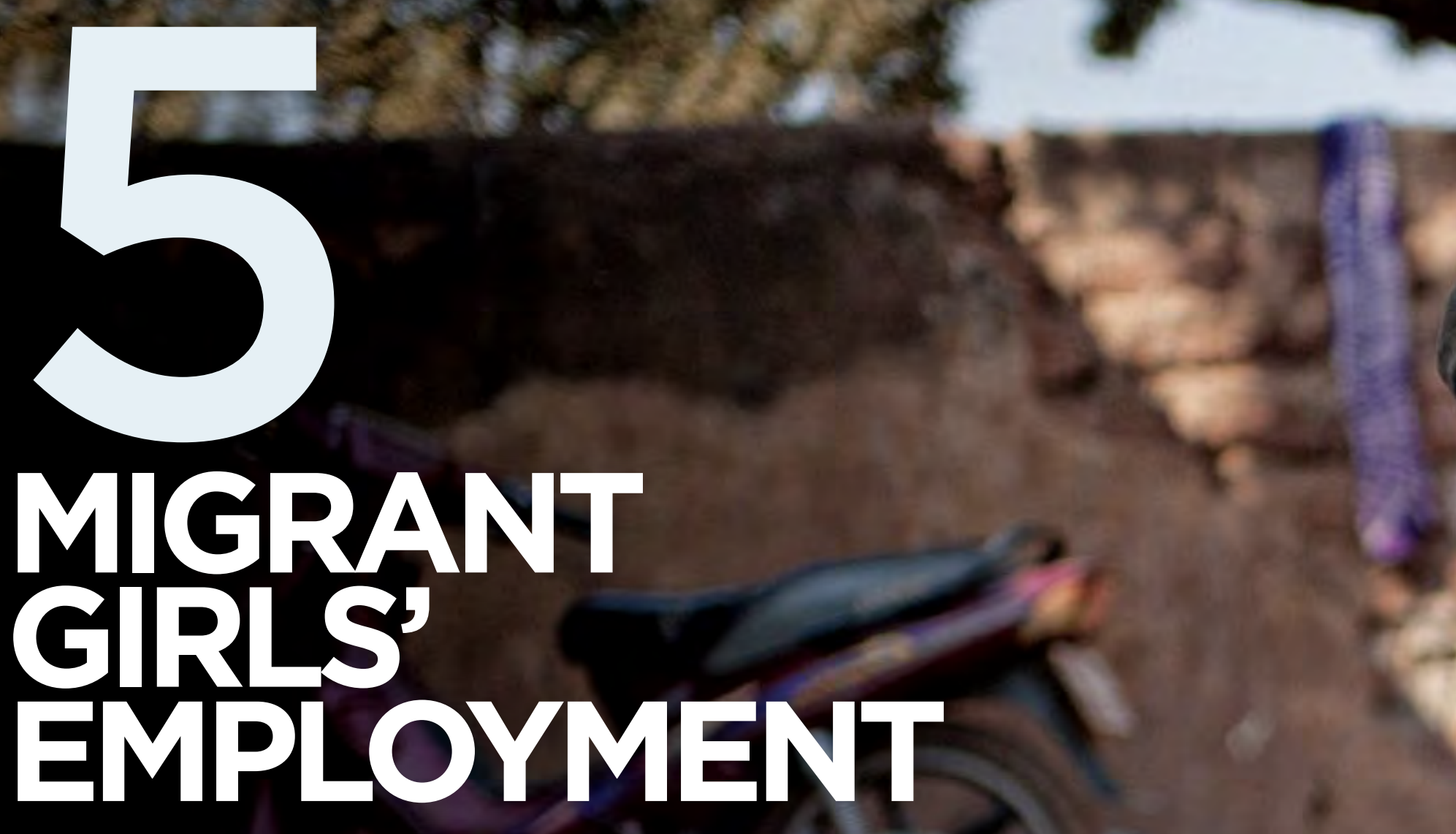




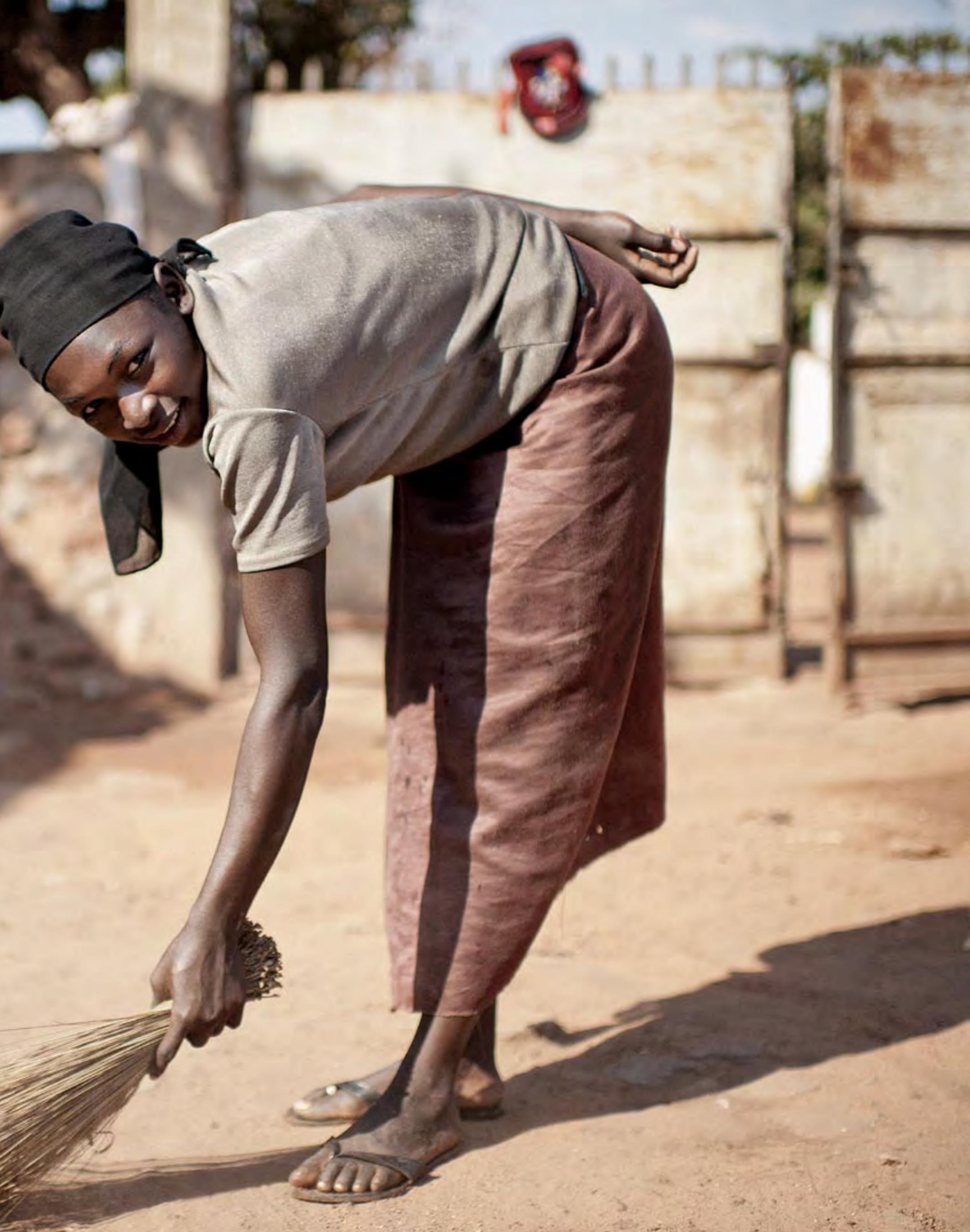


The lack of suitable work opportunities is one of the principal factors driving rural girls to urban areas. Likewise, the limited possibilities offered by smaller cities and towns may motivate urban girls to seek opportunities elsewhere. This chapter provides an overview of the most common features of employment for urban migrant girls and identifies industries where they often find jobs, including factory work and domestic labor.

\subsection{Migrant Labor: Limited Options and the "Three Ds"}

Employment is a major aspect of the lives of many migrant adolescent girls, even more so than for their non-migrant peers. A study in Ethiopia found that 47 percent of recent in-migrant girls aged 15 to 19 worked for wages, compared with only 16 percent of non-migrant girls of the same ages (Erulkar 2012). Migrants tend to work in poorly paid jobs, often earning less than the minimum wage where it exists (FTUB 2006). Employers may underpay migrants because of the large numbers willing to work for low wages and because workers lack alternatives when faced with exploitation. In some settings, inequitable gender norms mean that girls are even more severely underpaid than boys. Their work schedules also differ. Studies in Vietnam and China revealed that migrant girls worked longer hours but earned less than migrant boys, leaving girls less time to rest, attend school, and interact with peers (Anh 2006; Liang, Guo, and Duan 2008).

\subsubsection{Restricted employment options}

Although job markets are more diverse in urban than rural areas, limited human capital constrains migrant girls' work opportunities. Migrant girls tend to enter the labor market at younger ages and with less education compared with local urban girls. This leads many to unregulated industries and sectors. According to an ILO study of child labor in urban Uganda, 60 percent of children in the informal sector are migrants (2004b). Many young migrants of both sexes work in jobs characterized in terms of the Three Ds - "dirty, dangerous, and difficult" (or interchangeably, "degrading"). According to the same study, 82 percent of urban working children were involved in hazardous work (2004b).

Employment patterns for migrant girls are distinct from those of boys. Girl migrants work in bars, restaurants, domestic service, and hairdressing, and are also commercially sexually exploited, while migrant boys work in garage or repair shops, carpentry, hawking, and scavenging (ILO 2004b). In a study in Mali, rural boys primarily migrated to other rural settings to work as herdsmen or farm laborers, while nearly all migrant girls went to cities for domestic work (Hertrich and Lesclingand 2012).

Some employers prefer to hire girls. Their perception that girls are "docile" influences hiring practices in certain manufacturing industries, such as garment production in Cambodia, where employers seek obedient workers who are easy to control (Nishigaya 2002). Some employers of domestic workers favor younger girls over older girls and adults. Employers in Lusaka reported that young girls work harder and are more reliable, obedient, and trustworthy than adult workers. In Accra, younger domestic workers are seen as less desirable to male household heads than older ones, presenting less of a threat in the eyes of their wives (Oyaide 2000; Djobokou 2008).

\subsubsection{Working girls face risk and reward}

Many working migrant girls are vulnerable to occupational risks inherent in their work, such as exposure to hazardous chemicals or, as among the kayaye $i^{13}$ of Ghana, the physical strain of carrying heavy loads on their heads (Awumbila and Ardayfio-Schandorf 2008). Working migrant girls are also vulnerable to the risk of exploitation; this may be harder to reduce than occupational risk because it is grounded in social norms and pervasive gender inequality. Employers tend to have greater control over younger workers than older ones, leading to high rates of abuse of younger workers where effective regulation is absent. In a study of young migrant laborers in Thailand, over half of the employers within four industries studied (fishing and fish processing, domestic work, agriculture, manufacturing) believed that "we should lock migrants in at night to make sure they don't escape" (Pearson 


\section{CASE STUDY 4}

\section{Radha, Bangladesh, Age 16}

When I was 13, my parents arranged my marriage to a man in our village. Soon after I learned of their plans, a woman who used to live in our village returned for the holiday of Shawwal [Eid]. She said she was looking for girls to work in a garment factory in Dhaka, saying they would get paid Tk.800 (USD \$10) every week. I did not want to get married, so I begged my mother and father to let me go, saying I could help save for my dowry. Knowing we did not have much money, my father agreed. The next week, I took a car with the woman and a few other girls from our village. When we arrived in Dhaka, everyone was dropped off at different employers, and I saw the woman from our village receiving money from one of them.

My job wasn't at the factory as I had been promised, but as a waitress in small restaurant. The owners and I slept in the back of the shop, and since it was open every day there was little rest. My employers yelled at me each day and called me clumsy and stupid. Sometimes the wife would leave to go to the market in the middle of the day and the husband would force himself on me. I cried many nights, but I didn't tell my parents anything because I didn't want to go home and get married. For the first three months they did not pay me-they said I had to pay the travel fees to get to Dhaka.

When I was fifteen, I learned I was pregnant. Not knowing what to do, I told the owner and he gave me two Tk.500 bills (USD \$12) and told me to get out. With no other place to go, I moved onto the streets. Later a woman stopped and asked me if I was hungry, and then took me to a shelter. After hearing my story and seeing I was pregnant, she let me stay at the shelter. I had my baby there and after a while the staff tried to contact my family and send me back home. But I didn't want to go because I knew my baby and I would bring shame to my family. The shelter staff put me in touch with girls who used to live at the shelter who also decided to stay in the city. I moved into a room, and to earn money, they helped me find a job at a new restaurant. I'm much better at this job, since I actually learned a lot at the other restaurant. I feel good now because my employer gives me Thai Bht 80 (USD \$2.50) a day and I managed to buy some clothes for my daughter and even send money to my mother on holidays.
2006:43). In the Mekong region, working migrant girls reportedly face debt bondage, illegal confinement and confiscation of documents and IDs, and forced overtime, and they endure inadequate and unsafe living conditions (Caouette 2001).

Migrant girls working in industries that depend on male commercial activity may be especially vulnerable to exploitation. In coastal Liberia, for example, many men work in the fishing industry and adolescent girls sell the fish. The girls' dependency on men's yield puts them at risk of sexual exploitation: in this setting, some men reportedly demand sex before giving girls the fish they need to secure their livelihoods. ${ }^{14}$
While job instability and high turnover characterize some girls' working experiences, their strong desire to hold onto a job-no matter how difficult or unpleasant - for family or personal reasons prevents some workers from seeking recourse or quitting. Many working girls are unaware of their rights as children and as workers, which further prevents them from speaking up when mistreated. A large survey of migrant tribal women and girls in India showed they do not protest employers' economic exploitation because they do not know their rights, face acute poverty, fear job loss, and lack job alternatives (Tirpude College 2004). Research with girls in factory work in urban Cambodia found that their illiteracy
14

Personal communication, Doris Geedeh, Touching Humans In Need of Kindness (THINK) NGO, July 2009. 


\section{BOX 5.1}

\section{Remittances}

Migrant remittances are the most tangible link between migration and development, allowing migrants to send resources directly to their family and friends. While development policy has focused largely on international remittances, data from sub-Saharan Africa show that families are much more likely to receive domestic remittances than international remittances (Godoy et al. 2012). Data from sub-Saharan Africa also debunk the myth that men are the senders of remittances and women their recipients: both sexes are similarly likely to report sending and receiving money from family or friends (Godoy et al. 2012). When women and girls earn an income, they reinvest on average 90 percent of it into their families, compared to 30 to 40 percent for men (Fortson 2003).

Migrant adolescent girls are no exception. Although there is no largescale evidence on internal migrant girls' remittance patterns, frequency, or outcomes, evidence from small studies showed that working migrant girls share their earnings with their families. A study of migrant adolescent girls in domestic service in urban Burkina Faso found that roughly a third had sent home money in the past year (Engebretsen 2012a). Girls generally send remittances using informal channels. They may carry cash when they visit, or send cash with bus drivers, traveling acquaintances, or via informal hawala ${ }^{15}$ services. "Mobile money" services are also becoming more common in certain countries, allowing migrants to send funds electronically across the country using mobile phones (Godoy et al. 2012).

Migrant girls' remittances can be a significant source of support for poor families in the developing world. The concept that daughters should provide financially for aging parents is emerging in some places, which researchers in parts of Mexico attribute to increasing rates of girls' labor migration (Greene 2001). In Indonesia, rural parents rely on their daughters working in cities for money to buy food and household necessities, especially during drought and crop failure (Elmhirst 2002).

The experiences of working, earning money, and remitting to families can improve migrant girls' status within the family and give them greater influence in decisionmaking. Remittances also may have the effect of preventing child marriage, since parents who rely on daughters' remittances may be less likely to force girls to return home to marry. Ensuring that migrant girls have access to safe, fair, and appropriately compensated employment is essential. Empowering them to manage wages and safely remit them is another way to increase their economic potential. made them vulnerable, hindering their access to information and protection (Taylor 2011).

Concerns about girls in abusive and exploitative employment are well founded. However, public discussion about working conditions considered normal for girls at home also needs to change. A study in India illustrated the contradiction between the public's acceptance of girls' working conditions at home and public outcry about migrant girls' wage labor conditions in prawn-curing factories. Migrant girls from Kerala attracted attention because of media reports on the dire conditions of their paid factory labor. When the girls were interviewed, however, they said they enjoyed their experiences, valuing above all the respectability their income brought them at home. The same girls had onerous work obligations within their families before migrating, having no choice but to work alongside their mothers making coir rope from coconut husks, typically without pay. The researcher concluded that the work at home failed to spark public outrage because it was seen as part of a girl's normal upbringing within her family (Nieuwenhuys 1995).

The risks of migrant adolescent girls' employment should not be understated. But alongside such risks, employment can boost migrant girls' human capital, economically empower them, and expand their life choices. Girls taking the long view may believe that acquiring skills for their future is an investment worth current hardship (Thorsen 2005). Working also allows migrant girls to help their families (Castellanos 2007). As Box 5.1 discusses, girls who leave home to work often remit some of their wages to their families for siblings' school fees, essentials such as agricultural inputs, or much-valued luxury goods such as electronics (e.g., Mills 2005). For reasons like these, a study in Vietnam found that a majority of young migrant workers wished to stay and continue their work despite unfavorable conditions (Anh 2006).

\subsection{Common Jobs for Migrant Girls}

The chapter turns to two jobs common for migrant girls across regions: factory work and domestic labor. These jobs can be a path to upward mobility. At the same time, it is worth noting that many of the jobs migrant girls take are in service and entertainment sectors. These jobs can serve as "gender traps," locking 
girls into low-status and demeaning circumstances (Cerrutti 2009; Gaetano 2008). Even the emancipating impact of manufacturing work - not a typical female domain-may be more evident outside the factory than inside, where highly inequitable norms surround girls with new constraints (Murphy 2008).

\subsubsection{Factory work}

Adolescent girls and young women migrate to work in factories, a fact that is widely documented in parts of Asia and Latin America. In a random sample of more than 1,000 female garment workers in Bangladesh, the majority were young migrants; 87 percent came from rural areas, a proportion consistent with studies from other countries, and nearly 70 percent of respondents were under 20 when they began work (Amin et al. 1998). Migrant girls often find their way to factories through their social networks, such as Bangladeshi garment factory workers who find jobs through family and friends or known intermediaries (Heissler 2009).

\section{Conditions of work}

While factory working conditions vary, glimpses into the situation of young female factory workers reveal a general pattern of long hours and low pay in often unsafe and unsanitary working conditions. For example, in the Cambodia study mentioned above, over 2,300 incidents of garment workers fainting were reported in the first half of 2011, attributed to poor air circulation and long overtime hours (Nimol and Maclsaac 2011; Keo 2011 in Taylor 2011). Working conditions for young Burmese women in Thai garment factories were similarly bleak. Workers were paid well below the national minimum wage for excessive hours; faced involuntary salary deductions for food and lodging and/or were forced to sleep in factories; and endured bonded labor, employers' seizure of identity and registration documents, and vulnerability to arbitrary firing, arrest, or deportation (Kusakabe and Pearson 2010; FTUB 2006).

Employers' control over young female migrant workers is also documented in Latin America. In Honduras, rural girls who migrate to work in maquilas ${ }^{16}$ face excessive employer controls, which extend to their reproductive lives. One study found that young women were forced to undergo pregnancy tests when applying for factory jobs. If hired, they worked for a reduced salary for a trial period until a second test confirmed

\section{BOX 5.2}

\section{Getting ahead in Bangladesh's garment industry}

Given the right combination of characteristics - being shrewd and opportunistic in this setting-migrant girls can increase the benefits of factory work. Vanessa, a 16 year-old migrant from rural Bangladesh, lied to get her first job in the garment industry and did the same to get a promotion (Heissler 2009). A female relative acting as an intermediary encouraged Vanessa to lie about her age to get an interview at a garment factory. Once in the interview, Vanessa's improvisational skills got her the job:

I had never done garment work before... [but during the interview] they gave me a test to find out if I knew how to do "Finishing." I looked at what the other girls were doing and imitated them and got the job.

After nine months of working in finishing, Vanessa and a friend took the initiative to find higher-paying, higher-status jobs:

We went to the eleventh floor and asked for a job in "Quality" and the people there... asked what we did and we lied and told them that we worked in "Quality."... They gave us a test and asked us to tell them how many inches were on the tape measure. I didn't know and said I had forgotten. The factory people told me it was 60 inches long and I said, "Yes, I know. Sorry I have had a break [holiday] and forgot." Then they gave us trousers to check and I looked carefully and pointed out the mistakes so they decided they would give me Taka 1600 (USD \$20) per month and my friend Taka 1400 per month because she didn't find all the mistakes and didn't do as well as me.

Vanessa independently circumvented hiring practices that were intended to separate the experienced from the inexperienced workers. This shows the importance of personal characteristics and attributes that are essential aspects of agency (Heissler 2009).

they were not pregnant. In an effort to maximize worker output regardless of their human rights, some employers forced workers to take contraceptive pills or even advised female employees to undergo abortions if they became pregnant (Pine 2009).

\section{What do girls say?}

Despite these risks, many girls report that factory employment has higher status than other forms of migrant labor. Bangladeshi girls in Dhaka garment
15

Hawala, Arabic for transfer, is an informal money transfer system based on a wide network of money brokers. It is an alternative remittance system that exists alongside traditional banking channels. Money is transferred from one broker to another without actually moving it. The system is based on trust and connections (Godoy et al. 2012:8).

Maquilas are factories for construction and processing of export goods. 


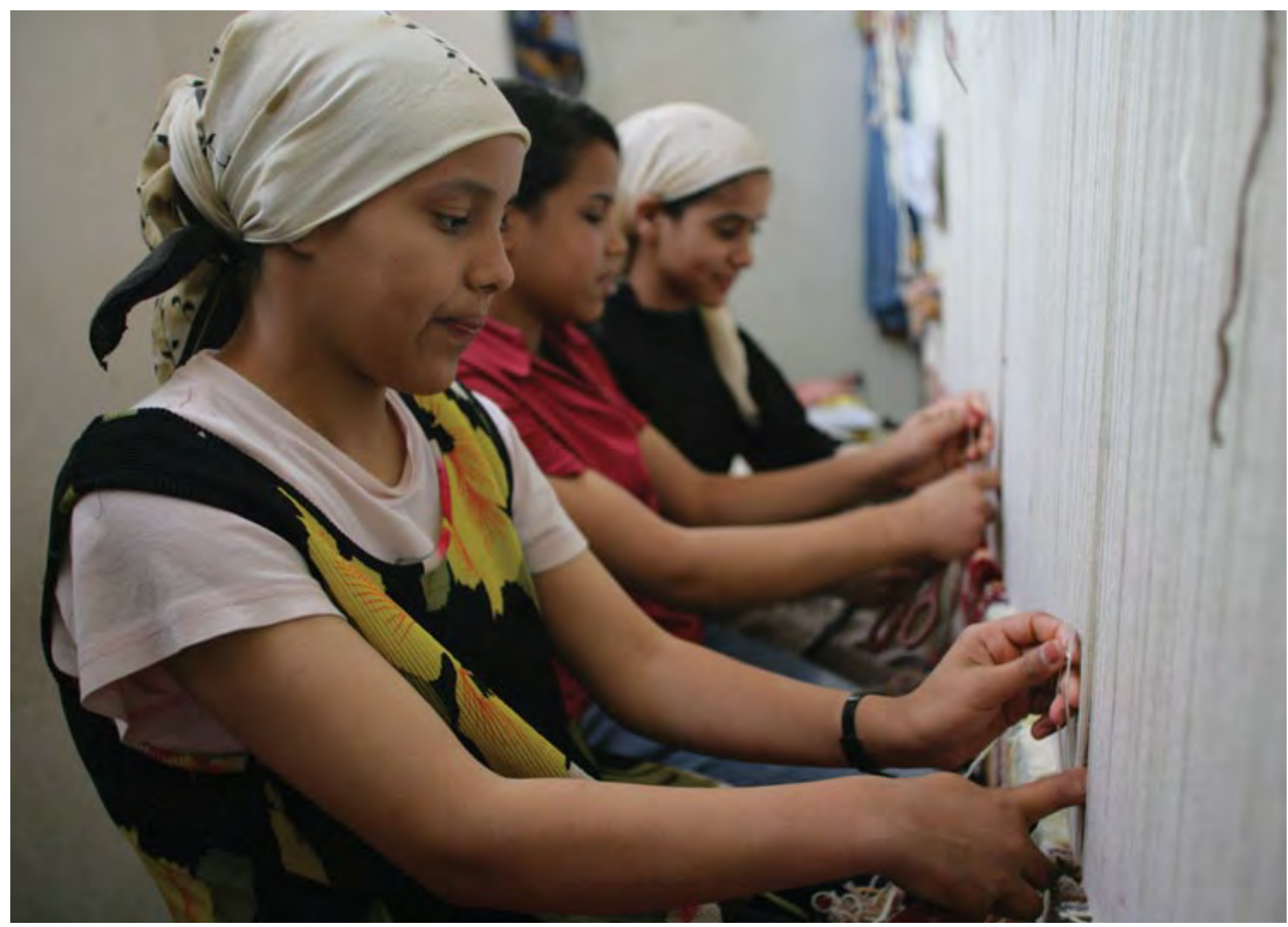

Photo Credit: Giacomo Pirozzi

Girls work at a loom, in a carpet factory in Fez, capital of the northern Fès-Boulemane Region in Morocco. factories value the better working conditions and higher pay they enjoy compared to domestic laborers (Amin et al. 1998; Heissler 2009). Garment factory work also provides the opportunity for promotion, as Box 5.2 illustrates. Parents may also prefer factory employment. A study in Indonesia found that parents accepted their migrant daughters' employment in garment factories because it was consistent with their notions of female beauty (keeping girls' skin out of the sun and untanned), it expanded girls' experience and social skills, and it increased their value on the marriage market (Elmhirst 2002).

At the same time, some girls reported that migration for factory work is not always socially accepted. In Cambodia, family members and community elders disapproved of girls' migration for factory work because they conflated it with casual and paid sex: "old people often look down [on] women garment workers and think that the workers have to sell sex to have money to send to their families" (Taylor 2011:28). Similarly, research found that migrant boys in carpet factories in urban Nepal differentiated between the "pure" girls in villages and the "sluts" working in the city, despite evidence showing that young people's sexual activity often started in villages before they migrated (Puri and Busza 2004).

Some migrant girls described enhanced social capital as a benefit of factory work. Young women in Bangladesh garment factories formed attachments with peers, using friendship groups for practical purposes such as rotating funds and sharing information about work, living conditions, and job alternatives (Amin et al. 1998; Phouxay and Tollefsen 2011). Taken together, the opportunities provided by factory employment 
can offer migrant girls the potential for advancement and emancipation if unsafe working conditions and exploitation are addressed.

\subsubsection{Domestic work}

The ILO estimates that more girls under 16 are employed in domestic service than in any other occupation, although estimates are imprecise because domestic work occurs in private homes and is often hidden (IPEC 2004). The ILO also estimates that the majority of domestic laborers are migrant girls and women (ILO 2010). In a study of adolescents in low-income areas of Addis Ababa, Ethiopia, nearly all domestic workers were migrants, with over 80 percent from rural areas (Erulkar and Mekbib 2007). While some migrant girls in domestic work suffer extreme exploitation, many value the benefits domestic work can provide in the form of income, new skills, increased schooling options, and exposure to new ideas.

Social networks are the primary mode of recruitment for domestic work, although in Ghana and elsewhere in the region, domestic worker recruitment agencies are emerging. This signals the formalization of a heretofore informal arrangement and creates the possibility of regulation and oversight (Tsikata 2011). A study of over 300 child domestic workers in Accra found that nearly 16 percent used an agency, with the rest finding their current job through family and friends, again underscoring the importance of social networks (Tsikata 2011).

Some migrant girls reported they knew they were moving to be domestic workers, while in other cases, recruiters and employers - even relatives - lie to recruit girls. An Ethiopian girl helping her aunt with housework explained:

My aunt who lives in Addis Ababa brought me here, and she promised to send me to school. After I came, she locked me in her house and didn't allow me to go out.

Addis Ababa, age 16

(Erulkar, Semunegus, and Mekonnen 2011:3)

\section{Conditions of work}

Child domestic workers typically perform household tasks such as cleaning, washing, cooking, caring for children and the elderly, and shopping (Edmonds and Shrestha 2009; Rao 2011; Klocker 2008). Domestic

\section{BOX 5.3}

\section{Recognizing child domestic workers' diversity}

Researchers and advocates often characterize child domestic workers as a homogeneous group. An in-depth study of child domestic workers in Abidjan, Côte d'Ivoire revealed more heterogeneity than meets the eye (Jacquemin 2012). Three types of domestic workers were apparent there, variations of which also exist in other regions.

1. Little Niece - La Petite Nièce: Traditional fostering, whereby parents entrust a rural girl to an urban relative. Typically, the Petite Nièce does housework while her "auntie" provides food, shelter, clothing, and education.

2. Hired Help - L'Enfant Louée: This type of child domestic worker is placed with a non-relative under the protection of a "guardian." Enfants Louées earn wages, which are paid to guardians rather than girls directly. They also may receive food and clothing, though of poorer quality than those received by family members.

3. Salaried Maid - La Petite Bonne Salariée: These domestic workers have neither family ties nor guardians. Girls are recruited by placement agencies or independently find employers. Employers generally provide food and shelter, and girls receive a monthly salary.

It is impossible to generalize about which of the three types is best for girls. For example, working for relatives is not a guarantee of better treatment than working for strangers. Notably, the emergence of wage-based, non-familial forms of domestic labor signifies increasing recognition of the economic value of girls' domestic activities (Jacquemin 2012).

workers' conditions are diverse, as Box 5.3 describes, although long hours, insufficient sleep and rest, and little time off characterize many workers' lives (Ray and lyer 2006; Anderson, Minaya, and Figueroa 2010; Terre des Hommes 2003). A young girl from the Philippines described a typical day:

My employer promised me that I would just clean the house, but when I got there I had to do a lot more. In the morning I would wake up at around 6 a.m. and would do the laundry until 9 a.m. Then I would man the [hardware] store... I was asked to carry cement bags, plywood, nails, and steel gates... After the store 


\section{Sexual exploitation}

Research on adolescent girls' migration and commercial sexual exploitation is limited, but existing evidence indicates the two intersect in critical ways. A large study of the sex trade in Ethiopian cities found that just under 90 percent of sexually exploited 15 to 19 year olds were migrants from rural areas or small towns (Girma and Erulkar 2009). ${ }^{17}$ Migrants comprised a third of sexually exploited young people studied in Ghana and half in the Philippines and Ecuador (ILO 2004b). In towns and cities, factors such as low wages, the difficulty of gaining decent paid employment, and the failure of some employers to pay for work push migrant girls into commercial sexual exploitation.

Some girls in domestic work turn to sexual exploitation after experiencing abuse or extreme exploitation in their employers' homes. As a study from India described, "Some of the respondents were recruited as domestic help... where they received very low wages, sometimes none at all, were abused verbally and physically, were sexually harassed and often summarily dismissed when they dared to protest. Some of them were [subsequently brought to red light areas and sold off to brothel keepers]" (Bandyopadhyay et al. 2008:107).

A study in Ethiopia also found that some girls who first work as domestic laborers leave because of difficult working conditions and abuse from their employers, and end up being sexually exploited in the face of limited alternatives. As one girl working in bars (slang for sexual exploitation) describes:

I came to work as a maid but the work was very hard and I did not earn any money. When I got to Nazareth I saw the girls working in the bars and then decided that I could also make money.

Genet, 17, Ethiopia (Van Blerk 2008:248)
Some girls pulled to the city by the prospect of a legitimate job end up being sexually exploited. Girls in Vietnam were told they would secure a service job when they moved, only to find themselves forced or tricked into selling sex on arrival. As a young woman described:

A woman from my commune told me to go to Do San to work as a dishwasher. I discussed it with my parents and they agreed I could work as a servant. I came with the woman to Do San and [she] gave me to the bar owner. When I got there I was forced to sell sex. I was locked in a room and after one week they sold my virginity to a middleman.

Bian, 25, Vietnam (Rushing 2006:482)

Friends working in Vietnam's sex industry also recruited girls without fully disclosing what they could expect on arrival. One girl reported:

My sister told me to come here [to the hotel/bar] to wash bowls. One week after that I began with sex work. My co-villagers think I am a garment worker. Thanh, 23, Vietnam (Rushing 2006:482)

Thanh's experience illustrates another important point: many sexually exploited migrant girls lie to avoid family disapproval, hoping to be protected by the distance even while contributing to family budgets. Nearly all of the parents of sexually exploited migrant girls in the Vietnam study were under the impression their daughters did domestic work.

Girls cite pressure to support their families as one reason they end up sexually exploited. As a migrant girl who was forced into sexual exploitation explained:

If you are the older sister and have a younger sister who would like to continue studying, what would you do?

Lien, 17, Vietnam (Rushing 2006:481) 
Some girls who migrate to avoid marriage end up being sexually exploited. One girl describes:

I come from Debrezeit. When I lived there I did not know about men or sex but my family arranged for me to marry a man I did not know so I left. I am doing bar work now and I am able to rent my own home and support myself. I also send money to help my younger brothers.

Kalkidan, 18, Ethiopia (Van Blerk 2008:249)

These situations make clear that migrant girls are often faced with limited opportunities when they arrive at their destination, leading some into sexual exploitation. The economic outcome for these girls varies. A study in Addis Ababa found that the income that sexual exploitation provided could be much greater than migrant girls earned elsewhere, at nearly seven times the earnings from domestic work (Ferede and Erulkar 2009). In a study of 20 girls in Vietnam, four reported they voluntarily entered into sexual exploitation because the money exceeded what could be earned in a factory. However, they were not fully aware of either the working conditions or the consequences of their choice (Rushing 2006). Another study in Ethiopia found that many girls realized the gap between their pre-entry financial expectations and the risky reality following their entry into sexual exploitation (Yntiso et al. 2009).

The sex industry can be financially precarious (Van Blerk 2008). Again in Ethiopia, some sexually exploited girls were able to support themselves and their families at home. However, girls were unable to negotiate pay with violent clients or those who refused to pay, while those working in red light districts and bars also found themselves drawn into debt by borrowing money to meet their immediate needs.
Some sexually exploited girls manage to construct new social networks for help and protection, especially critical for migrants in light of weak family ties. An Indian study reported how organized workers banded together to protect a sexually exploited girl from her "madam" (brothel owner), "the sex workers of this area rallied together and persuaded the madam to leave Shohagi alone, saying that the madam has already made enough money from Shohagi in the past year and threatening dire consequences for the madam if she ever harassed Shohagi again" (Bandyopadhyay et al. 2008:105).

Expanding efforts to increase migrant girls' employment and education options, as well as ensuring that job opportunities are safe and fairly remunerated, will do much to prevent girls from resorting to sexual exploitation. Another urgent priority is to reduce risk for those who are sexually exploited by building their social networks and other forms of protection.
And personal communication with Annabel Erulkar, April 2012 


\section{Migrant girls make rational choices about their working lives, comparing the costs and benefits of migrant labor with those of working at home.}

closed at 8 p.m., I would have to clean the house and care for the elderly until 3 a.m. I would sleep only between 3 a.m. and 6 a.m.

Julia, 13, Philippines

(Flores-Oebanda 2006:4)

In some cases, domestic workers suffer verbal, physical, and sexual abuse and other forms of mistreatment, including being denied a proper place to sleep, sufficient and nutritious food, and medical care when ill (Ray and lyer 2006; Rao 2011; AGTR 2004). A study in Ethiopia found that girls in domestic labor were significantly more likely to experience early sexual initiation and coerced first sex than other young women. Researchers attributed this heightened vulnerability to their heavy dependence on their employers, social exclusion, and lack of awareness about where to get help (Erulkar and Ferede 2009).

It is typical for child domestic workers to live with their employers. A study in Nepal found that up to 90 percent "lived in" (CWISH 2009). Live-in workers typically are "on call" 24 hours a day, and seven-day work weeks are common (Rao 2011; Pearson 2006; Apt 2005). Girls working for relatives may work fewer hours than those working for non-relatives, but their days are still long. A study in Cambodia showed that girls working for family members worked an average of 13.5 hours compared with nearly 16 hours per day for non-relatives (Brown 2007).

Most children in domestic work have limited mobility and free time. One worker per household is typical, implying little contact with peers (Apt 2005; ILO 2010). Many child domestic workers complain of feeling isolated from their social networks (Klocker 2008). In a study in Ethiopia, 7 percent of adolescent domestic workers reported having many friends compared with 27 percent of other girls (Erulkar and Mekbib 2007). Migrant girls' physical distance from their families compounds the difficulties of social isolation faced by all domestic workers. Social isolation can threaten domestic workers' emotional and psychological development and lead to low self-esteem (ILO 2004b). The Ethiopia study found that girls in domestic work had significantly lower self-esteem and optimism than their peers (Erulkar and Mekbib 2007:251).

The "behind closed doors" nature of domestic work means it is poorly regulated by governments, with few efforts made to enforce policies where they exist (IPEC 2004). Formal contracts for domestic workers are rare, and, in the case of children, parents or relatives often negotiate the terms of employment on their behalf (Apt 2005; Tsikata 2009; AGTR 2004). A study of child domestic workers in Ghana, Ecuador, and the Philippines revealed that girls were unclear about benefits, hours of work, and other work conditions (ILO 2004b).

Typically domestic workers receive some remuneration, which comes in various forms. Girls working for relatives often go unpaid, though they may receive room, board, schooling support, and other assistance (Kifle 2002). In South Africa, domestic workers who were considered part of the family received lower and more erratic wages than those who were not, suggesting it was easier for employers to rationalize under-paying domestic workers whom they viewed as family members (Miles 1999). In some cases, child domestic workers who were promised pay received none or less than what was expected; many were 
paid late or irregularly, and pay can be docked or incomplete (ILO 2004b).

\section{What do girls say?}

Research on domestic laborers indicates that most girls view the experience as a positive one. In Burkina Faso, over 80 percent of migrant girls in domestic work were satisfied with their jobs, even though over half reported the work was not what they expected. Their complaints about the lack of respect from employers' families were counter-balanced by their appreciation of the modern conveniences of city life (such as running water and grinding mills) and the opportunities for education and better employment (Terre des Hommes 2003; ILO 2004b).

Girls' situations at home, conditions of residence, status, pay, and other factors make child domestic work a complex phenomenon with both risks and benefits. Domestic workers who speak for themselves provide a reminder of how important it is to consider girls' individual strategies when assessing domestic work. Within a limited range of job options, they make rational choices about their working lives, comparing the costs and benefits of migrant labor with those of working at home. Establishing and enforcing regulations to improve working conditions for domestic laborers is essential, along with providing opportunities for workers to increase their social support and learn about their rights.

Migrant girls who leave home to pursue employment

often face limited job options and exploitative working conditions. Despite the risks, migrant girls opt to stay in their industries or jobs. When allowed to speak for themselves, girls compare the experiences of migrant labor with difficult but unpaid work at home or child marriage, pointing out that work in factories, domestic labor, or service industries allows them to earn money, gain skills, and potentially improve their lives. Migrant girls make decisions about work based on an assessment of their situation. It is easy to overlook the diversity of migrant girls' employment situations and the degree to which working girls exercise agency. Taking better account of working migrant girls' own views would help avoid inappropriate child labor programs. It would also reduce the risk of undermining the very girls who are in a position to achieve their potential given the right protection and support, including more safe work opportunities. Chapter 6 follows with a discussion of migrant girls' education and health status, aspects of their human capital that are essential to realizing their potential. 
Her 1 11

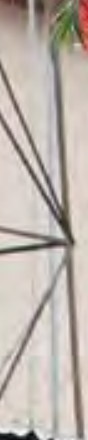

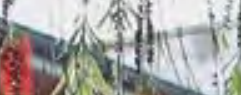

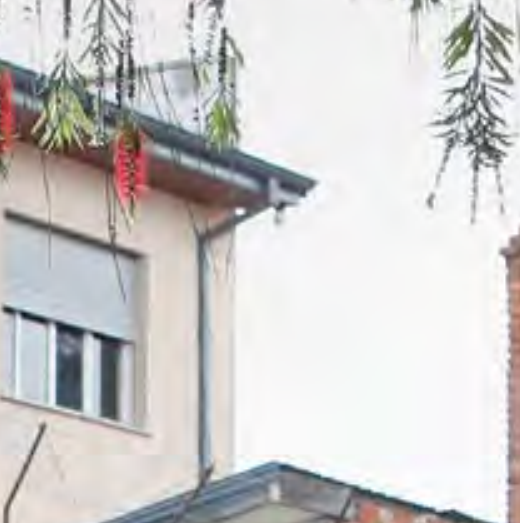

MII $7 x^{2}+x^{2}$

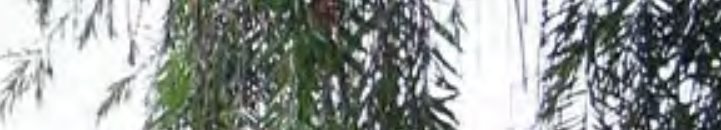

待.

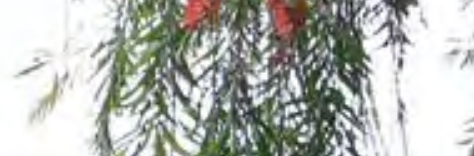

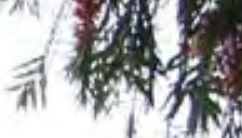

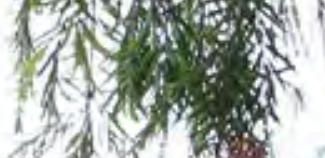
$\left.7 x^{\prime}\right)^{2}$ 1978
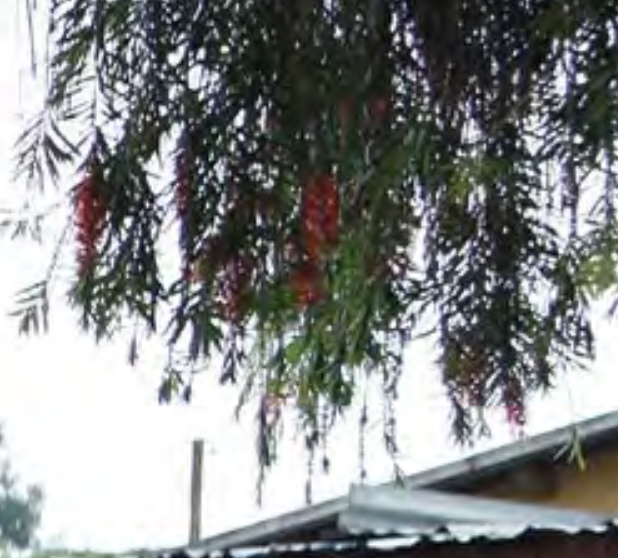
80
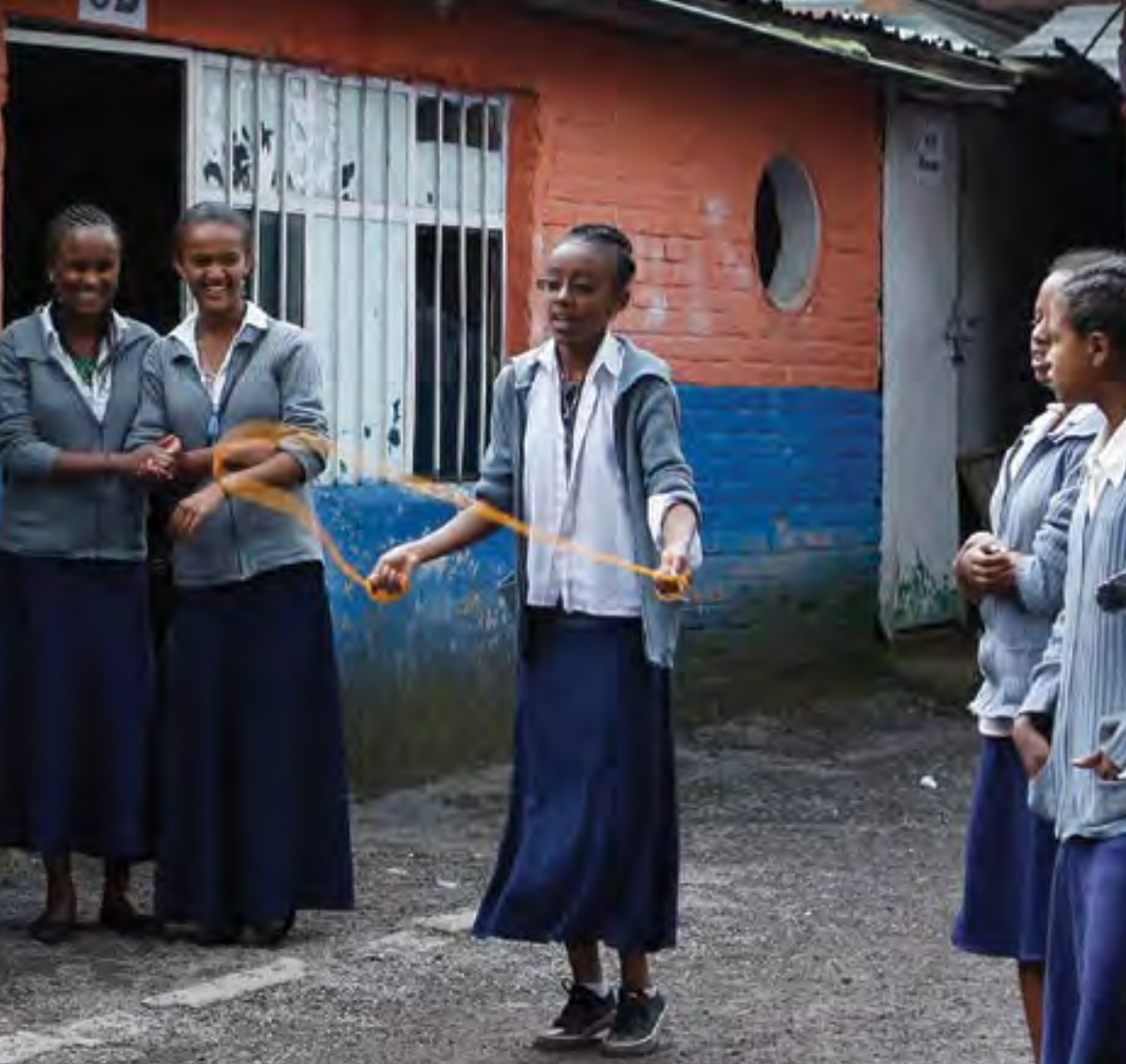

sita: s.t.
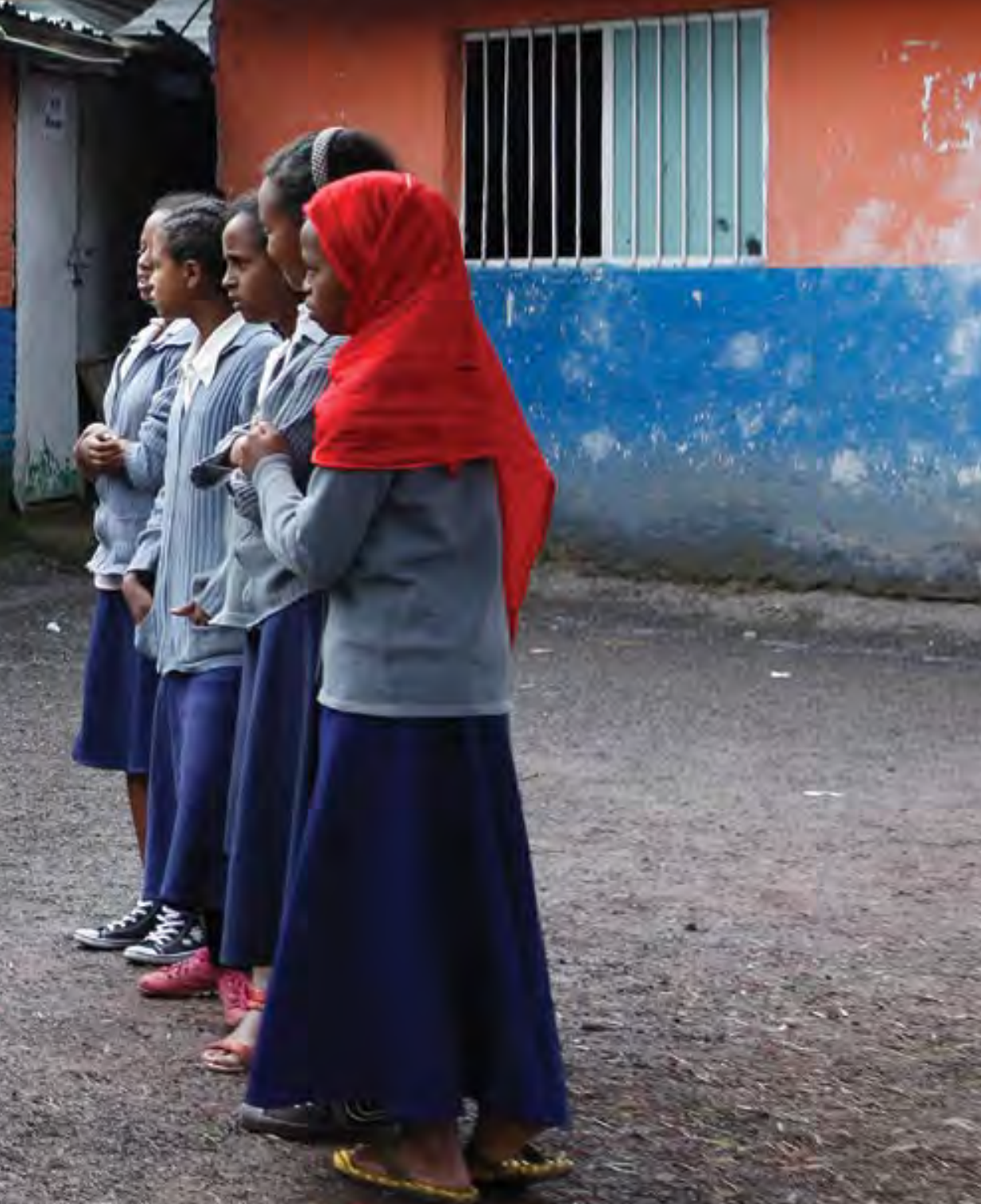
Migrant girls leave home with different degrees of preparation

for what lies ahead. Their human capital complements whatever plans they make for the journey. Girls' educational level and health status are particularly relevant to shaping their adjustment, their capacity to negotiate urban environments, their employment options, and their ability to make social connections. Migration in turn affects adolescent girls' education and health status in different ways.

\subsection{More Educated than Rural Girls, Less Educated than Urban Girls}

In developing countries, schooling is seen as essential for escaping the drudgery and uncertainty of agriculture for a life perceived to be easier and more rewarding. The benefits of a basic level of schooling are well documented for girls, significantly improving the prospects for them and for their future children and household economies (Lloyd 2012). More schooling increases the likelihood of migration, although less is known about how such moves can further educational attainment (Lucas 1997).

Urban in-migrant girls achieve levels of education that are mid-way between those of rural non-migrant girls and local urban girls. Figure 6.1 depicts the differences between migrant and rural non-migrant girls in attainment of secondary schooling, showing urban migrant girls' higher education level compared with rural non-migrant girls.

Although they are better educated than their rural peers, urban in-migrant girls' levels of educational attainment generally do not match the levels achieved by urban non-migrant girls, as Figure 6.2 illustrates. Differences in educational attainment probably understate the advantages that local urban girls eventually acquire in terms of completed schooling, because local girls are more likely than migrants to be enrolled and continuing to develop their educational assets, as Figure 6.3 shows.

\subsubsection{Migration can create opportunities for schooling \\ For some migrant girls, moving to a city or town opens opportunities for formal education and skill- building that are not available at home. A migrant girl in Lima, Peru described the consequences: \\ When I was 13, I...told my mom I was leaving. A lady that lived [in the city], a distant aunt...said that she would take me. Now, I don't want to go back. There my parents didn't support my education. Yeah, they sent me, but there they teach in Quechua and plus, you don't learn anything.}

Natalia, 19 years old, secondary education

(Blomster 2004:19)

Some migrant children benefit from non-formal schools, which have been established for children who would miss out on their right to schooling if not for such special initiatives. Critics have doubts about the quality of non-formal education, arguing that two-tiered systems perpetuate inequality while encouraging child labor (Kabeer, Nambissan, and Subrahmanian 2003 in Giani 2006). Even so, some migrant children benefit from non-formal education programs aimed at working children (Whitehead and Hashim 2005).

Migration is a strategy girls use to overcome parents' inability (or unwillingness) to pay for school. Some girls manage to combine domestic work and schooling: a study in Ecuador found that two-thirds of domestic workers in the sample attended some form of school while working, while one-third had to drop out of school to work (ILO 2004b). Night school and nonformal approaches enable child domestic workers to attend school. This can be a way for girls to get an education and an essential opportunity to build their social capital, as Box 6.1 summarizes.

For adolescent girls, parents provide a critical form of social support that helps them stay in school. Many migrant girls lack this support because they live away from their parents, which could partially explain their schooling disadvantage relative to urban nonmigrants. In Kisumu, Kenya, migrant girls who were 


\section{CASE STUDY 5}

\section{Cecelia, Peru, Age 17}

I was always a good student and my teachers told my parents I was doing well at school. Our village does not have a secondary school, though, so when I was old enough my parents decided to send me to live with my aunt, Julia, in the regional capital, Ayacucho. Our family had been to visit Tia Julia before, and I was excited to move to the city and live in her house. She has electricity, hot water, and a TV-my cousins even have their own rooms.

School is really difficult in Ayacucho, and the teachers make us do much more work than in my village. But I know studying hard is important so I can get a good job and help pay for my sisters' schooling. To help pay for my keep at Tia Julia's, I've been helping out with chores. For the most part, I really like living with my aunt and uncle. They buy me new clothes at the beginning of each school year and take me to the hospital if I get sick.
My only trouble is because of my uncle's friend. When I first arrived, he told me how beautiful I was. I told Tia Julia it made me uncomfortable, but she said he was harmless and that I should be happy to get such nice compliments. But one weekend my aunt had a birthday party for my uncle and everyone had been drinking. My uncle's friend kept bothering me all night and touching me. I kept trying to ignore him, but late at night after I had gone to bed, he found me in my room and forced himself on me. Now I'm worried I might be pregnant. I don't want to tell Tia Julia because I'm worried she will make me leave. And I can't tell my parents because they are giving up a lot to pay for me to go to school. They would be so angry if they knew I did anything to upset Tia Julia. I'm hoping some of my friends from school can help me figure out what to do. cared for by a relative other than parents and those whose mother or father had died were much more likely to have dropped out of school than those with both parents caring for them (Clark and Cotton 2012). Similarly, Chinese migrant children living with both parents were more likely to be in school than children in other kinds of families (Liang, Guo, and Duan 2008).

Lack of social support is only one of the many barriers to schooling migrant girls encounter. Barriers may also be administrative in nature, as illustrated by a study in Indore, India. On making contact with a school in the city, girls were asked for a range of documents, including certificates of their school results, transfer certificates, and case certificates for accessing scholarships. The possible outcomes included having to return to the village to obtain the necessary documents, paying bribes, or even having to change their choice of school (Agarwal and Jones 2012). This could be avoided by increasing migrant girls' access to personal documentation.

\subsubsection{Acquiring skills as education}

Many girls who migrate for work report that gaining skills through work is the only educational option realistically open to them (Hertrich and Lesclingand 2012). A young migrant who started working in Accra as a domestic worker and then as a telephone operator illustrates this. At the time of the interview, she was unemployed, sleeping outdoors on a veranda, and rarely ate three meals a day. She explained why she chose to continue enduring these hardships rather than returning home:

I intend [to continue] my education! I would like to go back but not without any skills or a proper job here in Accra...in the computer business or sewing. Even if I get money now, I will not return until I have had some skills. If I return without any skills, I would have wasted my time here.

Zuera, 19, Accra (Anarfi et al. 2005:34) 
FIGURE 6.1

\section{Urban migrant girls have higher levels of education than rural non-migrant girls}

Attainment of secondary schooling or higher AGE $16{ }_{18}{ }_{22}$

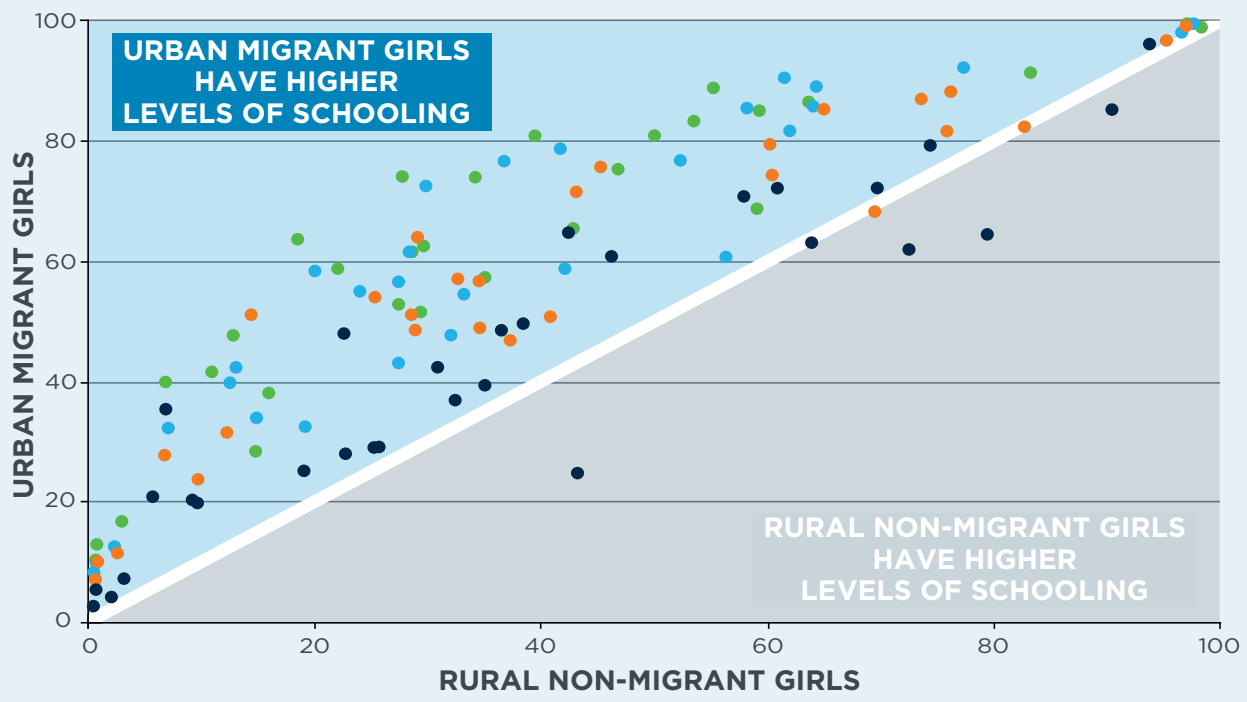

FIGURE 6.2

\section{Urban migrant girls have lower levels of education than urban non-migrant girls}

Attainment of secondary schooling or higher
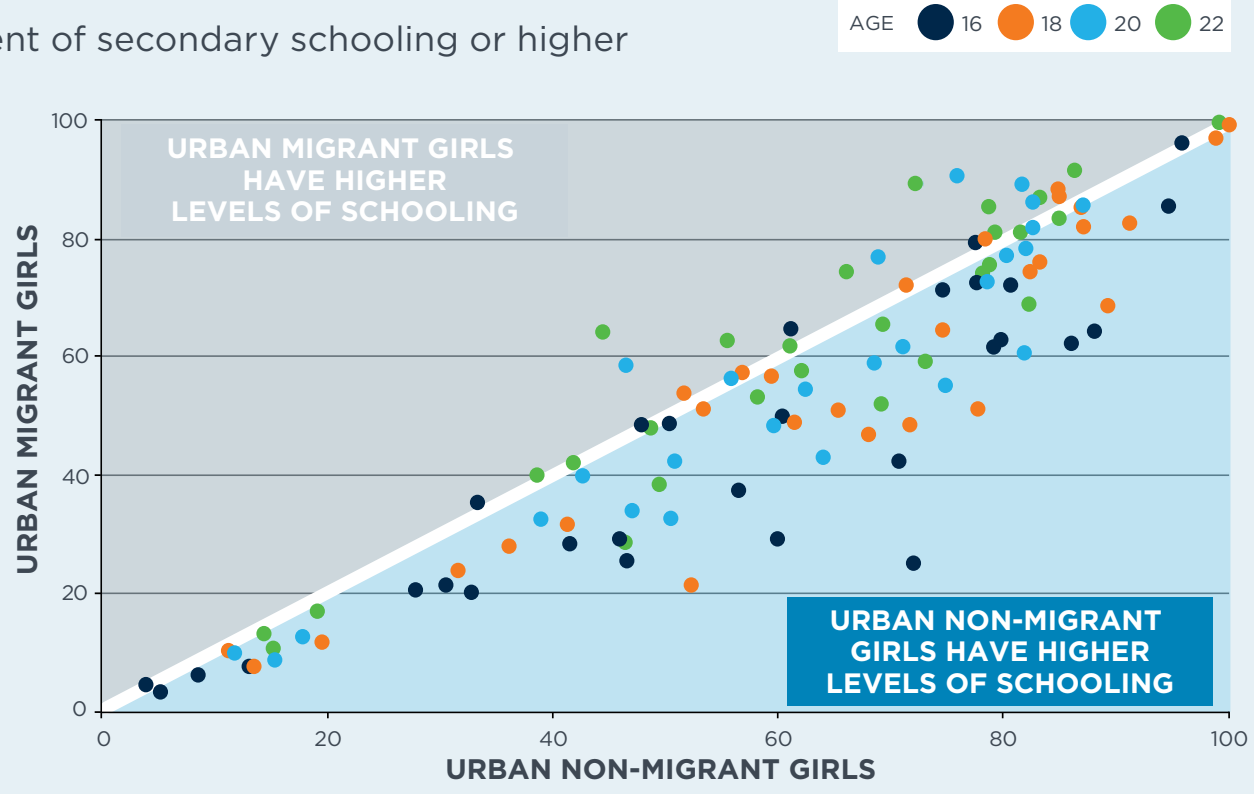
Migrant children frequently state a preference for vocational training over traditional academic education. Apprenticeships - a common form of such training are a popular alternative to formal education among young migrants in West Africa (Hashim 2004). Girls perceive that apprenticeships improve marriage prospects and teach practical skills, which can provide a degree of independence even within marriage. In Ghana, where migration for tailoring apprenticeships is common, a young woman explained:

"If her husband says, 'You are looking to me to support you,' she can say, 'No I have my own thing'” (Hashim 2007:923).

Migration provides some girls with the opportunity to expand their schooling and acquire new skills. Migrant girls also are likely to encounter new norms about gender, childbearing, and other determinants of adolescent girls' health. The chapter now examines the ways in which migration influences girls' access to health care and selected health outcomes.

\subsection{Migrant Girls' Health}

Some urban in-migrant girls exhibit a health disadvantage relative to urban locals. This is not always attributable to their migration status as such, but may have more to do with the background characteristics and circumstances that migrant girls tend to have in common. Migrant girls' constrained employment options and their health are inter-related: harsh working conditions and occupational risk can make girls sick. Young female migrant factory workers in Bangladesh complained of losing weight, eyesight problems, and other illnesses (Amin et al. 1998). Migrant girls' living conditions also cause health problems, especially for those in slums, which can be unsanitary and unsafe (UN-Habitat 2010; Montgomery 2009a). Some employer-provided housing, such as dormitories for factory workers, presents health risks as well. In Ho Chi Minh City, a study found that employee hostels were constantly damp and had poor water quality contaminated by high aluminum levels (Taylor 2011; Thi 2008).

\subsubsection{Understanding migration's impact on girls' health}

Assessing migration's influence on girls' health underscores the difficulty of drawing conclusions about migration's impact on girls' overall well-being with the limited evidence available. Several factors prevent

BOX 6.1

For child domestic workers in Peru, benefits of non-formal education extend beyond academics

Research in Lima, Peru sheds light on child domestic workers' schooling experiences. Circumstances were not ideal: classes took place from 6:00 p.m. to 10:00 p.m. after long, hard work days that left little time for homework. Many of the teachers also came to class after a full day of teaching, tired and unprepared. The girls opted to walk to school rather than spend their hard-earned money on public transportation, further tiring them (Blomster 2004).

Education quality and learning experiences in night school were sub-optimal. However, girls benefited from the opportunity to interact with peers and form social connections. School also provided girls with an opportunity to express themselves freely, which they were unable to do during the work day (Baek 2008). For these girls, some school was clearly better than no school, even if the education quality was less than ideal.

a clear picture of migrant girls' health. Girls who migrate may be healthier before the move than their non-migrant peers who stayed behind. ${ }^{18}$ This innate healthiness would continue to protect them at their destination (Lu and Treiman 2007). Studies on this topic rarely include baseline measures, making it difficult to disentangle the effect of migration from other factors. Researchers use a variety of comparison groups to assess migrant girls' health, limiting comparability of results. Finally, adolescent girls migrate from and to a variety of places; the few studies that conduct separate analyses of migrants from different origins and destinations (e.g., rural vs. urban) turn up significantly different health outcomes between these groups (Zavier, Jejeebhoy, and Acharya 2012).

\subsubsection{Access to health services}

Migrant girls use a variety of techniques to get the health care they need. Across diverse settings, studies document the propensity of migrants to self-medicate through pharmacy purchases (Yoddumnern-Attig
18

Lu and Treiman (2007:4) observe what is known as the "healthy migrant phenomenon": "younger migrants are positively selected with respect to health, presumably because they are more capable of cecauring the argors of moving or managing the difficulties and stress associated with migration." 


\section{Local urban girls are more likely than migrants to be enrolled in school}

School enrollment percentages of urban girls by migration status and age

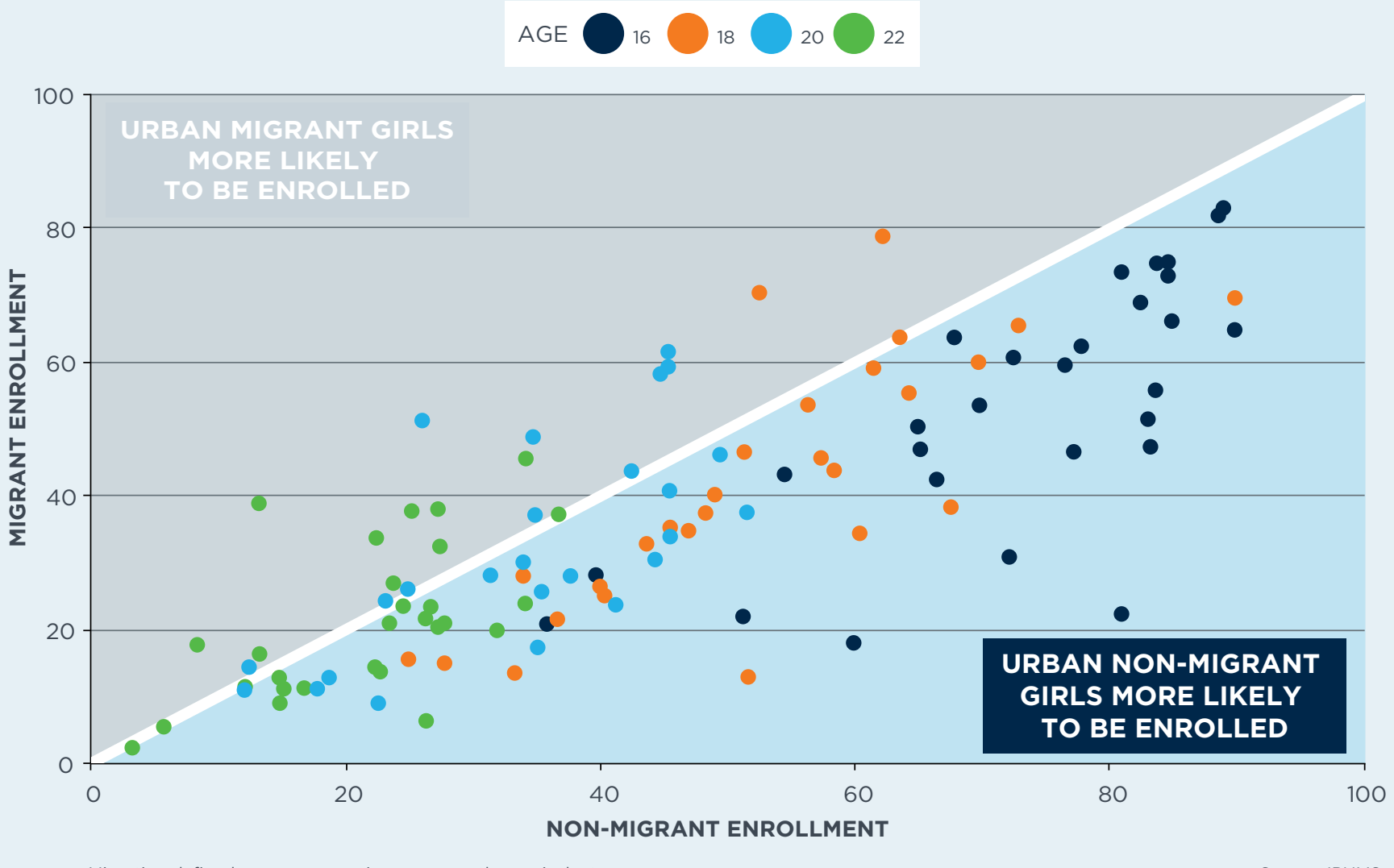

et al. 2007; Kusakabe and Pearson 2010; Caouette 2001). Kayayei in Ghana report that when one of them falls ill, she buys a remedy based on a friend's suggestion without guidance on the proper dosage (Kwankye et al. 2007). NGOs provide services in some neighborhoods where many poor migrants live and work (Kusakabe and Pearson 2010). Employerprovided services are another source of health care for migrants, though they can be unsatisfactory: a Ho Chi Minh study of health services embedded in factories found that health staff were too over-loaded and under-supplied to be useful (Thi 2008).
A number of barriers keep migrant girls from affordable, quality health services. Newcomers may not speak the local language and may be unfamiliar with the surroundings. The extent to which the urban health system is monetized also affects migrant girls' position in urban health systems (Montgomery 2009b). While urban in-migrant girls may be closer to services than they were in rural areas, they may not have the cash they need for the private care that is available. Quality is a concern, and poor urban residents who pay for their health care often receive little in return (Das, Hammer, and Leonard 2008). Until a migrant girl 
learns which options in her neighborhood are affordable and offer services of minimally acceptable quality, she may not know where to go when sick or injured.

The barriers to health services may be especially formidable for temporary migrants. In many Indian cities, a health center is an important source of nutritional supplementation and basic health care for community members. But health center staff are often reluctant to enroll temporary migrants, who they suspect will soon leave and create disorder in record-keeping, thus exposing staff to criticism (Agarwal and Jones 2012).

Migrants of all ages report that health care providers' attitudes discourage them from using services (Akileswaran 2005). Adolescent migrants in China and Southeast Asia reported that workers' judgmental attitudes kept them away from sexual and reproductive health services. They were willing to attend clinics with the support of a friend, but avoided doing so because they had no one to accompany them (Yoddumnern-Attig et al. 2007). Where girls' in-migration is common, frontline health workers need to learn about the special considerations of migrant girls and be sufficiently sensitive and flexible to allow them to participate in programs.

Migrants' misconceptions about their entitlements to health care also prevent them from seeking services. A study in China found that female migrant workers under 25 years old mistakenly believed that unmarried people were not eligible for publicly provided contraception (Yoddumnern-Attig et al. 2007). Few rural Burmese women working in urban Thailand knew about their right to public health services, despite the Thai government's guarantee of these entitlements for migrant children and registered foreign workers (Save the Children 2006; Kusakabe and Pearson 2010). Action to increase adolescent girls' access to personal documentation and to educate them about their rights has the potential to improve their health care access.

Migrant girls' characteristics and circumstances jointly influence specific health outcomes such as their sexual, reproductive, and mental health and their risk of experiencing violence. Many studies highlight migrant adolescent girls' disadvantage, although the results come from diverse study designs using a range of comparison groups, making it difficult to draw conclusions.

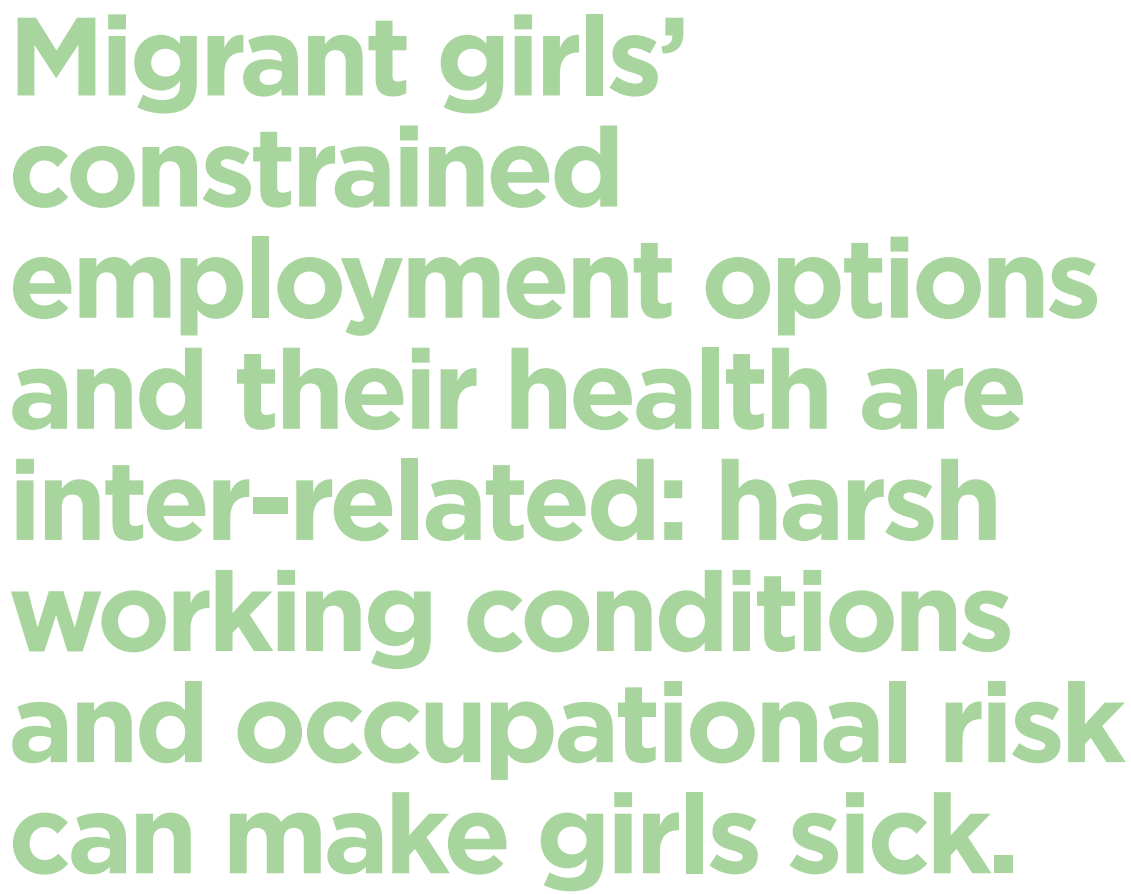




\section{Personal, household, and community characteristics can have a more important influence on the age of migrant girls's sexual initiation than migration per se.}

\subsubsection{Sexual and reproductive health}

Migrant adolescent girls' sexual initiation might occur at a younger age than that of non-migrant girls (Clark and Cotton 2012; Acharya, Santhya, and Jejeebhoy 2010). However, personal, household, and community characteristics can have more important influences on the age of migrant girls' sexual initiation than migration per se (Mberu and White 2011). A study in Kisumu, Kenya found that girls' migrant status and their lack of family support increased the likelihood they would drop out of school and the likelihood they would get married, which in turn led to their early sexual initiation (Clark and Cotton 2012). Access to information can also play a role. An analysis of national survey data in India found that migrant girls were less likely than non-migrants to be informed about sexual and reproductive health (Zavier, Jejeebhoy, and Acharya 2012). Migrant girls need access to comprehensive sexuality education and services. Health policymakers and local governments can help by reducing the unique barriers migrant adolescent girls face.
It is difficult to determine whether migration leads to girls' early sexual initiation or whether girls who are sexually active are more likely to migrate than others, because studies rarely measure the sequence of migration and sexual initiation. Migrant girls' sexual activity may have started before they moved and may have precipitated their departure. In Nepal, contrary to the widespread view that young migrant workers were attracted by the sexually permissive environments in Kathmandu factories, research revealed that, for many girls, sexual activity preceded migration. Researchers hypothesized that the "distress and shame" of forbidden early sexual activity in rural areas stimulated girls' migration (Puri and Busza 2004:150).

\section{Fertility}

The influence of migration on female fertility may be the best-studied aspect of migrant health. Studies mostly focus on rural-to-urban migrants, comparing female migrants' fertility levels with levels of both women left behind and women in the new location. In general, the fertility of migrants in urban areas is somewhat higher than that of urban non-migrants and lower than that of rural residents. Researchers attribute these fertility differences to the higher costs of living and childrearing, greater social acceptance of lower fertility, and better access to contraceptive services in urban areas compared to rural areas (Panel on Urban Population Dynamics 2003).

This pattern persists in studies of adolescent migrants. According to Indian survey data, 17 to 19 year-old migrant girls began childbearing earlier than their urban non-migrant peers (Zavier, Jejeebhoy, and Acharya 2012). The Kisumu, Kenya analysis cited above suggests reasons for migrant girls' early pregnancy that are similar to the reasons for their early sexual initiation. Migrant girls were more likely to be out of school and socially isolated than their local urban peers, which increased their risk of early pregnancy (Clark and Cotton 2012). Increasing migrant girls' opportunities to attend school and build social networks could reduce their risk of early pregnancy and the threats early motherhood poses to achieving their potential.

Barriers to antenatal care can be a serious problem both for migrant girls who become pregnant and for their babies. Researchers in China blamed insufficient antenatal care for the much higher rates of stillbirths 


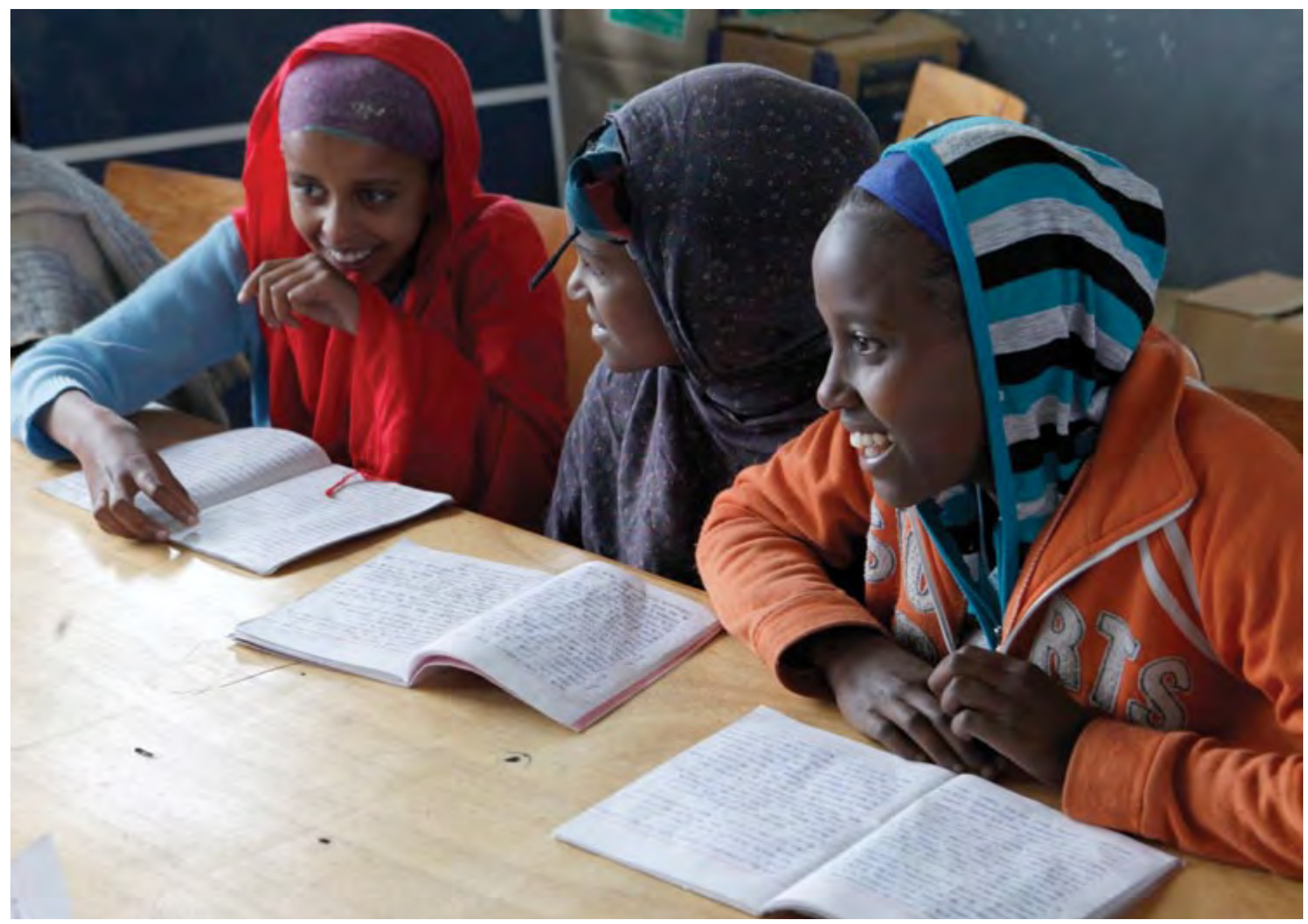

among young migrant women than non-migrants in urban areas (Feng et al. 2005). Here, lack of urban registration papers and health insurance drove migrant young women to illegal services-affordable but unregulated and often unsafe (Blas, Sommerfeld, and Kurup 2011). Chapter 7 describes an innovative approach the Chinese government took to overcome this inequity. Survey data revealed a similar problem in India, where 15 to 19 year-old migrant girls in both rural and urban areas were less likely to deliver in an institution than non-migrants of the same age (Zavier, Jejeebhoy, and Acharya 2012).

\section{HIV infection}

There is some evidence that migrants face higher risk of HIV infection than the general population, although only a few studies look specifically at migrant adolescent girls' risk. In urban Ethiopia, migrant girls ages
15 to 19 were nearly twice as likely to be living with HIV as their native urban peers (Erulkar, Mekbib, and Tegegne 2008). The circumstances some migrant girls face, such as extreme poverty, can increase their HIV risk. A study of young migrant girls in the sex trade in Zimbabwe illustrated how poverty can trump HIV prevention knowledge:

Yes we use condoms. [But] there will be more money without a condom. ... He didn't want to wear a condom and he said that if I agreed to have sex without a condom he was going to give me $\$ 20$ for short time and I said it was okay.

$\sim$ Tsitsi, 19, Zimbabwe

(Busza 2011:18)

Given the elevated HIV risk adolescent girls face in high-prevalence settings, it is urgent to ensure that 


\section{Violence and harassment are common occurrences for gilils in the slums where many migrants reside; migrant girls in exploitative work also face considerable risk of abuse.}

appropriate HIV prevention information and programs reach girls who are most likely to be overlooked, including those on the move.

\subsubsection{Gender-based violence}

Gender-based violence (GBV) is a regular event in many adolescent girls' lives, from street harassment to extremes of rape. A WHO multi-country study revealed that more than one-third of girls aged 15 to 19 reported physical and/or sexual abuse by their partner (WHO 2009, cited in Temin and Levine 2009). GBV is a risk for migrant girls as it is for all girls, though migrant children may under-report histories of abuse and violence (Robin and Ndiaye 2012).

Violence and harassment are common occurrences for girls in the slums where many migrants reside; migrant girls in exploitative work also face considerable risk of abuse (Erulkar and Matheka 2007). Harassment was a constant for Haitian girls living in a Dominican border town who worked in domestic labor, living under the thumb of their older Dominican employers (Petrozziello 2012). Migrant adolescent girls may have difficulty responding to violence because of the same types of barriers that prevent them from accessing health services described above. The Haitian girls did not seek institutional protection when they experienced GBV; instead, they went to members of their social networks. They explained that they were unaware of their rights and did not know where to go to stay safe (Petrozziello 2012).

\subsubsection{Mental health}

The stress of poverty, separation from social networks and familiar environments, harsh treatment, discrimination, and other factors can threaten migrant girls' mental health. Evidence on child laborers' mental health is relevant. In Ethiopia, working children have more emotional and behavioral disorders than nonworking children. The effect of working persisted even after controlling for migration, indicating that work, not migration, was causing their problems (Fekadu, Atalay, and Hägglöf 2006). A study of young agricultural workers in Mexico found high levels of anxiety and stress, which were even higher for girls than for boys (Noriega 2009). This is consistent with evidence that adolescent girls are more often affected by common mental health disorders than boys (e.g., Harpham, Grant, and Rodriguez 2004). 
Research from China provides some of the best information on young migrants' mental health, although the use of different comparison groups yields different conclusions. Rural-to-urban migrant factory workers in their early twenties had high levels of mental health problems, which researchers attributed to high stress from work and family and to interpersonal problems (Mou et al. 2011; Chen 2011). In this study, migrant workers' mental health was worse than that of rural non-migrants but comparable to that of urban non-migrants, suggesting that urban living rather than migration was the cause of the mental health problems. More studies that use comparison groups consistently and disaggregate results by age and sex are needed to uncover the true burden of mental health problems among migrant adolescent girls.

Urban in-migration places girls closer to education and health services, offering them the opportunity to improve their stock of human capital. However, major challenges remain in connecting migrant girls to neighborhood resources and improving their education and health status. The evidence implicates poverty, living and employment conditions, and lack of documentation and social capital as fundamental causes of migrant girls' disadvantage more than their migration status per se. Efforts to increase adolescent girls' access to schooling and health services have the potential to reduce some of the barriers facing migrant girls. Dedicated efforts to reduce the underlying causes of migrant girls' disadvantage are also necessary to complement broader initiatives. Specific efforts might include expanding access to personal documentation, building friendship and mentor networks, regulating employment and employer-provided housing, and targeting girls who are hardest to reach with specific outreach. A small number of such activities are underway for migrant adolescent girls. The nature of current programs and policies is the topic of the next chapter. 


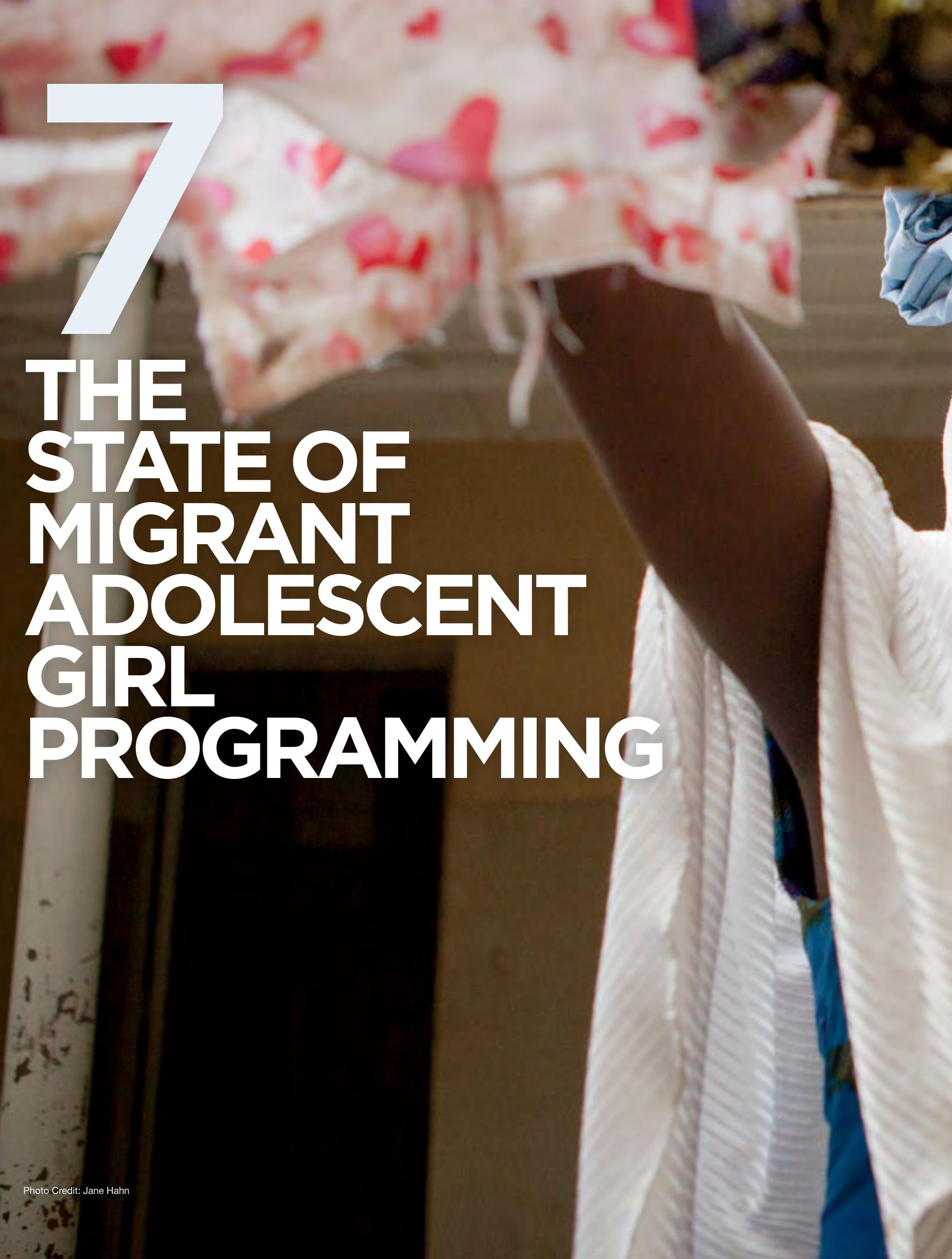




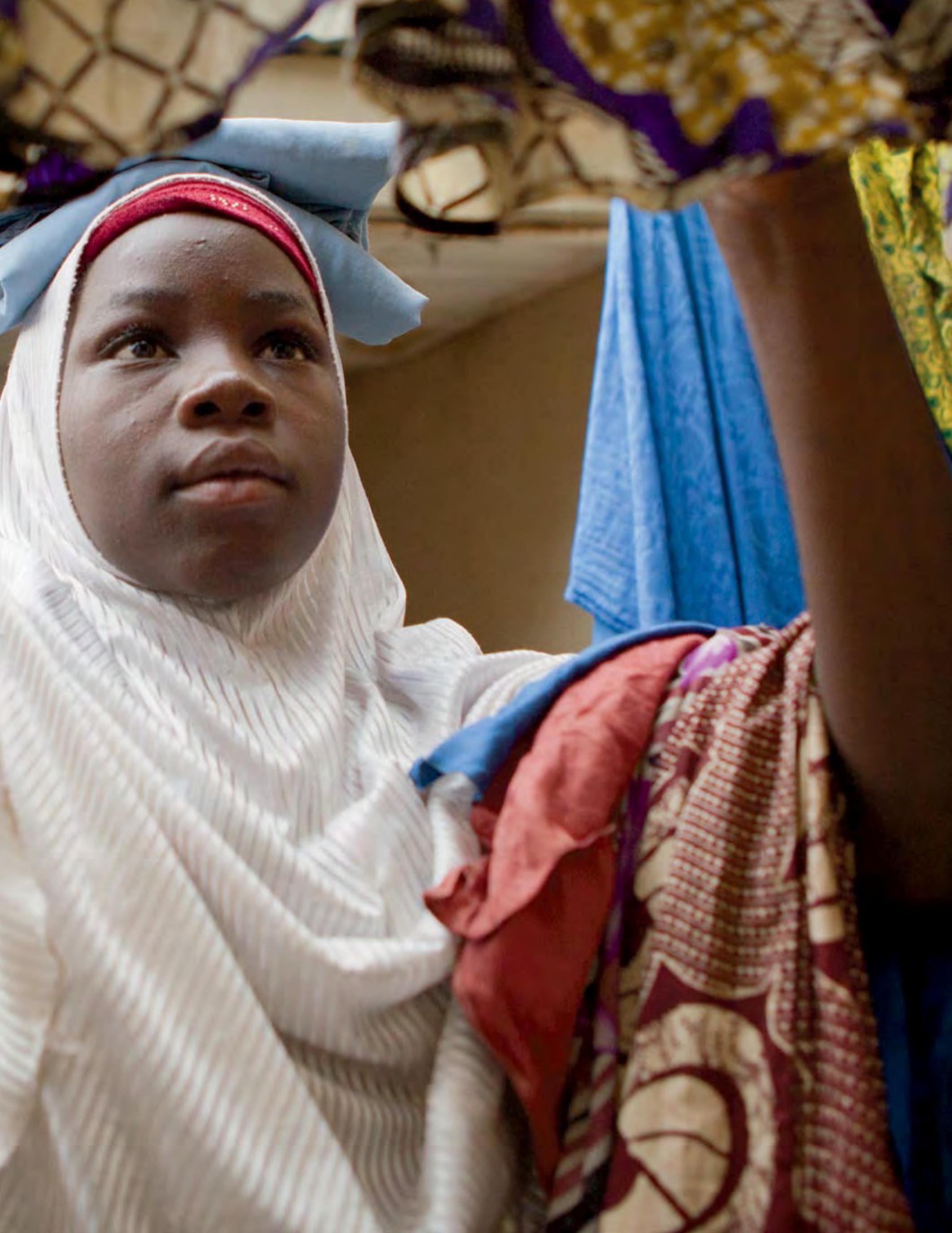


Migration can present girls with opportunities to fulfill their potential. But for many migrant girls, significant barriers stand in their way. The previous chapters described constraints of limited social networks, schooling disadvantage, hazardous and unregulated work options, limited access to health care, early marriage and early sexual initiation, and pregnancy. Immediate and long-term consequences affect migrant girls, their families, and their communities. Policies designed with migrant adolescent girls in mind can help make the most of the opportunities migration provides. Such investments can reduce vulnerability and ultimately spur economic and social growth in developing countries.

This chapter examines the current state of programs and policies for migrant girls. It is not an inventory of all initiatives. Instead, it outlines the range of current approaches with demonstrated effectiveness and describes program and policy challenges. Given limited evidence on effective approaches, this chapter includes examples from broader initiatives targeting other population groups that hold promise for migrant adolescent girls. Figure 7.1 illustrates the importance of tailoring programs and policies to migrant girls at each stage of their experience.

Current approaches to reach migrant girls have had limited impact. In general, they tend to reflect evidence on the worst outcomes rather than the diversity of their experiences. This has resulted in programs intended to mitigate negative effects rather than those seeking to maximize the benefits of migration and reduce risk by developing girls' protective assets. Most programs for migrant girls take the form of NGO service delivery, which tends to operate separately from government efforts to improve social systems for excluded populations. Small-scale NGO programs have not achieved sufficient coverage or sustainability in places where adolescent girls' migration is widespread. Few programs have been evaluated, making it difficult to identify, replicate, and expand the most effective approaches.

Few governments have policies on internal migration that recognize its social and economic benefits; fewer still recognize the unique needs of migrant adolescent girls. Yet some broad population-based approaches reach migrant girls. Government-led efforts to develop accessible systems and national safety nets for various vulnerable populations have potential. Policies and reforms to systems for rural development, child protection, education, child labor, and health all hold promise for migrant girls. Evidence on whether these approaches make a measurable difference for them is lacking, however.

\subsection{Current Programming Approaches}

This section summarizes the different approaches currently underway for migrant girls. Taken together, these promising approaches can help girls build the protective assets that are essential for successful migration (see Figure 7.2). When adequately equipped, migrant adolescent girls are well positioned to capitalize on the benefits of migration.

\subsubsection{Increasing rural girls' human capital} Investments to increase rural girls' human capital as they approach and move through adolescence can help ensure they are better prepared for the future, whether or not they migrate. Rural investments can also ensure girls are making a "real" choice to migrate rather than leaving to escape the lack of opportunity at home (Migration DRC 2009).

\section{Safe spaces and female platforms}

Safe spaces and community-based platforms provide places where girls can develop practical skills. These programs target vulnerable girls and benefit them whether they stay at home or migrate. One example is the Population Council's Abriendo Oportunidades program in Guatemala's Mayan highlands. The program develops health, social, and economic assets of marginalized rural indigenous girls aged 8 to 18 . The girls join clubs in safe spaces and follow a curriculum on life skills, self-esteem, sexual and 


\section{Promising approaches for migrant girls at each stage of their journey}

\section{PRE-MIGRATION}

- Accessible and relevant education (formal and non-formal)

- Life skills

- Vocational training

- Preparation for urban employment, savings, and risk management

- Portable assets such as birth certificates, identity cards, and mobile savings accounts

\section{IN TRANSIT AND \\ ON ARRIVAL}

- Trustworthy travel companion

- Adequate travel funds

- Information in transit hubs

- Access to mobile phones

- Safe accommodation

- Access to migrant or community groups

\section{SETTLING IN}

- Accessible and relevant education (formal and non-formal)

- High quality, accessible health services

- Structured and regular access to same-sex peers

- Technology to stay in touch with family and friends

- Safe employment opportunities

- Access to savings programs reproductive health, financial skills, and planning for the future. An evaluation demonstrated that girls' access to positive role models in the community increased, their sources of social support expanded, and they gained confidence, self-esteem, and new skills (Catino, Colom, and Ruiz 2011). If these girls migrate, their increased capabilities will help them navigate city life and maximize the opportunities available in their new homes.

\section{Vocational training centers}

With limited options for advanced formal education, some potential migrants develop their skills through vocational training centers. In rural Tanzania, where employment opportunities are limited, many girls aged 9 to 15 migrate from rural to urban areas to work as domestic laborers (ILO 2001:20). Recognizing this, the Tanzanian Conservation, Hotels, Domestic and Allied Workers' Union worked with local government and community members to build a vocational training center in a rural district (IPEC 2006). The center provides girls with basic literacy classes and training on the practical skills necessary to enter skilled employment. Such formal training can teach girls about their rights and may help them negotiate a better salary and better working conditions with their employers. This, in turn, can reduce labor-related exploitation in unregulated industries.

\section{Life skills and pre-departure migrant preparation programs}

A number of NGO and community-based programs aim to improve readiness for safe, informed migration by providing information on legal procedures, services, and support systems in destination communities. Pre-departure programs are especially relevant in communities with set migration routes and strong infrastructure, involving networking between sending and receiving communities. In response to high rates of rural-to-urban labor migration, World Education Cambodia implemented the Pre-Industry Life Skills Programme (PILS) in a sending community, reaching almost 600 adolescents ( 90 percent female). PILS provided health skills and knowledge about safer 


\section{Expanding migrant girlls' use
of mobile phones
is an approach that
holds great promise.}

migration, including information on securing a job in garment factories, labor issues, factory maps, living in a new city, and financial management. Pre- and post-test measures showed that the program raised knowledge and developed girls' ability to protect themselves (World Education 2011:10).

\subsubsection{Child protection in transit and on arrival} Many countries are changing their approach to child protection from specific programs for different neglected groups toward protection systems for all vulnerable children, thereby increasing efficiency. This means integrating efforts to protect groups of children-child soldiers, street children, children in the sex trade, unaccompanied migrants-who were previously addressed separately. Migrant girls can clearly benefit from efforts to strengthen child protection systems. For example, expanding safety nets for all children in crisis or enhancing indigenous protection mechanisms has the potential to reduce migrant girls' vulnerability and exclusion. Vulnerable girls on the move can also benefit from protection programs designed specifically for them.

Protecting unaccompanied girls in transit hubs Transit hubs such as bus and train stations can be particularly dangerous for unaccompanied girls, who may be easily preyed upon as they enter cities. The International Programme on the Elimination of Child Labour (IPEC) and the Project to Prevent Trafficking in Girls and Young Women for Labor Exploitation launched the Spring Rain Campaign in bus and train stations in China, where they distributed nearly 1 million brochures and provided young female migrants with basic information on transport, accommodation, and employment agencies that link migrant girls to legitimate work opportunities on arrival. Following the campaign, more than 60,000 girls visited eight recruitment agencies, resulting in one-third of them finding employment (ILO and CP-TING 2008). The local government adopted the campaign messages and materials and incorporated them into their work in a number of cities. Campaigns continue to be organized at transportation hubs in China (ILO 2010; CP-TING 2011).

\section{Safe accommodation for recent arrivals}

Arrival into a city can be risky for unaccompanied migrant girls, especially those who lack social contacts, do not speak the local language, and enter sub-standard accommodation and exploitative employment (Tirpude College 2004). A few local grassroots organizations and charities provide safe accommodation for vulnerable children and women, including migrant girls. The Philippine Ports Authority founded the Port Halfway House in Manila to provide temporary shelter to stranded passengers, especially women and children. Passengers are allowed to stay for three days, during which they can sleep in safe quarters and receive adequate food, counseling, protection, and other legal and administrative assistance (PPA 2012).

\section{Mobile phones and hotlines}

On arrival in a new city, some unaccompanied children use mobile phones to contact family members at home, often through inexpensive text messaging 
services (Siddiqui 2008; Bunmak 2012). Mobile phone and hotline services have been designed to provide vulnerable young people, including migrant girls, with referrals to local services. One such initiative is the Childline India Foundation, a public-private partnership with national and state government involvement (Childline India 2010). This toll-free service received nearly 23 million calls as of March 2012, ${ }^{19}$ with 62 percent of the callers between ages 11 and 18 (Childline India 2011). Notably, two-thirds of beneficiaries to date are boys, underscoring the importance of girlspecific programs to ensure that vulnerable girls are not overlooked. Expanding migrant girls' use of mobile phones is an approach that holds great promise.

\subsubsection{Building migrant girls' social capital}

Social networks can stabilize migrant girls' lives and help them deal with unexpected events (Huong 2007). Because migrant girls often lack social support, they miss out on the documented benefits of group membership. For example, research in KwaZulu Natal, South Africa found that girls' group membership resulted in delayed sexual onset, reduced incidence of non-consensual sex, and greater condom use compared with girls who had no program affiliation; girls in groups were eleven times more likely to use a condom at last sex than girls not in a group (Hallman 2008). ${ }^{20}$

Recognizing how a move disrupts girls' social support, a small number of NGOs and community-based organizations have developed social networks and group affiliations to benefit migrant adolescent girls. These groups are guided by older female mentors from similar backgrounds. In addition to expanding girls' social capital, safe spaces serve as locations for training, education, and referral to other services. Box 7.1 describes a safe space program for vulnerable adolescents that reaches migrants without focusing on them explicitly.

\section{Prioritizing isolated girls' social capital}

Existing efforts to build the social capital of isolated girls-especially child brides and domestic workers are relevant for migrant girls, who are disproportionately represented among these groups. The creation of married girls' clubs can help girls build critical connections with each other and with guiding mentors, increasing their visibility and autonomy in their communities and improving sexual and reproductive

\section{BOX 7.1}

\section{A targeted approach to build social capital: The Biruh Tesfa (Bright Future) program in urban Ethiopia}

The Biruh Tesfa program aims to address the social isolation of 10 to 19 year-old out-of-school girls living in low-income urban areas of Ethiopia, including domestic workers and orphans. ${ }^{21}$ Nearly two-thirds of program participants are migrants. This is a partnership between the Population Council, the Ethiopian Ministry of Women, Children, and Youth (WCY) Affairs, Regional Bureaus of WCY, and local administrations. Nearly 60,000 girls in 18 cities had participated in Biruh Tesfa as of late 2012.

Using a group-based mentoring model segmented by age, the program builds girls' social capital and provides training on basic literacy, financial literacy, HIV/reproductive health education, menstruation, and genderbased violence. The program is led by women ranging in age from 20 to 40 years, with at least 12 years of education, who live in the project site and are respected community members. In addition to group meetings, girls receive wellness checkups and subsidized medical services from over 70 clinics in the public and private sector using a coupon system. Girls receive material support once a year in the form of exercise books, pens, pencils, a program identification card, reusable sanitary pads, and four bars of soap. Referrals to shelters, legal agencies, and other social services are also provided.

An evaluation showed that girls in the program were more than twice as likely to report social support compared to girls in control sites. They were also twice as likely to have high scores related to HIV knowledge, to know where to obtain voluntary counseling and testing, and to want testing compared to girls not in the program.

health knowledge and contraceptive use (Erulkar and Mekbib 2007; Santhya, Haberland, and Das 2008). Technology, though not a replacement for faceto-face interactions, can also help reduce migrant brides' isolation; in rural Kenya young married girls use mobile phones to maintain contact with family members back home (Murphy and Priebe 2011).

Such approaches can also help isolated domestic workers. A study in Burkina Faso revealed that
19

Personal communication with Foundation, July 2012.

20 Results were not specific to migrants.

21 Erulkar et al. 2012; Erulkar 2011 Nipa Bhansali, Childline India 


\section{Innovative programs builld migrant girls" portable and protective assets such as skills and knowledge, social networks, personal documentation, and savings.}

Susus are informal banking systems whereby accredited individuals visit market places and homes on a daily basis to collect voluntarily donated funds from clients, generally women. This is saved and payments are made to the clients at the end of each month less the thing for day, which is reta banker' as a commission (Kwanky et al. 2007)
95 percent of migrant adolescent girls in domestic service belonged to no social group. A Population Council program, Filles Éveillées (Girls Awakened), increased the social capital of migrant adolescent girls in domestic work, along with linking them to services and building their financial, health, and life skills. Program staff also observed that the girls' selfconfidence and self-esteem improved, and they were better able to express themselves as a result of the program (Engebretsen 2012a).

\section{Informal indigenous social networks for girls} Indigenous traditions of creating ways for migrants to socialize and build their networks are documented in Africa and Asia. A few such networks have evolved specifically for migrant girls. In an area in Indonesia where females increasingly migrate from rural areas to work in urban factories, an informal kinship network offers young migrants a home away from home and a social network. This network is highly organized: registration books are kept detailing personal information and employment history of members, providing information about possible employment opportunities (Elmhirst 2002).

\subsubsection{Building migrant girls' portable assets Providing personal documentation}

Programs in a number of settings provide personal documentation to mobile populations to give them an identity and access to entitlements, though few of these are girl-specific. Some migrants, international migrants in particular, have benefited from birth registration, civil registration, and personal identification cards. These cards may include vital demographic information and a photo. Uses vary, but they have helped girls access health and education services and social benefits. The Migrant Labour Support Program of Gramin Vikas Trust in India issues identification cards to internal migrants and their families. Program evaluations showed that having an identification card reduced migrants' stress during an emergency, improved recovery of unpaid wages, and increased the social and economic returns from migration (Deshingkar and Kumar 2006).

\section{Enabling girls to save money safely}

Working migrant girls need reliable means of saving money. In a few settings, informal systems and NGO programs give migrant girls financial capabilities and access to savings products before they migrate and after they start working. These steps are part of a broader move to overcome financial barriers and help girls meet financial goals.

Migrant girls use informal systems for saving and transmitting funds back home such as susus ${ }^{22}$ in Ghana, logeurs elsewhere in West Africa, and hawala couriers in India. Social capital is necessary for such informal savings systems to work. In Laos, young migrant women living and working in factories reported that good relations with other factory workers resulted in mutual reinforcement of savings behavior. In groups of ten, these young migrants each contributed $\$ 20$ per month to the group collective, which allowed for a rotation of funds whereby each young woman could send home \$200 in remittances to her family every 10 months, thus improving her family situation (Phouxay and Tollefsen 2011). 


\section{FIGURE 7.2}

\section{Protective assets for successful migration}
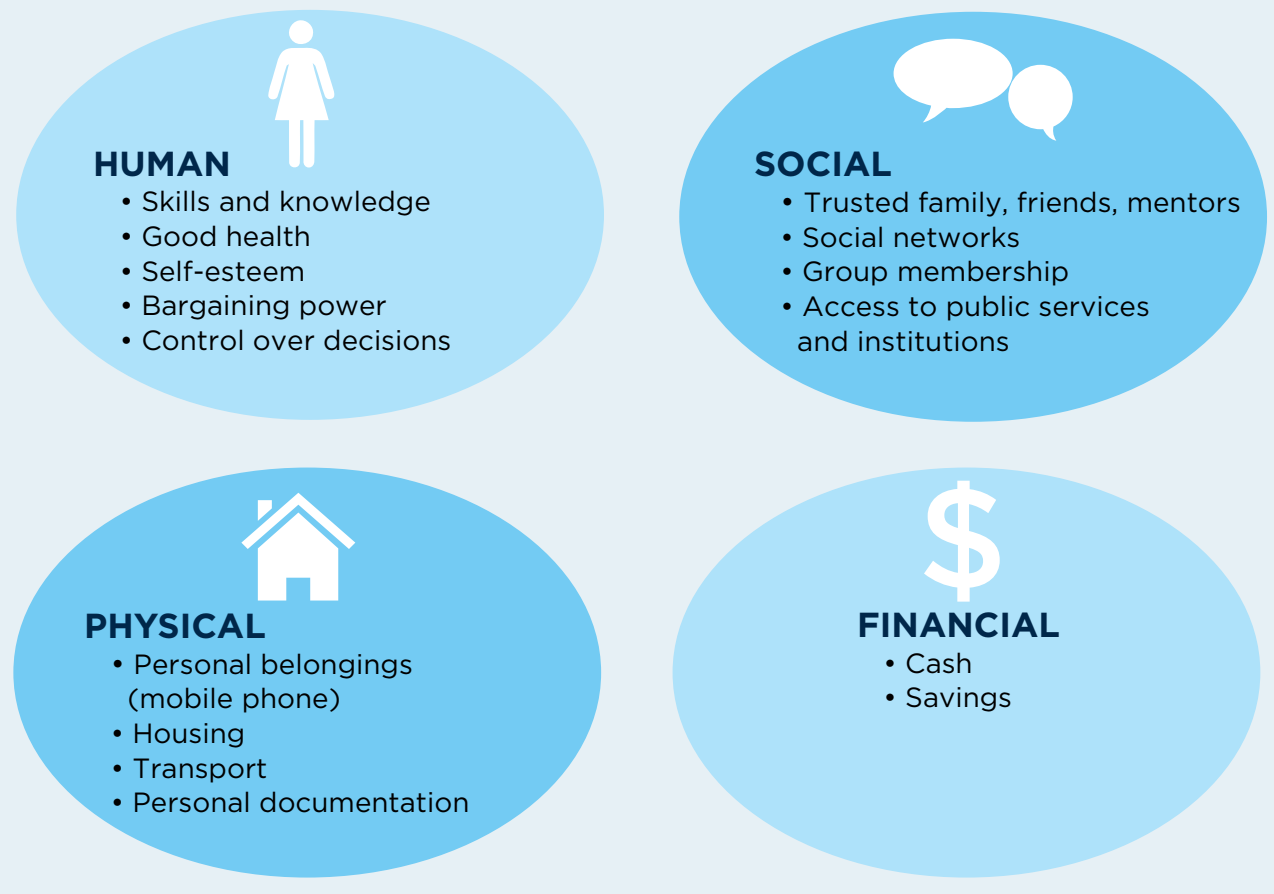

Source: Adapted from Austrian and Ghati (2010)

Adolescent girls also benefit from formal savings programs, although migrant girls have not been the sole beneficiaries of such efforts. For example, the Population Council and Microsave cooperate with financial institutions in slums of Kenya and Uganda to deliver the Safe and Smart Savings Products for Vulnerable Adolescent Girls program. This program gives girls financial education, health training, and individual savings accounts in local financial institutions. Findings from the Uganda pilot show that adolescent girls who were affiliated with a financial institution were more likely than other girls to save using formal and informal saving methods (Austrian 2011). Likewise, girls in the program were more likely to have a savings plan and a budget and to save more money than other girls. Of note, girls with savings accounts who were not affiliated with a group were less likely to have someone to borrow money from in an emergency, demonstrating again the importance of social capital.

\subsubsection{Making girls' work safer}

Migrant girls may face higher risks of labor exploitation than other workers, making efforts to address child labor relevant. Much of the action on child labor focuses on enforcement of labor laws such as the minimum legal age for employment. Other efforts include development and enforcement of employer codes of conduct, identification of the worst forms of child labor, and protecting children from the worst forms. Child labor efforts also focus on developing vocational training centers to improve opportunities for young people who are out of school. Other initiatives include large-scale income-support schemes to expand adolescents' chances of pursuing incomegenerating activities. 


\section{BOX 7.2}

\section{The power of collective worker action}

In the Philippines, the Visayan Forum Foundation established the SUMAPI program for domestic workers of all ages (SUMAPI 2012). Domestic workers in this program developed a "magna carta" document acknowledging their rights, and the Philippines House Committee on Labor and Employment approved the proposed document, which soon became law (Congress of the Philippines 2012). SUMAPI also organized two national summits of domestic workers. These summits resulted in increased awareness, advocacy, and policy change aimed at ensuring decent work for domestic workers.

Through efforts at the first summit, SUMAPI was recognized as an active voice in the advocacy for domestic workers, and in 2009 the ILO-Manila office asked the Visayan Forum to chair ILO's technical working group on Decent Work for Domestic Work (ILO 2011). Two years later, the government and worker and employer delegates of the ILO adopted Convention 189 on Decent Work for Domestic Workers, aimed at improving the working and living conditions of tens of millions of domestic workers worldwide, many of whom are migrants (ILO 2012).

\section{Employee organizing for social capital and collective bargaining}

A promising approach to making migrant girls' work safer involves connecting working girls with their colleagues. In Laos, young migrant women working in factories live together in dormitories and form collective organizations. Within these groups factory workers discuss their work and living conditions with a representative of the Lao Women's Union, who then presents this information to factory management (Phouxay and Tollefsen 2011). In addition to formal efforts, informal employee organizing can build migrant girls' social capital and facilitate collective bargaining. For example, older domestic workers in Burkina Faso, known as grandes soeurs (big sisters), identify girls in domestic work and empower them to negotiate with employers for better working conditions (Terre des Hommes 2010).
7.1.6 Increasing migrant girls' educational opportunities

Expanding the definition of basic education and targeting subsidies to the most disadvantaged are proven approaches to increasing girls' schooling (Lloyd 2009). Policymakers and program planners are devising strategies to help girls make the transition from primary to secondary school-a transition that often occurs around the time of girls' puberty and the onset of greater social constraints. Despite clear evidence linking migrant girls' vulnerability to their lack of education, the needs of migrant girls have not featured in these efforts. An exception is Save the Children's Cross-Border Project in the Mekong Region. The Chinese government collaborated with local schools in one province to reduce out-migration by making middle school education compulsory (Save the Children 2007). The project likewise helped persuade the government to allow in-migrant children to attend school regardless of their parents' migration status, although police and immigration officers often contradicted policy by arresting parents outside of schools (ILO 2008).

\section{Education subsidies}

Subsidies can increase girls' education, but not all approaches will work. Room to Read's Girls' Education program in nine countries provided scholarships or other material support such as bicycles, clean uniforms, or a room in a boarding house close to school for rural girls (Room to Read 2012). There is a risk that education subsidy programs will overlook migrant girls because of their tenuous or unstable living situations. Those in temporary situations or those who are not considered members of established households (such as domestic workers) may miss out on targeting and registration for subsidies. Furthermore, many migrant girls lack the documentation they may need to establish their right to subsidized schooling.

\section{Non-formal education and flexible schooling}

Non-formal education approaches can develop migrant girls' skills and increase their potential for income generation. Migrant girls benefit from nonformal education that is integrated with the formal school system (Lloyd 2009). The School for Life Programme in Ghana provided fostered girls with vocational skills and allowed early dropouts to reenroll in the formal school system. This program used textbooks that reflected the local context, using 


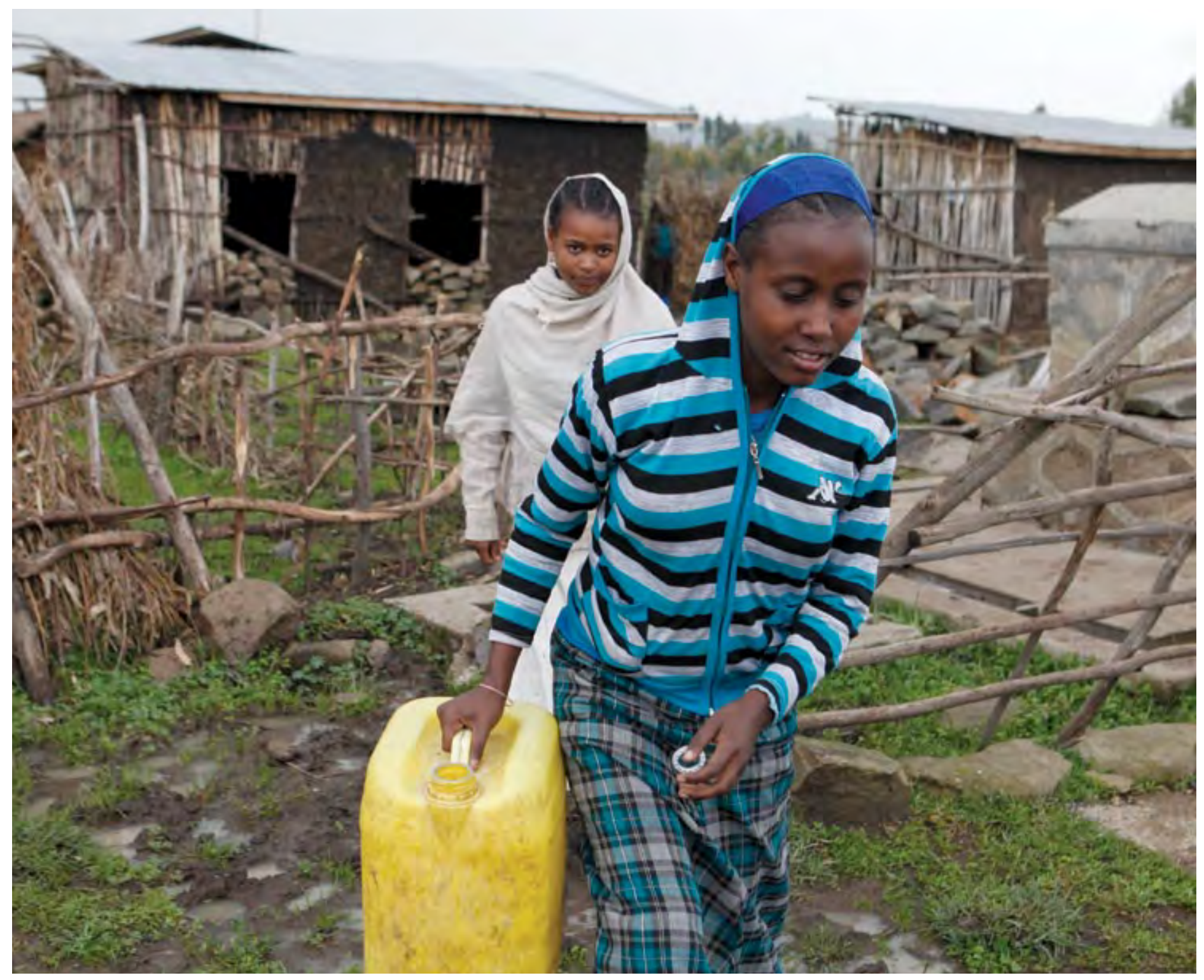

economic activities such as farming to illustrate points (Akyeampong 2004).

Recognizing that many migrant girls need to combine work and school, some NGOs bring non-formal education to the places where girls live and work. Save the Children's partner Foundation for Education Development found that mobile education units were an effective way to reach migrant children with non-formal education in remote areas and rubber plantations in southern Thailand (GHRED 2011). "Earn-and-learn" schools allow children to attend school while working. Through a public-private partnership, the Tanganda
Tea Estates Earn-and-Learn School was established in Chipinge, Zimbabwe, where tea plantations are common. The Ministry of Education provided teachers' salaries and a small allowance for each child. Tea companies covered costs of boarding, ancillary staff, land, buildings, and equipment for the schools. Children attended school in the morning and worked in fields each afternoon (Bourdillon 2000:14). The money they earned in the fields covered their school fees.

The scheduling of non-formal education programs is also important for working girls, since employers may be reluctant to allow girls time off to attend class. Photo Credit: Melodie McDaniel 


\section{Programs that target beneficiaries based on one criterion, such as migrant status, will not work for girls who do not identify themselves as migrants.}

23

COBET was a basic education program aimed at providing life skills (nutrition, hygiene, HIV/AIDS prevention), literacy, and vocational training opportunities to out-ofschool children aged 8 to 18 in Tanzania (UNICEF 2009)
The Complementary Basic Education in Tanzania (COBET) program ${ }^{23}$ allowed students to choose their own timetables, which students felt was an important reason for the program's success (Miske 2008). NGOs increasingly recognize the importance of reducing transport costs and fees associated with non-formal education. An NGO in Peru, Asociación Grupo de Trabajo Redes, provides transportation and informal education programs to socially isolated groups of domestic workers living in Lima (Anderson, Minaya, and Figueroa 2010).

\subsubsection{Protecting and improving migrant girls' health}

Initiatives to provide migrant-friendly health services hold promise for adolescent girls. IOM Zambia works as part of the regional Partnership on Health and Mobility in Southern and Eastern Africa (PHAMESA), which focuses on health promotion among migrants and mobile populations. PHAMESA Zambia trains service providers in migrant-friendly health services as part of its larger aim to build capacity for delivering HIV and health promotion services (IOM 2011).

\section{Linking migrant girls to urban health services}

Migrant girls' access to health services may be limited by residence, culture, language, poverty, and age-related norms. A study of migrant girls in India showed that family planning and reproductive health services were the least frequented by eligible girls among a range of available health, education, job-training, and social services, with only 29 and 20 percent reporting use of such services respectively (Tirpude College 2004:129). Some initiatives seek to address this inequity. Motivated by evidence that rural-to-urban migrant women in China do not access maternal health services as a result of poverty, high costs, perceived discrimination, and negative attitudes toward migrants, the Minhang District Health Bureau in Shanghai established a migrant delivery center for rural-to-urban migrants. The district government was involved in the program design phase and eventually assumed full leadership of the delivery centers, with the goal of expanding throughout Shanghai. Since the delivery center opened, the number of migrant women delivering at the health center has risen significantly (Xu et al. 2011).

\section{Workplace sexual and reproductive health information and services}

The Women and AIDS Research Program and the International Center for Research on Women designed a program for migrant girls aged 14 to 24 working in garment factories in Chiang Mai to improve sexual and reproductive health knowledge, attitudes, and behaviors (Cash, Anasuchatkul, and Busayawong 1995). A four-arm research design - with health education materials, health education materials plus health promoters, health education materials plus peer educators, and controls-compared effectiveness for improving workers' sexual and reproductive health. Person-to-person models proved more effec- 
tive than the information-only model, demonstrating the importance of social capital in improving migrant girls' access to health information and services.

\subsection{Programs and Policies Often Miss the Mark}

\subsubsection{Programs that are inversely related to need}

Programs and policies for migrant girls generally overlook evidence that shows an inversion of care in conventional youth programs. That is, those who begin with the greatest advantages - typically older in-school males-receive a disproportionate share of resources, and those who begin with the fewest advantages - typically younger out-of-school femalesreceive the fewest resources (Weiner 2011). Many migrant girls move to urban areas, where services are typically more widely available than in rural areas. However, they do not access services at the same rate as local urban peers because of access barriers, as described in Chapter 6. Research in slum areas of Addis Ababa indicated that girls do not benefit from youth resources: only 7 percent of girls aged 10 to 19 visited a youth center in the past year (Erulkar et al. 2006). It is an urgent challenge for NGOs delivering services to expand segmented approaches that reach disadvantaged populations and reduce the inversion of care.

Recognizing the inversion of care between those in need and those receiving services could help policymakers and program planners take into account the fact that investments in migrant adolescent girls make sense from an economic as well as a human rights perspective. Broader experience with adolescent girls shows that, rather than building their protective assets, policies and programs often respond to girls only after something has gone wrong in their lives. Prevention is not only ethical, but also likely to be more cost-effective than responding to problems (Sewall-Menon et al. 2012).

\subsubsection{Targeting based on migrant status}

Identifying and reaching migrant girls who need support requires better evidence of vulnerability and an understanding of how to identify them within the general population (Engebretsen 2012b). Programs that target beneficiaries based on one criterion, such as migrant status, will not work for girls who do not identify themselves as migrants. For example, young migrant women in Guatemala who mentioned leaving their communities in search of work or marriage did not refer to this process as "migration" (Rodas 2012). Likewise, young women who moved within Zimbabwe's borders did not self-identify as migrants. Given that "mobility appeared to be seamlessly integrated into their lives," the term migrant was reserved for laborers who entered Zimbabwe from Zambia and other neighboring countries (Busza 2011). These girls would miss out on program opportunities without refined targeting approaches.

\subsubsection{Reintegration programs}

Reintegration programs seek to remove migrant children from exploitative work or living conditions and return them to their natal homes. These programs generally view child migration as a problem that needs to be fixed, based on the assumption that those on the move always experience the worst outcomes, such as trafficking or exploitation (Reale 2008:20). Reintegration programs are not always in the best interests of migrant girls, however, overlooking the reasons why they left home. Sending a girl back can put her at risk of forced marriage or other situations that could threaten her safety, health, and well-being.

The transformative potential of migrant girls is enormous, but current approaches do not realize this potential. Only a small fraction of migrant girls have had contact with dedicated programs designed to meet their needs. Programs are often small-scale and designed to fix problems after they occur, leaving considerable room for improvement. Migrant girls stand to benefit from broader population-based approaches. The migrant-specific impact of action to decrease the worst forms of child labor, increase girls' education, and other relevant initiatives has yet to be explored. The following chapter outlines recommendations to fill these gaps and accelerate action for migrant girls. 



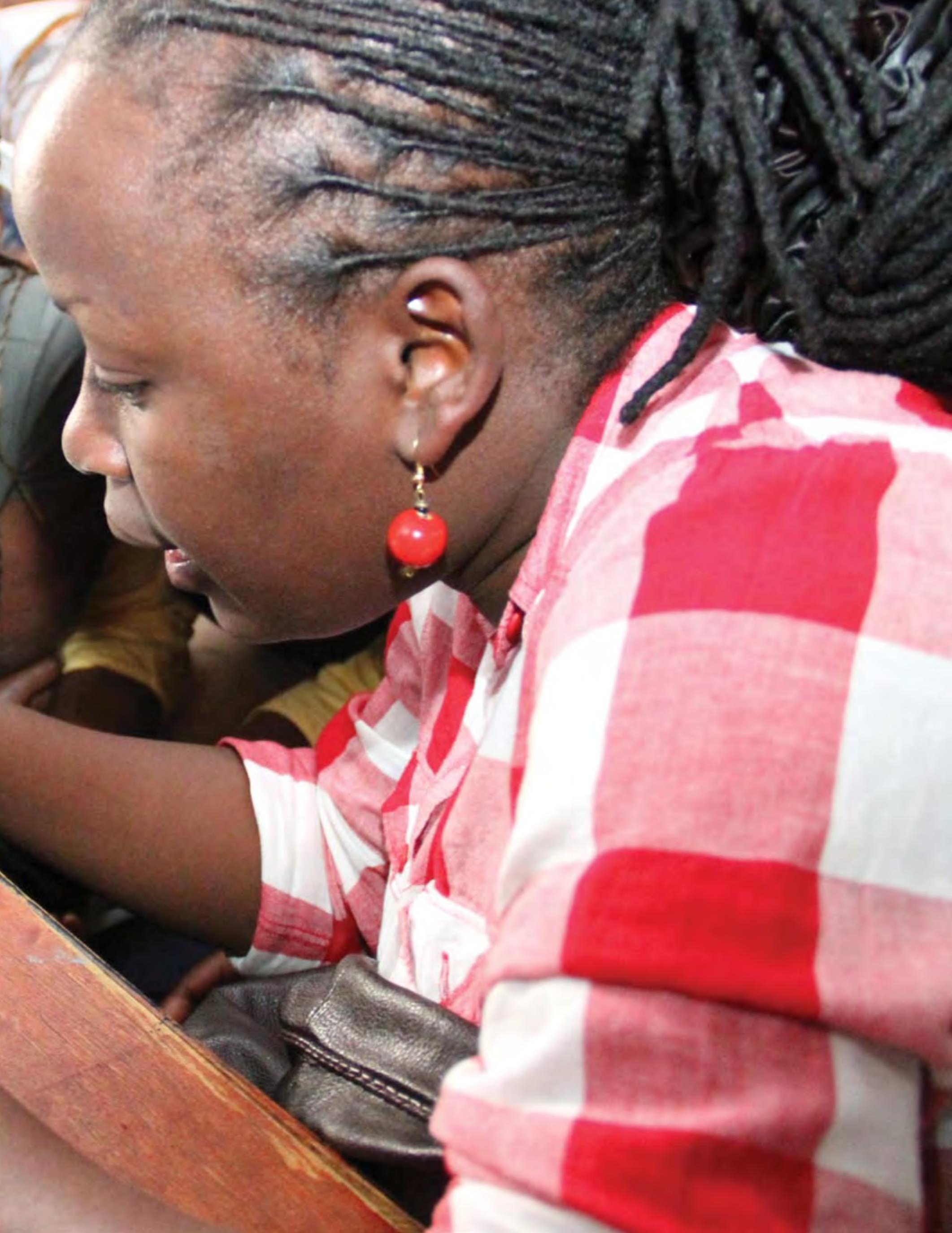




\section{Individually, migration can offer an adolescent girl a path to upward mobility. Collectively, migrant girls are poised to accelerate progress toward development goals at the top of the international agenda. Such progress is possible if the enabling environment is right.}

This chapter sets out an action agenda to ensure that migrant adolescent girls have the opportunity to fulfill their potential. The chapter does not offer a major policy overhaul. Relatively minor adjustments to existing policies can generate significant, tangible benefits when designed with migrant girls in mind. Such an agenda also requires focused investments to improve programs for girls at highest risk. To take account of the diversity of migrant girls' situations, policymakers and program managers and planners need to consider the factors that shape a girl's migration experience. These include her poverty level and age, knowledge and understanding of the implications of migration, norms about girls' migration, whether her move is voluntary or forced, and the resources available at her destination.

\subsection{The Time Is Right}

Turning program and policy options into genuine opportunities for migrant girls is an important challenge; it is also a timely one. Governments in developing countries are beginning to understand that urbanization is inevitable. Within the next 20 years, national populations are likely to tip from being majority rural to majority urban (UNDESA 2012), with voluntary migration being an important element in this transition. Forward-looking governments are already aware that natural disasters cause internal displacements. Many displaced persons, girls among them, are moving to cities and towns. Recognition of these transformations may allow policymakers to see the situation of urban adolescent girls clearly and respond accordingly.

Interest in adolescent girls has grown at both global and national levels. Recognition that migrants are a significant sub-group of adolescent girls could influence resource flows, research, and other steps to improve program effectiveness and value for money. With countries looking ahead to a second phase of commitments to reduce poverty following the Millennium Development Goals, the approach of 2015 presents an opportunity to advocate for migrant adolescent girls, especially the poorest and most marginalized among them.

\subsection{Multiple Actors for Migrant Girls}

Who is ultimately responsible for migrant girls? To date, meaningful government and international action for migrant adolescent girls has been limited. First, internal migrants have not been a focus of international bodies such as IOM because most governments view internal migration as a domestic issue. Second, the welfare of internal migrants does not fall neatly within the agenda of any single sector or government ministry. The constituencies interested in issues relevant to migrant girls - such as child labor and child protection - tend to work in parallel. Effective action requires collaboration across sectors, which is difficult to sustain. Third, the unique concerns of migrant adolescent girls can be politically sensitive in places where their cheap labor underlies household and national economies, leading those in power to turn a blind eye. Finally, it is unusual for organizations working on migration to differentiate their efforts according to migrants' age and sex, and these organizations have not factored in the fundamental differences that separate migrant adult men from migrant adolescent girls.

Governments from the municipal to the national level share the responsibility to protect the rights of their vulnerable and overlooked citizens, including those on the move who are additionally disadvantaged by being young and female. Ministries of urban planning, transport, health, education, youth, and social welfare all have roles to play. With administrative decentralization, municipal governments are increasingly important actors, taking greater responsibility for social protection and welfare programs in their jurisdictions. Laws and policies which ensure that migrants receive the benefits due to all citizens are also necessary.

There is substantial need to improve on current programs for migrant girls. Promising civil society approaches can be expanded with the goal of learning more about impact, coverage, and sustainability. 
Working through indigenous community-based organizations, such as slum-dwellers' associations, is an effective strategy for reaching high-risk migrant girls. In collaboration with NGOs, these associations work closely with municipal governments to improve housing and services in their neighborhoods (D'Cruz and Satterthwaite 2005). In this way, they link poor slumdwellers to local governments to sustain programs over the long term. Civil society organizations can also play a watchdog role to assess whether migrant adolescent girls benefit from government policies on child labor, migrant school access, and other relevant concerns. The private sector can work alongside NGOs to increase migrant girls' access to mobile phones, which can help them connect with family members and access services and entitlements.

The multilateral system can do more to recognize and support girls who migrate within national borders. International agencies including IOM, UNICEF, WHO, UNFPA, ILO, UN Women, and USAID can include migrant girls in their work on child protection systems, migrant health, child labor, data collection, and other relevant topics. If they were to act collaboratively, these agencies could support governments and civil society organization to effectively help migrant girls onto a positive trajectory.

Greater donor investment to reach migrant girls is also needed. As international donors increase their emphasis on adolescent girls as a group, they should ensure that the particular needs of the migrants among them receive attention. Their investments should be grounded in evidence, supporting program approaches that take heed of the diversity of girls and their experiences. The donor community can do more to support the generation of quantitative and qualitative evidence on the magnitude, rates, and outcomes of adolescent girls' migration, thereby ensuring that the full range of migrant girls' voices is heard.

\subsection{The Action Agenda for Migrant Adolescent Girls}

Taken together, the recommendations below can make migrant girls more highly visible, reduce their vulnerability to risk, and maximize their potential. These actions could become policy priorities, initially focusing on a few countries where a large percentage of girls are on the move-Cambodia, Malawi, and

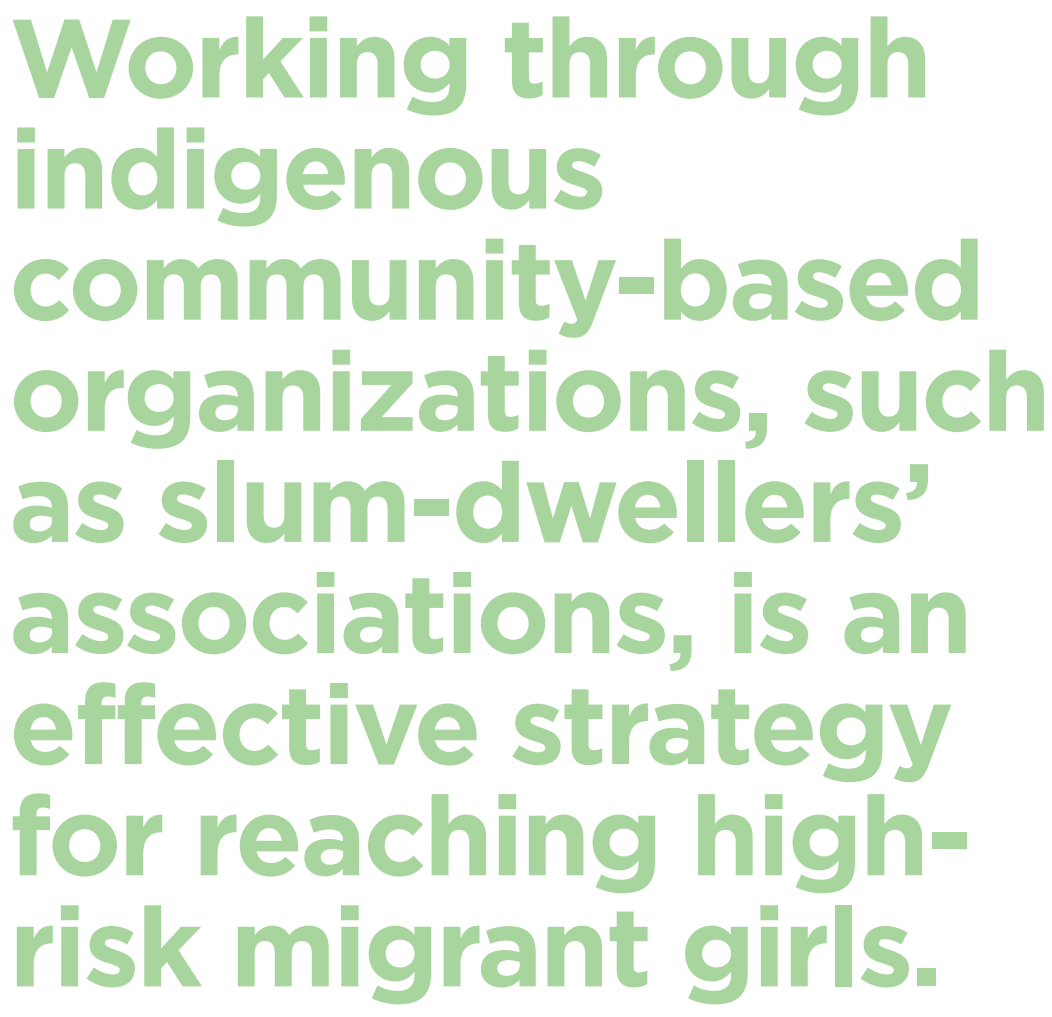

Vietnam are good candidates (see Chapter 1, Figure 1.3). A number of approaches to girls' migration suggest that some governments and NGOs overlook the potential benefits migration can provide for girls, their families, and their communities. The goal is to ensure that policies and programs are sensitive to the unique circumstances of migrant girls by taking two types of action: adjusting broad initiatives so as to extend benefits to larger segments of the population that include migrant girls, and delivering dedicated programs that reach migrant girls.

\section{Prepare and equip girls before they migrate}

Before girls move they need education, good health, and life skills to prepare them to manage risks and take advantage of opportunities that arise during their journey. They should be primed with education, life skills training including financial management, and information about what they will experience during the journey and on arrival. Girls should also be equipped 


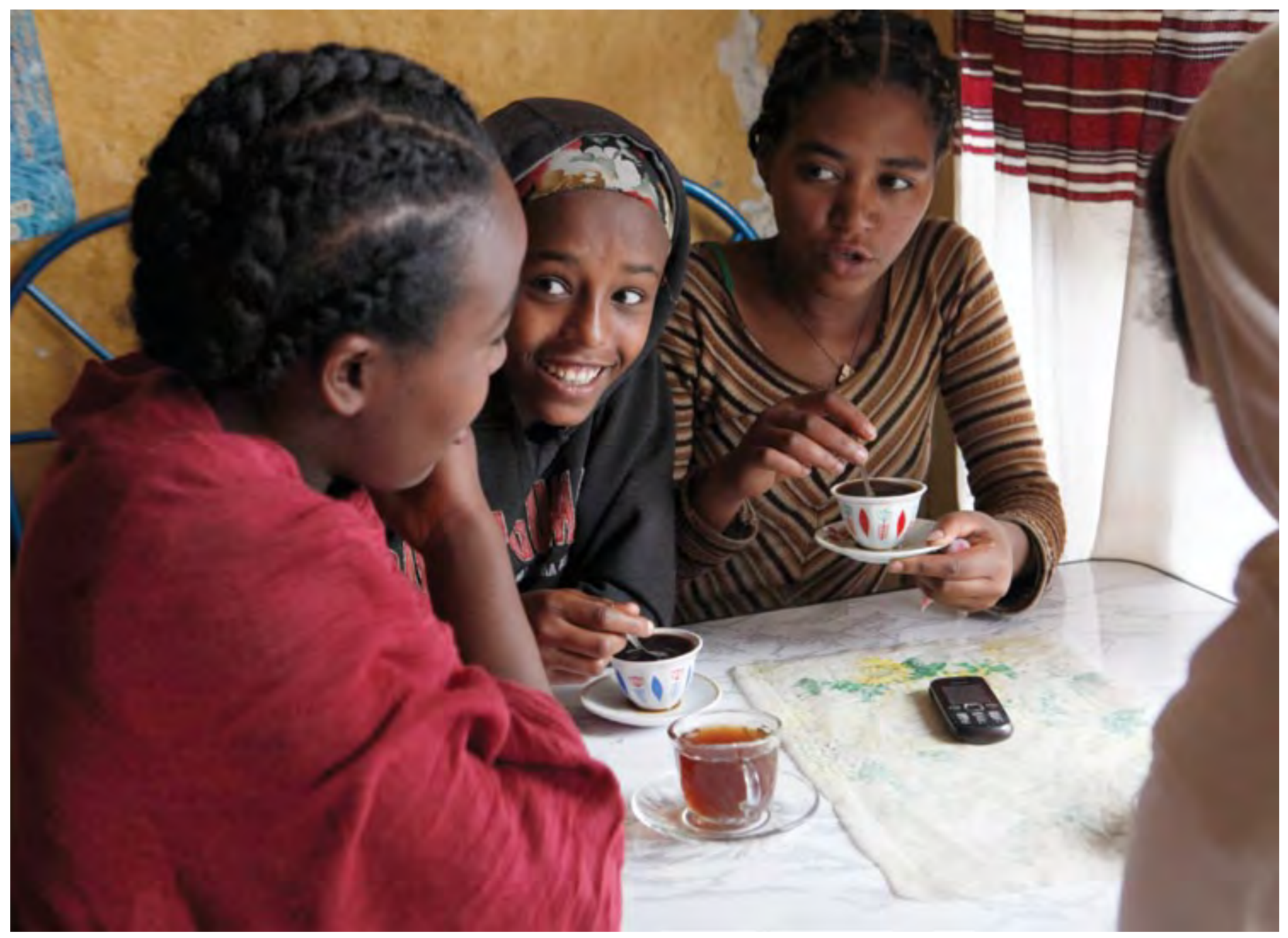

with knowledge of their human rights so they are aware of their entitlements and can take action if they encounter exploitation or abuse. Personal documentation such as birth registration and identification cards are also important resources for migrant girls that can facilitate access to health and education services and social benefits in girls' new communities.

\section{Ensure a smooth landing: a safe place to stay and social connections}

Girls on the move need safe places to go on arrival and measures to prevent or reduce isolation at their destination. Safe accommodation is an important first step. Neighborhood groups, including women's groups and associations of the urban poor, can help migrant girls expand their social capital immediately on arrival before girls fall into harm's way. With sup- port to extend their capacity, these groups will be well-positioned to welcome new arrivals, ensure their lodging, help locate safe and adequate employment, and stand ready to provide girls with social, financial, and logistical assistance and protection. The role of informal employee groups should also be enhanced to provide migrant girls with peer support, assistance, and training on critical topics such as life skills and personal financial management.

\section{Create time and space for migrant girls to meet friends and mentors}

Migrant girls have limited access to the social support-friends, trusted adults, community groupsthat is essential in times of trouble. In order to reduce migrant girls' isolation and prepare them for success, girls need to be connected to peers and trusted 
adults who can help them make healthy and informed decisions. In places where chain migration occurs, informal groups of migrants of common origin have the potential to immediately contact migrant girls and provide protection through support, referrals, and financial assistance. Community-based safe spaces can offer migrant girls places to gather with peers and trusted female mentors and can provide life skills and training programs.

\section{Make services "migrant girl friendly"}

Efforts to expand basic service access for populations of international interest, such as the urban poor and children in exploitative and dangerous employment, rarely recognize migrant adolescent girls. Initiatives to lower barriers and increase access of the urban poor to basic essential services will be beneficial to migrant girls if they take their unique needs into account. Services should emphasize cultural sensitivity and non-judgmental attitudes among employees, especially public-sector teachers and health workers. Service providers in areas with many migrants could learn key phrases in the migrants' language and become familiar with their cultural traditions to make them feel welcome. Health provider training could integrate a module on migrant girls' and women's health throughout the life cycle to reduce a key factor that keeps young migrants away from health services: discrimination by front-line workers.

\section{Test innovative ways to prepare migrant girls for success}

Current programs for migrant girls tend to be reactive rather than proactive. Girls on the Move calls for a new generation of programs that reach girls before problems arise. Experimenting with programs to develop girls' protective assets should be a research priority. This new generation of programs could test the impact of providing migrant girls with life skills and building their human capital before migration; making safe spaces and personal documentation available immediately on arrival; building social capital including connections to associations of urban poor; and providing mobile technology, mobile savings products, and financial capabilities. Careful program monitoring and rigorous evaluation should ensure that programs are evidence based and build on lessons from current programs for adolescent girls. In all cases, migrant girls' voices and experiences should be central to program design and evaluation.
Policies and

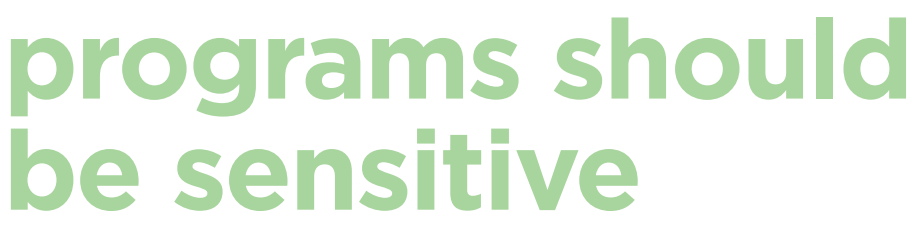

to the unique

circumstances of

migrant girls by

taking two types

of action: adjusting broad initiatives so as to extend benefits to larger segments of the population that include migrant girls, and delivering dedicated programs that reach migrant

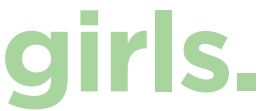




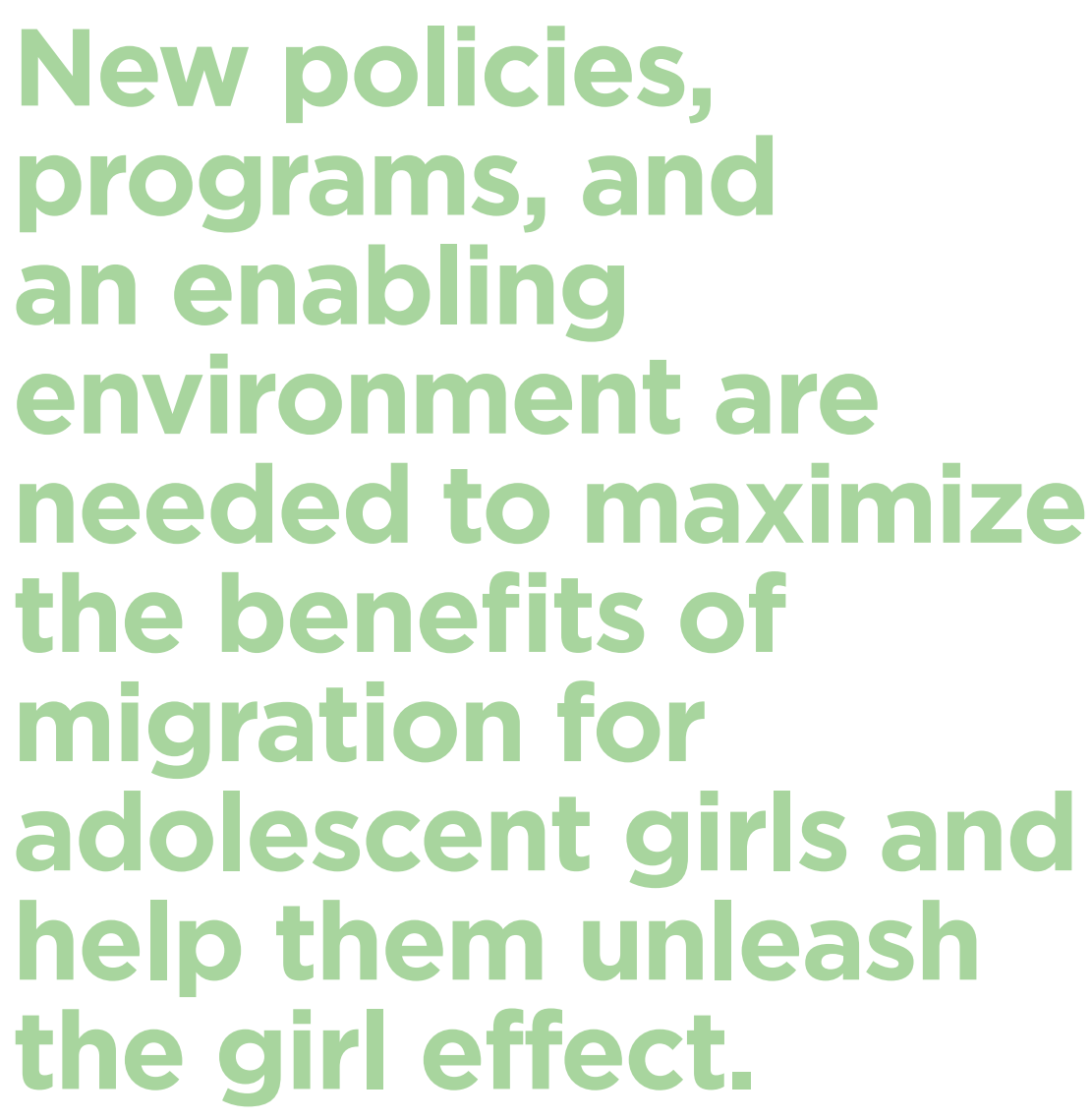

\section{Focus on the most isolated and vulnerable}

Many child domestic workers, child brides, and sexually exploited girls are migrants. For those who are vulnerable and socially isolated, safe space approaches are a program priority. Given domestic workers' limited power, the impact of safe space approaches will be enhanced by requiring employers to give workers time off to participate in programs. Married girls' clubs are important in communities where young brides migrate to join their husbands. Strengthening social networks of sexually exploited girls can bolster their sources of protection, support, and assistance in times of need. Giving mobile phones to vulnerable, isolated migrant girls can allow them to keep in touch with families at home. To find and engage the most socially isolated migrant girls, programs should use targeted, purposeful recruitment; routine approaches will continue to overlook the most excluded.

\section{Fill critical evidence gaps}

Most approaches to migrant girls conflate the worstcase experiences of the few and the more routine experiences of the many. Appropriate programs and policies will only be possible with better evidence on the diversity of girls' migration experiences. This evidence will help policymakers allocate resources proportionate to need and program managers to design targeted strategies rather than "one size fits all" approaches. Important questions include which sub-populations of migrant girls face the greatest risks, what those risks are, and where the greatest numbers of these girls reside. These questions can be answered by:

- Ensuring that large-scale surveys such as USAID's Demographic and Health Surveys and UNICEF's Multiple-Indicator Cluster Surveys collect age- and sex-disaggregated migration data, including data on urban-to-urban migration given its demographic importance.

- Conducting longitudinal surveys on the implications of migration for girls' social, economic, and health outcomes; such information will also shed light on differences between younger and older adolescent migrants, identify long-term consequences of negative events, and highlight entry points for intervention at critical transitions. 
- Conducting qualitative research to better understand migrant girls' experiences and design responses based on demonstrated need.

- Evaluating programs to assess their effect by migrants' age, origin, and timing of move, as well as sustainability of benefits over time; increasing understanding of the cost-effectiveness of different programs to guide donors and governments on allocating limited resources.

\section{Increase migrant girls' visibility through policy and advocacy}

Migrant girls will benefit from policy engagement and advocacy to promote girls' education and economic empowerment, strengthen child protection, and combat gender-based violence and child marriage-benefits that are rarely found in current programs for girls. In addition, policy reforms for internal migrants as a group, such as reducing barriers to internal migration, facilitating remittance flows, and improving living conditions in migrant arrival areas, can also help migrant girls. These efforts need to be sensitive to age, sex, and migration status to make a sustained difference for migrant girls.

Migration has the potential to catalyze the girl effect. The available evidence indicates that most migrant adolescent girls end up in cities, where they encounter new opportunities, better resources, and less restrictive gender norms. When adolescent girls leave home for positive reasons, travel safely, and integrate fully into their new homes and social structures, they will be able to take advantage of education, work opportunities, savings and remittances programs, health services, and new ideas around them. Experiences gained through migration can enable them to negotiate restrictive social perceptions, inspire younger girls, contribute financially to their home and migrant communities, and make positive and meaningful change in the urban landscape. Policies, programs, and an enabling environment can maximize the benefits of migration for all migrant adolescent girls and help them unleash the girl effect. 


\section{KEY DEFINITIONS}

Chain migration: When migrants from a particular locality follow others from the same locality to a new administrative unit, whether in an immigrant receiving country or in a new location in the home country. The term implies that those moving earlier ease the process of adjustment of later migrants to circumstances at destination.

Child trafficking: The Palermo Protocol (see next page) defines child trafficking as the recruitment, transportation, transfer, harboring or receipt of children (as old as 18) for the purpose of exploitation (UNICEF 2011).

Independent child migrant: A child who travels or lives at his or her destination without an adult.

In-migrant: A person who has moved into a locality (a political or administrative unit, or a geographicallydefined social, economic or cultural environment) from another such locality in the same country, whose place of usual residence after the move is in the destination area (Becker 2008). To distinguish from immigrant, a person who has moved into a political or administrative unit from another country and who at the time of the move is not a citizen of the destination country. Also to distinguish from residential mover, a person who has changed dwelling within a locality.

Internal migration: Movement within the borders of a country that involves a change of locality and place of usual residence. To distinguish from residential mobility, which involves a change of dwelling within a locality.

International migration: Movement across country borders involving a change in usual residence.

Migrant: A person who moves from one locality to another, changing his or her place of usual residence. The term migrant is commonly understood to refer to people whose decision to migrate is or was voluntary, that is, without external compulsion.
Migration: A process of moving, either across an international border or within a country, which results in a temporary or permanent change of locality and place of usual residence.

Mobility: Any kind of movement of people, regardless of duration or cause. This term encompasses permanent migration, seasonal and temporary migration, residential mobility, and even daily commuting.

Out-migrant: A person who moves from a political or administrative unit to another such unit within the same country, taking up usual residence in the destination unit. To be distinguished from emigrant, a person who moves to another country (Becker 2008).

Relay migration: Process in which migrant parents or relatives return and are replaced by their children.

Step migration: Process in which a migrant moves from origin to destination via one or more intermediate destinations, typically from smaller to larger cities.

Temporary migration: A non-permanent migration implying return or onward movement. Such movements are undertaken by students, seasonal workers and the like.

Unaccompanied child migrant: A child who travels without parents and/or other relatives and is not being cared for by an adult who, by law or custom, is responsible for doing so. 


\section{ANNEX}

\section{International human rights conventions that protect migrant adolescent girls}

\section{Human rights law applies to all human beings at all times. International protocols and conventions protect migrant girls' rights, including (IOM 2012):}

\section{- The Universal Declaration of Human Rights}

(1974), "a common standard of achievement for all peoples and nations." Article 2 defines the fundamental principle of non-discrimination, which is highly relevant to migrants. This guarantees that every human being is entitled to the rights and freedoms set forth in the Declaration without distinction of any kind, including national or social origin. Other articles relevant to migrant girls are (IOM 2012):

- Right to life, liberty and security of person (Article 3)

- Prohibition of slavery or servitude (Article 4)

- Prohibition of torture or inhuman or degrading treatment or punishment (Article 5)

\section{- The Convention on the Elimination of All} Forms of Discrimination Against Women (CEDAW) (1979) defines what constitutes discrimination against women and provides an agenda for national action to end it. CEDAW provides the basis for realizing equality between women and men by ensuring women's equal access to, and equal opportunities in, political and public life as well as education, health and employment. CEDAW is relevant to migrants because it obliges States' parties to take all appropriate measures, including legislation, to suppress all forms of traffic in women (IOM 2012).

\section{- The Convention on the Rights of the Child}

(CRC) (1989) sets standards of treatment of children under 18 years of age. It refers to rights to health, education, family, an adequate standard of living, and others. Article 2 specifies that whatever benefits a State gives to children who are its citizens, it must give to all children including migrants (IOM 2012). The convention guarantees the participation of children in matters concerning them. Article 3.1 stresses children's best interests as a primary consideration in all decisions and actions affecting them. Article 12 encourages states to pay "particular attention...to ensuring that marginalized and disadvantaged children, such as exploited children, street children or refugee children are included" (UN 2009).

- The International Convention on the Protection of the Rights of All Migrant Workers and Members of their Families (1990) was created in recognition of the vulnerable and unprotected positions of migrant workers and their families. The underlying goal is to provide an instrument that protects those in undocumented or irregular situations (IOM 2012).

\section{- The Convention against Transnational Or-} ganized Crime (2000) contains the Protocol to Prevent, Suppress and Punish Trafficking in Persons, especially Women and Children (sometimes known as the anti-trafficking or Palermo protocol). Article 3 provides a definition of child trafficking which has since become a widely accepted standard and used in other international instruments (UNICEF 2011):

- The recruitment, transportation, transfer, harbouring or receipt of a child for the purpose of exploitation shall be considered "trafficking in persons" even if this does not involve the threat or use of force or other forms of coercion, of abduction, of fraud, of deception, of the abuse of power or of a position of vulnerability or of the giving or receiving of payments or benefits to achieve the consent of a person having control over another person. 


\section{REFERENCES}

Abdul-Korah, Gariba B. 2006. "'Where is not home?': Dagaaba migrants in the Brong Ahafo Region, 1980 to the present," African Affairs 106(422): 71-94.

Acharya, Rajib, K.G. Santhya, and Shireen J. Jejeebhoy. 2010. "Association between mobility and transition to sexual life among unmarried young people: Evidence from India," New Delhi: Population Council.

Adamo, Susana. 2012. "Mapping internal migration patterns of adolescent girls in Latin America and the Caribbean," Unpublished Background Paper for Girls on the Move: Commissioned Research Paper Series. New York: Population Council.

Agarwal, Siddharth, and Eleri Jones. 2012. "Migrant adolescent girls in urban slums of India," Unpublished Background Paper for Girls on the Move: Commissioned Research Paper Series. New York: Population Council.

AGTR (Asociación Grupo de Trabajo Redes). 2004. "No somos invisibles: Resultados de consulta a trabajadores infantiles domésticos (TID) y ex trabajadores infantiles domésticos (EXTID) en Perú," Lima: Asociación Grupo de Trabajo Redes (AGTR).

Akileswaran, Chitra. 2005. "Bridging migration, HIV/ AIDS, and violence among women in Rustenburg, South Africa: A preliminary report," Phokeng, South Africa: Royal Bafokeng Nation.

Akyeampong, Kwame. 2004. "Aid for self-help effort? A sustainable alternative route to basic education in Northern Ghana," Journal of International Cooperation in Education 7(1): 41-52.

Albuja, Sebastián, and Marcela Ceballos. 2010. "Urban Displacement and Migration in Colombia," Forced Migration Review FMR34: 10-11.
Amin, Sajeda, lan Diamond, Ruchira T. Naved, and Margaret Newby. 1998. "Transition to adulthood of female garment-factory workers in Bangladesh," Studies in Family Planning 29(2): 185-200.

Anarfi, John, Saskia Gent, Iman Hashim, Vegard Iversen, Sumaiya Khair, Stephen Kwankye, Cynthia Addoquaye Tagoe, Dorte Thorsen, and Ann Whitehead. 2005. "Voices of child migrants: 'A better understanding of how life is," "Sussex, UK: Development Research Centre on Migration, Globalisation \& Poverty, University of Sussex.

Anderson, Bridget, and Julia O'Connell Davidson. 2005. "Border troubles and invisibility: Child rights and migration in Europe," Stockholm: Save the Children Sweden.

Anderson, Jeanine, Li Minaya, and Blanca Figueroa. 2010. "Child domestic labor: Perceptions of girls, boys and adolescents," Lima: Asociación Grupo de Trabajo Redes (AGTR).

Anh, Dang Nguyen. 2006. "Employment and vocational training among young people aged 15-17 in VietNam: National report," Hanoi: International Labour Organisation (ILO).

Ansell, Nicola, and Lorraine van Blerk. 2004. "HIV/ AIDS and children's migration in Southern Africa," Cape Town: Southern African Migration Project (SAMP).

Apt, Nana Araba. 2005. "A study of child domestic work and fosterage in Northern and Upper East Regions of Ghana," Paris: United Nations Children's Fund (UNICEF). 
Austrian, Karen. 2011. "Safe and smart savings products for vulnerable adolescent girls in Kenya and Uganda: Results from the Uganda pilot evaluation" presented at the Global Youth Economic Opportunities Conference, September 9, Washington, DC.

Austrian, Karen, and Dennitah Ghati. 2010. "Girl-centered program design: A toolkit to develop, strengthen and expand adolescent girls programs," Nairobi \& New York, NY: Population Council.

Awumbila, Mariama, and Elizabeth Ardayfio-Schandorf. 2008. "Gendered poverty, migration and livelihood strategies of female porters in Accra, Ghana," Norsk Geografisk Tidsskrift-Norwegian Journal of Geography 62(3): 171-179.

Baek, Eugene. 2008. "Between work and education: Child domestic workers in Lima, Peru," The Hague, The Netherlands: Institute of Social Studies.

Balakrishnan, Revathi. 2005. "Rural women in household production: Increasing contributions and persisting drudgery," in Rural Women and Food Security in Asia and the Pacific: Prospects and Paradoxes. RAP Publication 2005/30. Bangkok: Food and Agriculture Organization of the United Nations, Regional Office for Asia and the Pacific.

Bandyopadhyay, Nandinee, Swapna Gayen, Rama Debnath, Kajol Bose, Sikha Das, Geeta Das, M. Das, Manju Biswas, Pushpa Sarkar, Putul Singh, Rashoba Bibi, Rekha Mitra, and Sudipta Biswas. 2008. "Streetwalkers show the way: Reframing the global debate on trafficking from sex workers' perspectives," IDS Working Paper 309: 104-111.

Bastia, Tanja. 2005. "Child trafficking or teenage migration? Bolivian migrants in Argentina," International Migration 43(4): 58-89.
Beauchemin, Eric. 1999. "The exodus: The growing migration of children from Ghana's rural areas to the urban centres," Accra: Catholic Action for Street Children (CAS) \& UNICEF.

Becker, Stan. 2008. "Measurement of migration," Baltimore: Johns Hopkins University.

Béguy, Donatien, Philippe Bocquier, and Eliya Zulu. 2009. "Migration dynamics in Nairobi slums," paper presented at the Population Association of America 2009 Annual Meeting, Detroit, 2 May.

Blas, Erik, Johannes Sommerfeld, and Anand Sivasankara Kurup. 2011. "Social determinants: Approaches to public health. From concept to practice," Geneva: World Health Organization.

Blomster, Veera. 2004. "From the countryside to the capital: Domestic workers - Lima, Peru," Lima: Asociación Grupo de Trabajo Redes (AGTR).

Bourdillon, Michael. 2000. "Child labour and education: A case study from South-eastern Zimbabwe," Journal of Social Development in Africa 15(2): 5-32.

Brady, Martha, Lydia Saloucou, and Erica Chong. 2007. "Girls' adolescence in Burkina Faso: A pivot point for social change," Ouagadougou: Population Council.

Brown, Eleanor. 2007. "Out of sight, out of mind? Child domestic workers and patterns of trafficking in Cambodia," Geneva: International Organization for Migration (IOM).

Bunmak, Suttiporn. 2012. "Cell phone networks and migrant networks: The case of Nayu migrant workers in Malaysia," Geografia: Malaysia Journal of Society and Space 8(1): 38-49. 
Busza, Joanna. 2011. "'We move around at night': Experiences of young mobile sex workers in Zimbabwe," Unpublished Background Paper for Girls on the Move: Commissioned Research Paper Series. New York: Population Council.

Busza, Joanna, Sarah Castle, and Aisse Diarra. 2004. "Trafficking and health," BMJ 328(7452): 1369- 1371.

Caouette, Therese M. 2001. "Simple dreams beyond hope: The lives of migrant children and youth along the borders of China, Myanmar and Thailand. A participatory action research project of Save the Children, UK," London: Save the Children, UK.

Cash, Kathleen, Bupa Anasuchatkul, and Wantana Busayawong. 1995. "Experimental educational interventions for AIDS prevention among Northern Thai single migratory female factory workers," Washington, DC: International Center for Research on Women (ICRW).

Castellanos, M. Bianet. 2007. "Adolescent migration to Cancún: Reconfiguring Maya households and gender relations in Mexico's Yucatán Peninsula," Frontiers: A Journal of Women Studies 28(3): 1-27.

Catino, Jennifer, Alejandra Colom, and Marta Julia Ruiz. 2011. "Equipping Mayan girls to improve their lives," Transitions to Adulthood Brief No. 5. New York: Population Council.

Cerrutti, Marcela. 2009. "Gender and intra-regional migration in South America," Human Development Research Paper 2009/12. New York: United Nations Development Programme (UNDP).

Chalasani, Satvika. 2012. "Migration among adolescents from rural Malawi," Unpublished Background Paper for Girls on the Move: Commissioned Research Paper Series. New York: Population Council.

Chen, Juan. 2011. "Internal migration and health: Re-examining the healthy migrant phenomenon in China," Social Science \& Medicine 72(8): 1294-1301.
Childline India. 2010. "Childline India Foundation: Annual report 2009-2010,” Mumbai: Childline India Foundation. www.childlineindia.org.in/pdf/ChildlineAnnual-Report-09-10.pdf.

2011. "Childline India Foundation: 2010-2011 Annual report," Delhi: Childline India Foundation. www.childlineindia.org.in/pdf/Annual-Report-10-11. pdf

Clark, Shelley, and Cassandra Cotton. 2012. "Transitions to adulthood in Urban Kenya: A focus on female adolescent migrants," Unpublished Background Paper for Girls on the Move: Commissioned Research Paper Series. New York: Population Council.

CP-TING (Project to Prevent Trafficking for Labour Exploitation in China). 2011. "Summer anti-trafficking and safe migration publicity campaign kicks off in Chengdu," Beijing: CP-TING.

Congress of the Philippines. 2012. "House measures referred to labor and employment committee," Manila: 15th Congress of the Philippines.

Conticini, Alessandro, and David Hulme. 2006. "Escaping violence, seeking freedom: Why children in Bangladesh migrate to the street," UK: Institute of Development and Policy Management.

Cos-Montiel, Francisco. 2000. "Sirviendo a las mesas del mundo: Las niñas y niños jornaleros agrícolas en México," La Infancia Vulnerable De Mexico En Un Mundo Globalizado.

Crawford, Mary. 2010. Sex Trafficking in South Asia: Telling Maya's Story. London and New York: Routledge.

Curran, Sara R., and Abigail C. Saguy. 2001. "Migration and cultural change: A role for gender and social networks," Journal of International Women's Studies 2(3): 54-77.

CWISH (Children-Women In Social Service and Human Rights). 2009. "Domestic workers in Kathmandu: Survey report 2009," Kathmandu: Children-Women In Social Service and Human Rights (CWISH). 
D'Cruz, Celine, and David Satterthwaite. 2005. "Building homes, changing official approaches: The work of the urban poor organizations and their federations and their contributions to meeting the Millennium Development Goals In urban areas," Human Settlements Working Paper Series Poverty Reduction in Urban Areas No. 16. IIED, London.

Das, Jishnu, Jeffrey Hammer, and Kenneth Leonard. 2008. "The quality of medical advice in low-income countries," Journal of Economic Perspectives 22(2): 93-114.

Das, Kailash Chandra, and Arunanand Murmu. 2010. "Female migration to mega cities of India," paper presented at the Population Association of America 2010 Annual Meeting. Dallas, 16 April.

Davies, Anne, and Karen Jacobsen. 2010. "Profiling urban IDPs," Forced Migration Review FMR34: 13-15.

DeGraff, Deborah S., and Richard E. Bilsborrow. 2003. "Children's school enrollment and time at work in the Philippines," The Journal of Developing Areas 37(1): 127-158.

Delaunay, Valerie, and Catherine Enel. 2009. "Les migrations saisonnieres feminines: Le cas des jeunes bonnes à Dakar," in Thérèse Locoh (ed.), Du Genre Et De l'Afrique. Paris: Institut National Études Démographiques (INED), pp. 389-402.

Deshingkar, Priya. 2010. "Migration, remote rural areas and chronic poverty in India," ODI Working Paper 323. London: Overseas Development Institute (ODI).

Deshingkar, Priya, and Sushil Kumar. 2006. "Migration: Labour flows and capital transfers," London: DFID / India: Madhya Pradesh Rural Livelihood Project (MPRLP).

DHS. 2012. "Measure DHS: Demographic and health surveys," www.measuredhs.com/data/availabledatasets.cfm

Djobokou, Koffivi Papavi. 2008. "Étude sur le flux Akébou - Accra des jeunes filles domestiques," Lausanne \& Lomé: Terre des Hommes.
Dodson, Belinda, Hamilton Simelane, Daniel Tevera, Thuso Green, Abel Chikanda, and Fion De Vletter. 2008. "Gender, migration and remittances in Southern Africa," Migration Policy Series No. 49. Cape Town: Southern African Migration Project (SAMP).

Dottridge, Mike. 2008a. "Young people's voices on child trafficking: Experiences from South Eastern Europe," Innocenti Working Paper (IWP-2008-05). Florence: UNICEF Innocenti Research Centre.

2008b. "Kids abroad: Ignore them, abuse them or protect them? Lessons on how to protect children on the move from being exploited," Geneva: Terre des Hommes International Federation.

Dottridge, Mike, and Olivier Feneyrol. 2007. "Action to strengthen indigenous child protection mechanisms in West Africa to prevent migrant children from being subjected to abuse," Geneva: Terre des Hommes.

Dottridge, Mike, and Ann Jordan. 2012. "Children, adolescents and human trafficking: Making sense of a complex problem," Issue Paper 5. Washington, DC: Center for Human Rights \& Humanitarian Law, Washington College of Law, American University.

Edmonds, Eric, and Maheshwor Shrestha. 2009. "Children's work and independent child migration: A critical review," Innocenti Working Papers. United Nations Children's Fund (UNICEF) Innocenti Research Centre.

Elmhirst, Rebecca. 2002. "Daughters and displacement: migration dynamics in an Indonesian transmigration area," Journal of Development Studies 38(5): 143-166.

Engebretsen, Sarah. 2012a. "Baseline and endline findings of Filles Eveillées (Girls Awakened): A pilot program for migrant adolescent girls in domestic service. Cohort 1 (2011-2012), Bobo-Dioulasso," New York: Population Council

2012b. "Using data to see and select the most vulnerable adolescent girls," A Girls First! Publication. New York: Population Council. 
Ennew, Judith, William E. Myers, and Dominique Pierre Plateau. 2005. "Defining child labor as if human rights really matter," in Burns $\mathrm{H}$. Weston (ed.), Child Labor and Human Rights: Making Children Matter. Boulder, CO: Lynne Rienner Publishers, p. 539

Erulkar, Annabel. 2011. "Biruh Tesfa (Bright Future) program for domestic workers and rural-urban migrants in low income urban Ethiopia," presentation at Adolescent Girls' Migration: Advisory Group Meeting, New York, 2 August.

2012. "Preliminary analysis on Ethiopia Youth \& Gender survey (2009-2010)," Unpublished Background Paper for Girls on the Move: Commissioned Research Paper Series. New York: Population Council.

Erulkar, Annabel S., Abebaw Ferede, Woldemariam Girma, and Worku Ambelu. 2012. "Evaluation of 'Biruh Tesfa' (Bright Future) HIV prevention program for vulnerable girls in Ethiopia." Vulnerable Children and Youth Studies iFirst article: 1-22.

Erulkar, Annabel, and Abebaw Ferede. 2009. "Social exclusion and early or unwanted sexual initiation among poor urban females in Ethiopia," International Perspectives on Sexual and Reproductive Health 35(4): 186-193.

Erulkar, Annabel, and James Matheka. 2007. "Adolescence in the Kibera slums of Nairobi, Kenya," Nairobi: Population Council.

Erulkar, Annabel, and Tekle-Ab Mekbib. 2007. "Invisible and vulnerable: Adolescent domestic workers in Addis Ababa, Ethiopia," Vulnerable Children and Youth Studies 2(3): 246-256.

Erulkar, Annabel, Tekle-Ab Mekbib, and Mesfin Tegegne. 2008. "Biruh Tesfa: Creating a "Bright Future" for migrant girls in urban areas of Ethiopia," Transitions to Adulthood Brief. Addis Ababa: Population Council.

_. 2006. "Migration and vulnerability among adolescents in slum areas of Addis Ababa, Ethiopia," Journal of Youth Studies 9(3): 361-374.
Erulkar, Annabel, Belaynesh Semunegus, and Gebeyehu Mekonnen. 2011. "Biruh Tesfa provides domestic workers, orphans, and migrants in urban Ethiopia with social support, HIV education, and skills," Promoting Healthy, Safe, and Productive Transitions to Adulthood Series Brief no. 21. New York: Population Council.

Esara, Pilapa. 2004. "'Women will keep the household': The mediation of work and family by female labor migrants in Bangkok," Critical Asian Studies 36(2): 199-216.

Ezra, Markos, and Gebre-Egziabher Kiros. 2001. "Rural out-migration in the drought prone areas of Ethiopia: A multilevel analysis," International Migration Review 35(3): 749-771.

Fan, C. Cindy, and Ling Li. 2002. "Marriage and migration in transitional China: A field study of Gaozhou, Western Guangdong," Environment and Planning A 34(4): 619-638.

Fekadu, Daniel, Alem Atalay, and Bruno Hägglöf. 2006. "The prevalence of mental health problems in Ethiopian child laborers," Journal of Child Psychology and Psychiatry 47(9): 954-959.

Feng, W., P. Ren, Z. Shaokang, and S. Anan. 2005. "Reproductive health status, knowledge, and access to health care among female migrants in Shanghai, China," Journal of Biosocial Science 37(5): 603-622.

Ferede, Abebaw, and Annabel Erulkar. 2009. "Adolescent girls in urban Ethiopia: Vulnerability and opportunity," Addis Ababa: Population Council.

Flores-Oebanda, Cecilia. 2006. "Addressing vulnerability and exploitation of child domestic workers: An open challenge to end a hidden shame," Florence: UNICEF Innocenti Research Centre.

Ford, Kathleen, and Victoria Hosegood. 2005. "AIDS mortality and the mobility of children in Kwazulu Natal, South Africa," Demography 42(4): 757-768.

Fortson, Chris. 2003. "Women's rights vital for developing world," New Haven: Yale Daily News. 
FTUB (Federation of Trade Unions - Burma) Migrants Section. 2006. "The Mekong challenge - Working day and night: The plight of migrant child workers in Mae Sot, Thailand," Mekong Sub-regional Project to Combat Trafficking in Children and Women. Bangkok: International Labor Organization (ILO).

Gaetano, Arianne. 2008. "Sexuality in diasporic space: Rural-to-urban migrant women negotiating gender and marriage in contemporary China," Gender, Place and Culture 15(6): 629-645.

Gage, A. 2005. "The interrelationship between fosterage, schooling, and children's labor force participation in Ghana," Population Research and Policy Review 24(5): 431-466.

Gebre, Ayalew. 2012. "Migration patterns of children exposed to sexual exploitation in selected zones of Ethiopia," Journal of Children's Services 7(4): 262-274

GHRED. 2011. "Learning centers," Takuapa, Thailand: Grassroots Human Rights Education and Development (GHRED). www.ghre.org/en/programs/ education/323-learning-centers/

Giani, Laura. 2006. "Migration and education: Child migrants in Bangladesh," Sussex Migration Working Paper. Sussex: University of Sussex.

Girma, Woldemariam, and Annabel Erulkar. 2009. "Commercial sex workers in five Ethiopian cities: A baseline survey for USAID targeted HIV prevention program for most-at-risk populations," Addis Ababa: Population Council.

Godoy, Johanna, Bob Tortora, Jan Sonnenschein, and Jake Kendall. 2012. "Payments and money transfer behavior of sub-Saharan Africans," Social Science Research Network (SSRN).

Greene, Alison C. 2001. "Working girls, Cancun style: Reconfiguring private and public domains in practice," Anthropology of Work Review 22(3): 7-13.
Groupe Développement. 2006. "Lives in motion: Mobility, smuggling and trafficking along the Indo-Bangladesh border," Kolkata: Groupe Développement.

Guilmoto, Christophe, and Myriam De Loenzien. 2011. "Young women, migration and vulnerability in Vietnam: Lessons from the 2009 census," Unpublished Background Paper for Girls on the Move: Commissioned Research Paper Series. New York: Population Council.

Guterres, António. 2010. "Protection challenges for persons of concern in urban areas," Forced Migration Review FMR34: 8-9.

Haberland, Nicole, Erica L. Chong, and Hillary J. Bracken. 2004. "A world apart: The disadvantage and social isolation of married adolescent girls," Brief based on the WHO/UNFPA/Population Council Technical Consultation on Married Adolescents. New York: Population Council.

Hallman, Kelly. 2008. "Researching the determinants of vulnerability to HIV among adolescents," IDS Bulletin 39(5): 36-44.

Haour-Knipe, Mary. 2009. "Families, children, migration and AIDS," AIDS Care 21(1): 43-48.

Harpham, Trudy, Emma Grant, and Carlos Rodriguez. 2004. "Mental health and social capital in Cali, Colombia," Social Science and Medicine 58: 2267-2277.

Hashim, Iman M. 2004. "Working with working children: Child labour and the barriers to education in rural North-Eastern Ghana," D.Phil. Thesis, Brighton, UK: University of Sussex.

2005. "Exploring the linkages between children's independent migration and education: Evidence from Ghana," Brighton, UK: Development Research Centre on Migration, Globalisation and Poverty 
2006. "The Positives and Negatives of Children's Independent Migration: Assessing the Evidence and the Debates," Brighton, UK: Development Research Centre on Migration, Globalisation \& Poverty.

2007. "Independent child migration and education in Ghana," Development and Change 38(5): 911-931.

Hashim, Iman, and Dorte Thorsen. 2011. Child Migration in Africa. London: Zed Books.

Hatløy, Anne, and Anne Huser. 2005. "Identification of street children: Characteristics of street children in Bamako and Accra," Oslo: Fafo Research Program on Trafficking and Child Labour.

Heissler, Karin. 2008. "Children's migration for work in Bangladesh: The extra-and intra-household factors that shape 'choice' and 'decision-making', " Childhoods Today 2(1): 1-19.

2009. "'No one comes on their own': The system of child labour migration in Bangladesh," Centre on Migration, Policy and Society (COMPAS), University of Oxford.

Hertrich, Véronique, and Marie Lesclingand. 2012. "Adolescent migration and the 1990s nuptiality transition in Mali," Population Studies 66(2): 147-166.

Hertrich, Véronique, Marie Lesclingand, and Mélanie Jacquemin. 2012. "Girls' labour Migration in rural Mali. Patterns, trends and influence on marriage," Unpublished Background Paper for Girls on the Move: Commissioned Research Paper Series. New York: Population Council.

Hosegood, Victoria, and Kathleen Ford. 2003. "The impact of HIV/AIDS on children's living arrangements and migration in rural South Africa," paper presented at the Conference on African Migration in Comparative Perspective, Johannesburg, South Africa, 4-7 June.
Huijsmans, Roy. 2008. "Children working beyond their localities: Lao children working in Thailand," Childhood 15(3): 331-353.

Huong, Pham Quynh. 2007. "Social rotection for internal migrants in Vietnam," in Giang Thangh Long (ed.), Social Issues Under Economic Transformation and Integration in Vietnam. Hanoi: Publishing House of Social Labor, pp. 123-145.

ILO (International Labor Organization). 2001. "Project document: Supporting the time-bound programme on the worst forms of child labour in Tanzania," Geneva: ILO.

2004a. "Child kabour and the urban informal sector in Uganda," Geneva: ILO.

2004b. "Girl child labour in agriculture, domestic work and sexual exploitation: Rapid assessments on the cases of the Philippines, Ghana and Ecuador," Geneva: ILO.

2008. "Reaching out to migrant children: How an NGO helped put a national policy on education into practice," Mekong Sub-regional Project to Combat Trafficking in Children and Women. Bangkok: ILO.

2010. "Decent work for domestic workers," presentation at International Labour Conference, 99th Session. Geneva: ILO.

2011. "Decent work for domestic workers," Manila: ILO.

2012. "Decent work for domestic workers," Geneva:ILO. www.ilo.org/ilc/ILCSessions/ 100thSession/on-the-agenda/decent-work-for-domestic-workers/lang--en/index.htm.

ILO and CP-TING (Project to Prevent Trafficking for Labour Exploitation in China). 2008. "A summary of the spring rain campaign 2007," Beijing: ILO.

IOM (International Organization for Migration). 2011. "Report on adolescent girls and migration," Unpublished Manuscript. Geneva: IOM. 
2012. "Human rights instruments," Geneva: IOM. iom.int/jahia/Jahia/about-migration/ migrationmanagement-foundations/rights-obligations-migrants/human-rights-instruments.

IPEC (International Programme on the Elimination of Child Labour). 2004. "Helping hands or shackled lives? Understanding child domestic labour and responses to it," Geneva: IPEC.

2006. "Emerging good practices on child domestic labour in Kenya,Tanzania, Uganda and Zambia," Dar es Salaam: International Programme on the Elimination of Child Labour (IPEC), International Labour Organization (ILO).

IPUMS. 2012. "Integrated public use microdata series, international: Census microdata for social and economic research," https://international.ipums.org/ international/

Jacquemin, Mélanie. 2012. "Petites Bonnes" D’Abidjan: Sociologie Des Filles En Service Domestique. Paris: L'Harmattan.

Jampaklay, Aree. 2006. "How does leaving home affect marital timing? An event-history analysis of migration and marriage in Nang Rong, Thailand," Demography 43(4): 711-725.

Kabeer, Naila, Geetha Nambissan, and Ramya Subrahmanian, eds. 2003. Child Labour and the Right to Education in South Asia: Needs Versus Rights? New Delhi: SAGE Publications.

Kara, Siddharth. 2009. Sex Trafficking: Inside the Business of Modern Slavery. New York: Columbia University Press.

Keo, Mondul. 2011. "Hundreds faint in garment factory," Radio Free Asia, August 25. www.rfa.org/english/news/cambodia/faintings-08252011182914.html.

Khair, Sumaiya. 2005. "Voluntary autonomous child migration: Perspectives from Bangladesh," presentation at Children and Youth in Emerging and Transforming Societies, Oslo, 3 July.
Khatana, Virendar. 2010. "Migration of tribal women: Its socioeconomic effects - An in-depth study of Chhatisgarh, Jharkhand, M.P and Orissa," New Delhi: Government of India.

Kifle, Abiy. 2002. "Ethiopia: Child domestic workers in Addis Ababa. A rapid assessment," Geneva: International Programme on the Elimination of Child Labour (IPEC) / ILO.

Klocker, Natascha. 2008. "A participatory, action-oriented and youth-led investigation into child domestic work in Iringa, Tanzania," Thesis (PhD), The University of New South Wales.

Kojima, Yu. 2011. "Migrant women and their vulnerability in the trafficking-migration continuum: Evidence from Asia," In Transnational Migration and Human Security, Berlin: Springer-Verlag, pp. 147-158.

Koning, Juliette. 2005. "The impossible return? The post-migration narratives of young women in rural Java," Asian Journal of Social Science 33(2): 165-185.

Kusakabe, Kyoko, and Ruth Pearson. 2010. "Transborder migration, social reproduction and economic development: A case study of Burmese women workers in Thailand," International Migration 48 (6): 13-43.

Kwankye, Stephen, John Anarfi, Cynthia Addoquaye Tagoe, and Adriana Castaldo. 2007. "Coping strategies of independent child migrants from Northern Ghana to Southern Cities," Sussex, UK: Development Research Centre on Migration, Globalisation and Poverty.

2009. "Independent North-South child migration in Ghana: The decision making process," Working Paper T-29. Sussex, UK: Development Research Centre on Migration, Globalisation and Poverty.

Leinaweaver, Jessaca B. 2007. "Choosing to move: Child agency on Peru's margins," Childhood 14(3): 375-392. 
Liang, Zai, Lin Guo, and Charles Chengrong Duan. 2008. "Migration and the well-being of children in China," Yale China Health Journal 5(1): 25-46.

Limanowska, Barbara. 2005. "Trafficking in Human Beings in South Eastern Europe," Sarajevo: United Nations Development Programme (UNDP).

Lin, Angel, and Avin Tong. 2008. "Mobile cultures of migrant workers in Southern China: Informal literacies in the negotiation of (new) social relations of the new working women," Knowledge, Technology, and Policy 21: 73-81.

Lloyd, Cynthia B. 2009. "New lessons: The power of educating adolescent girls," A Girls Count Report on Adolescent Girls. New York, NY: Population Council.

2012. "Priorities for adolescent girls' education," A Girls First! Publication. New York: Population Council.

Lloyd, Cynthia B., Zeba A. Sathar, Judith A. Diers, Minhaj ul Haque, Monica Grant, Azeema Faizunnissa, and Munawar Sultana. 2002. "Adolescents and Youth in Pakistan 2001-02: A nationally representative survey," New York: Population Council.

Lu, Yao, and Donald J. Treiman. 2007. "Health selectivity of migration: A longitudinal analysis of health and internal migration in Indonesia," paper presented at the Population Association of America (PAA) Annual Conference, New York, 29-31 March.

Lucas, Robert E. B. 1997. "Internal migration in developing countries," in Mark Rosenzweig and Oded Stark (eds.) Handbook of Population and Family Economics, Amsterdam: Elsevier, pp. 721-798.

Lundberg, Mattias, and Alice Wuermli. 2012. "Children and youth in crisis: Protecting and promoting human development in times of economic shocks," Washington, DC: World Bank.

Madhavan, Sangeetha. 2004. "Fosterage patterns in the age of AIDS: Continuity and change," Social Science \& Medicine 58(7): 1443-1454.
Matsuo, Ayaka, and Jonathan Blagbrough. 2006. "Child domestic labour in South-East and East Asia: Emerging practices to combat it," Bangkok: International Labor Organization (ILO).

Mberu, Blessing Uchenna, and Michael J. White. 2011. "Internal migration and health: Premarital sexual initiation in Nigeria," Social Science \& Medicine 72(8): 1284-1293.

McDonald, Peter, Iwu Dwisetyani Utomo, Anna Reimondos, Ariane Utomo, Terry Hull, and Gavin Jones. 2010. "Human capital outcomes of young migrants to Greater Jakarta," paper presented at the International Seminar on Youth Migration and Transition to Adulthood in Developing Countries: IUSSP Scientific Panel, Rio de Janeiro, 8-10 December.

Migration DRC. 2009. "Making migration work for development," Brighton, UK: Development Research Centre on Migration, Globalisation and Poverty: Sussex Center for Migration Research.

Miles, Miranda. 1999. "Working in the city: The case of migrant women in Swaziland's domestic service sector," in Janet Henshall Momsen (ed.), Gender, Migration and Domestic Service, London and New York: Routledge, pp. 191-206.

Mills, Mary Beth. 2005. "Engendering discourses of displacement," Ethnography 6(3): 385-419.

Miske, Shirley J. 2008. "Learning from girls' education as an organizational priority: A review of UNICEF evaluations and studies, 2000-2005," New York: United Nations Children's Fund.

Mitra, Arup, and Mayumi Murayama. 2009. "Rural to urban migration: A district-level analysis for India," International Journal of Migration, Health and Social Care 5(2): 35-52.

Montgomery, Mark R. 2009a. "Urban poverty and health in developing countries," Population Bulletin 64 (2). 
2009b. "Urban health in low- and middle-income countries," in Roger Detels, Robert Beaglehole, Mary Ann Lansang, and Martin Gulliford (eds.) Oxford Textbook of Public Health. Oxford, UK: Oxford University Press, pp. 1376-1394.

Montgomery, Mark, Deborah Balk, Zhen Liu, and Susana Adamo. 2012. "Urban migrant girls: Quantitative findings from developing countries," Unpublished Background Paper for Girls on the Move: Commissioned Research Paper Series. New York: Population Council.

Moser, Caroline O. N. 2006. "Asset-based approaches to poverty reduction in a globalized context," Global Economy and Development Working Paper. Washington, DC: The Brookings Institution.

Mou, Jin, Jinquan Cheng, Sian M Griffiths, Samuel Y. S Wong, Sheila Hillier, and Dan Zhang. 2011. "Internal migration and depressive symptoms among migrant factory workers in Shenzhen, China," Journal of Community Psychology 39(2): 212-230.

Murison, Sarah. 2005. "Phase II thematic evaluation: Migration and development. Evaluation of DFID development assistance: Gender equality and women's empowerment," Glasgow: UK Department for International Development (DFID).

Murphy, Laura L., and Alexandra E. Priebe. 2011. "My co-wife can borrow my mobile phone!" Gender, Technology and Development 15(1): 1-23.

Murphy, Rachel. 2008. "The impact of socio-cultural norms on women's experiences of migration and the implications for development," paper presented at the Social Science Research Council (SSRC) Conference on Migration and Development: Future Directions for Research and Policy. 1 March.

Naved, Ruchira T., Margaret Newby, and Sajeda Amin. 2001. "The effects of migration and work on marriage of female garment workers in Bangladesh," International Journal of Population Geography 7(2): 91-104.
Nieuwenhuys, Olga. 1995. "The domestic economy and the exploitation of children's work: The case of Kerala," International Journal of Children's Rights 3(2): 213-225.

Nimol, Tep, and Vincent Maclsaac. 2011. "Fainting factory told to act," The Phnom Penh Post, September 1. www.phenompenhpost.com.

Nishigaya, Kasumi. 2002. "Female garment factory workers in Cambodia: Migration, sex work and HIV/ AIDS," Women \& Health 35(4): 27-42.

Noriega, José.Ángel.Vera. 2009. “Depresión, ansiedad y estrés en niños y niñas jornaleros agrícolas migrantes," Psico 40(30): 9.

O'Connell Davidson, Julia, and Caitlin Farrow. 2007. "Child migration and the construction of vulnerability," Save the Children, Sweden.

Orme, Julie, and Michael M.O. Seipel. 2007. "Survival strategies of street children in Ghana: A qualitative study," International Social Work 50(4): 489-499.

Oyaide, Omolara Dakore. 2000. "Child domestic labour in Lusaka: A gender perspective. The case of Kamwala, Kabwata, Libala, Chilenje, Woodlands Extension, Nyumba-Yanga," Lusaka: University of Zambia.

Palmary, Ingrid. 2007. "Children crossing borders: Report on unaccompanied minors who have travelled to South Africa," London: Save the Children, UK.

Panel on Urban Population Dynamics. 2003. Cities Transformed: Demographic Change and Its Implications in the Developing World. Eds. Mark R. Montgomery, Richard Stren, Barney Cohen, and Holly E. Reed. Washington, DC: National Academies Press.

Pearson, Elaine. 2006. "The Mekong challenge - Underpaid, overworked and overlooked: The realities of young migrant workers in Thailand," Bangkok: IPEC/ ILO. 
Petrozziello, Allison. 2012. "Haitian adolescent migrant girls' experiences: Quotes and qualitative analysis from a small sample in Elías Piña, Dominican Republic," Unpublished Background Paper for Girls on the Move: Commissioned Research Paper Series. New York: Population Council.

Phouxay, Kabmanivanh, and Aina Tollefsen. 2011. "Rural-urban migration, economic transition, and status of female industrial workers in Lao PDR," Population, Space and Place 17: 421-434.

Pilon, Marc. 2003. "Foster care and schooling in West Africa: The state of knowledge," UNESCO 2003 EFA Monitoring Report. UN Educational, Scientific and Cultural Organization (UNESCO).

Pine, Adrienne. 2009. "Tu eres gallo... pero la de los huevos soy yo," Trabajo y Género en las Maquiladoras 55: $63-75$.

Porter, Gina. 2010. "Transport planning in subSaharan Africa III," Progress in Development Studies 10(2):169-180.

PPA. 2012. "Bahay silungan," Philippine Ports Authority (PPA) Gender and Development (GAD) Focal Point. www.ppa.com.ph/ppa\%20web/t/GADweb/gad1bhyslng.htm.

Punch, Samantha. 2002. "Youth transitions and interdependent adult-child relations in rural Bolivia," Journal of Rural Studies 18(2): 123-133.

Puri, Mahesh C., and Joanna Busza. 2004. "In forests and factories: Sexual behavior among young migrant workers in Nepal," Culture, Health \& Sexuality 6(2): 145-158.

Rao, Nitya. 2011. "Respect, status and domestic work: Female migrants at home and work," European Journal of Development Research. 23(5): 758-773.

Ray, Manabendranath, and Asha N. Iyer. 2006. "Abuse among child domestic workers: A research study in West Bengal," Calcutta: Save the Children, Calcutta.
Reale, Daniela. 2008. "Away from home: Protecting and supporting children on the move," London: Save the Children, UK.

Richter, Linda M., Shane A. Norris, Tanya M. Swart, and Carren Ginsburg. 2006. "In-migration and living conditions of young adolescents in greater Johannesburg, South Africa," Social Dynamics 32(1): 195-216.

Robin, Nelly, and Mandiogou Ndiaye. 2012. "Adolescent girls and mobility in West Africa: From migration to trafficking..." Unpublished Background Paper for Girls on the Move: Commissioned Research Paper Series. New York: Population Council.

Rodas, Aracely Martinez. 2012. "Understanding Migration Experiences and Aspirations of Adolescent Girls in the Abriendo Oportunidades Program," Unpublished Background Paper for Girls on the Move: Commissioned Research Paper Series. New York: Population Council.

Rokicki, Slawa. 2011. "Residential Mobility in Accra, Ghana," Unpublished Background Paper for Girls on the Move: Commissioned Research Paper Series.

New York: Population Council.

Room to Read. 2012. "Room to Read - Girls' Education," San Francisco: Room to Read. www.roomtoread.org/page. aspx? pid $=465$

Roy, Nikhil Chandra, Thomas T. Kane, and Barkat-e Khuda. 2001. "Socioeconomic and health implications of adult deaths in families of rural Bangladesh," Journal of Health, Population and Nutrition 19(4): 291-300.

Rushing, Rosanne. 2006. "Migration and sexual exploitation in Vietnam," Asian and Pacific Migration Journal 15(4): 471-494.

Rwehumbiza, Annagrace, and Richard Mabala. 2011. "Through spike and spine, with family in the heart and dreams to accomplish: Stories of migrating adolescent girls' in Tanzania," Unpublished Background Paper for Girls on the Move: Commissioned Research Paper Series. New York: Population Council. 
Santhya, K.G., and Annabel Erulkar. 2011. "Supporting married girls: Calling attention to a neglected group," Transitions to Adulthood Brief No. 3. New York: Population Council.

Santhya, K.G., Nicole Haberland, and Arup Das. 2008. "Empowering married young women and improving their sexual and reproductive health: Effects of the first-time parents project," New Delhi: Population Council.

Save the Children. 2006. "Community-based initiatives against trafficking in children in the Mekong Sub-region (2003 - 2006). Project Completion Report," London: Save the Children, UK.

2007. "Safe migration channel for children on the move in China: An example of good practice in the cross-border project against trafficking and exploitation of migrant and vulnerable children in the Mekong Sub-Region," Bangkok: Save the Children.

Save the Children, UK. 2006. "Visitors from Zimbabwe: A preliminary study outlining the risks and vulnerabilities facing Zimbabwean children who have crossed illegally into Mozambique," London: Save the Children, UK.

Serra, Renata. 2009. "Child fostering in Africa: When labor and schooling motives may coexist," Journal of Development Economics 88(1): 157-170.

Sewell-Menon, Jessica, Judith Bruce, Karen Austrian, Raven Brown, Jennifer Catino, Alejandra Colom, Angel Del Valle, et al. 2012. "The cost of reaching the most disadvantaged girls: Programmatic evidence from Egypt, Ethiopia, Guatemala, Kenya, South Africa, and Uganda," New York: Population Council.

Shanthi, Krishnaraj. 2006. "Female labour migration in India: Insights from NSSO data," Working Paper 4/2006. Chennai: Madras School of Economics.

Siddiqi, Anooradha. 2012. "Missing the emergency: Shifting the paradigm for relief to adolescent girls," Washington, DC: Coalition for Adolescent Girls.
Simkhada, Padam. 2008. "Life histories and survival strategies amongst sexually trafficked girls in Nepal," Children \& Society 22(3): 235-248.

Skeels, Anna, and Monika Sandvik-Nylund. 2012. "Participation of adolescents in protection: Dividends for all," Forced Migration Review 40: 9-10.

Stark, Oded, and David E. Bloom. 1985. "The new economics of labor migration," The American Economic Review 75(2): 173-178.

SUMAPI. 2012. "Samahan at Ugnayan Ng Mga Manggagawang Pantahanan Sa Pilipinas (SUMAPI) or the national linkage association of domestic workers in the Philippine," sumapi.weebly.com/.

Taylor, Alice. 2011. "Women and the city: Examining the gender impact of violence and urbanization - a comparative study of Brazil, Cambodia, Ethiopia, Liberia and Nepal," Johannesburg: Actionaid.

Temin, Miriam, and Ruth Levine. 2009. "Start with a girl: A new agenda for global health," A Girls Count Report on Adolescent Girls. Washington, DC: Center for Global Development.

Terre des Hommes. 2003. "Les filles domestiques au Burkina Faso: 'Traite ou migration'?" Ouagadougou: Terre des Hommes.

2010. "Saly, grande soeur," Ouagadougou:

Terre des Hommes.

Thi, N. 2008. "Migration of youth to Ho Chi Minh City, Vietnam: Determinants of mobility and adjustment experiences," D.Phil. Thesis, University of Adelaide.

Thorsen, Dorte. 2005. "Child migrants in transit strategies to become adult in rural Burkina Faso," paper presented at Children and Youth in Emerging and Transforming Societies, Oslo, 3 July.

Tirpude College of Social Work. 2004. "A research study on migrant tribal women girls in ten cities: $A$ study of their socio-cultural and economic reference to social intervention," New Delhi: Government of India. 
Tsikata, Dzodzi. 2009. "Domestic work and domestic workers in Ghana: An overview of the legal regime and practice," Geneva: International Labour Organization (ILO).

2011. "Employment agencies and the regulation of domestic workers in Ghana: Institutionalizing informality?" Canadian Journal of Women and the Law 23(1): 213-233.

UN (United Nations). 2009. "The right of the child to be heard. General comment 12," New York: United Nations Committee on the Rights of the Child.

UNDESA. 2012. "World urbanization prospects: 2011 revision highlights," New York: United Nations Department of Economic and Social Affairs (UNDESA), Population Division.

UNESCO (United Nations Educational, Scientific and Cultural Organization). 2008. "People on the move: Handbook of selected terms and concepts," The Hague: UNESCO.

UNFPA (United Nations Population Fund). 2006. "Moving young: State of the world population 2006 youth supplement," New York: UNFPA.

UN-Habitat (United Nations Human Settlements Programme). 2010. "State of the world's cities 2010/2011: Cities for all: Bridging the urban divide," Nairobi: UN-Habitat.

UNICEF (United Nations Children's Fund). 2006a. "Background paper on child trafficking in Central and Eastern Europe / Commonwealth of independent states," New York: UNICEF.

2006b. "Excluded and invisible: The state of the world's children 2006," New York: UNICEF.

2009. "Promoting quality education for orphans and vulnerable children: A sourcebook of programme experiences in Eastern and Southern Africa," New York: UNICEF.
2010. "Progress for children: Achieving the MDGs with equity," New York: UNICEF.

2011. "Child protection from violence, exploitation and abuse," New York: UNICEF. www.unicef. org/protection/57929_58005.html.

UNODC (United Nations Office on Drugs and Crime). 2009. "Global report on trafficking in persons," Vienna: United Nations Office on Drugs and Crime (UNODC).

UN Women. 2011. "Progress of the world's women: In pursuit of justice," New York: UN Women.

Van Blerk, Lorraine. 2008. "Poverty, migration and sex work: Youth transitions in Ethiopia," Area 40(2): 245-253.

2011. "Negotiating boundaries: The sex work identities of 'bar girls' in Nazareth, Ethiopia," Gender, Place and Culture 18(2): 217-233.

Van Blerk, Lorraine, and Nicola Ansell. 2006. "Children's experiences of migration: Moving in the wake of AIDS in Southern Africa," Environment and Planning D: Society and Space 24(3): 449-471.

Waddington, Hugh, and Rachel Sabates-Wheeler. 2003. "How does poverty affect migration choice? A review of literature," University of Sussex: Development Research Centre on Migration, Globalisation and Poverty.

Weiner, Adam. 2011. "Assessing equity of access in programs for young people," Transitions to Adulthood Brief No. 28. New York: Population Council.

West, Andy. 2008. "Children on the move in SouthEast Asia: Why child protection systems are needed," London: Save the Children, UK.

Whitehead, Ann, and Iman M. Hashim. 2005. "Children and migration. Background paper for DFID migration team," London: UK Department for International Development (DFID). 
Whitehead, Ann, Iman M. Hashim, and Vegard Iversen. 2005. "Child migration, child agency and intergenerational relations in Africa and South Asia," Sussex, UK: Development Research Centre on Migration, Globalisation and Poverty (Migration DRC).

WHO. 2009. "WHO multi-country study on women's health and domestic violence against women, unpublished sub-analysis," Geneva: Department of Reproductive Health and Research, World Health Organization (WHO).

Workneh, Hiwot. 2008. "An assessment of the problems of internal trafficking on adolescent girls: The case of 'Arada' sub-city of Shashemene Town, Oromia Regional State," Addis Ababa University.

World Bank. 2012. "Information and communications for development 2012: Maximizing mobile," Washington, DC: World Bank.

World Education. 2011. "Pre-industry Life Skills Programme (PILS) final report," Boston: World Education, Inc.

Xu, Su, Jia Cheng, Zhuang Chanjuan, Zhan Shaokang, and Erik Blas. 2011. "Dedicated delivery centre for migrants in Minhang District, Shanghai: Intervention on the social determinants of health and equity in pregnancy outcome for internal migrants in Shanghai, China," Geneva: World Health Organization, pp. 49-62.

Yang, Ke. 2008. "A preliminary study on the use of mobile phones amongst migrant workers in Beijing," Knowledge, Technology, and Policy 21: 65-72.

Yaqub, Shahin. 2009. "Independent child migrants in developing countries: Unexplored links in migration and development," Florence, Italy: UNICEF Innocenti Research Centre.

Yntiso, Gebre, Ayalew Gebre, Rahel Shiferaw, and Hiwot Workneh. 2009. "The Bamboo Project: Resilience in children exposed to sexual abuse and sexual exploitation in Merkato, Addis Ababa, Ethiopia," Addis Ababa: Oak Foundation.
Yoddumnern-Attig, Bencha, Chanya Sethaput, Supanee Pluemcharoen, and Jirakit Boonchaiwattana. 2007. "Adolescent migrants in the Greater Mekong Sub-region: Are they equipped to protect themselves against sexual and reproductive health risks?" Salaya, Thailand: Institute for Population and Social Research, Mahidol University.

Young, Lorraine. 2004. "Journeys to the street: The complex migration geographies of Ugandan street children," Geoforum 35(4): 471-488.

Zavier, A.J. Francis, Shireen J. Jejeebhoy, and Rajib Acharya. 2012. "Exploring associations between migration and vulnerability among adolescent girls: Evidence from India," Unpublished Background Paper for Girls on the Move: Commissioned Research Paper Series. New York: Population Council. 


\section{ADVISORS}

The following individuals served on an expert Advisory Group for Girls on the Move. They brought a wealth of experience and knowledge to this report and its recommendations and continue their work to catalyze action on behalf of migrant adolescent girls around the world.

\section{Taina Bien-Aimé}

Taina Bien-Aimé was formerly the Executive Director of Equality Now, an international human rights advocacy organization that works to end violence and discrimination against women and girls. With offices in New York, Nairobi and London, issues of concern to Equality Now include sexual violence, discrimination in law, trafficking in women, female genital mutilation and other forms of human rights abuses affecting women and girls. Ms. Bien-Aimé holds a Juris Doctor from New York University School of Law (1991) and a Licence in Political Science from the University of Geneva/Graduate School of International Studies, Switzerland (1982). Prior to attending law school, she was a Program Officer for the African-American Institute, an international organization that provided education and training for African graduate students in the United States. Ms. Bien-Aimé practiced international corporate law at the Wall Street firm Cleary, Gottlieb, Steen \& Hamilton and was Director of Business Affairs/Film Acquisitions at Home Box Office.

\section{Mike Dottridge}

Mike Dottridge is a national of the United Kingdom. He spent 25 years working in London-based human rights non-governmental organizations (Amnesty International, where his focus was on sub-Saharan Africa, followed by Anti-Slavery International). For the past decade he has worked independently as a consultant on human rights and child rights issues. He works in English, French and Spanish and his work takes him to many parts of the world.

Since 1995, Mike's work has focused on various forms of exploitation, how to protect the people involved and how to prevent exploitation from occurring in the first place, whether it concerns child labour, the commercial sexual exploitation of children, servitude, forced labour or trafficking in human beings. While director of Anti-Slavery International, the organization put a particular focus on child domestic workers (boys as well as girls).

\section{Annabel Erulkar}

A social scientist with over 20 years' experience developing and managing research and programs related to adolescents, HIV and AIDS, reproductive health, and gender in sub-Saharan Africa. Annabel Erulkar is currently heading a Population Council country office and overseeing large projects related to married adolescents, domestic workers, and male involvement. She has established Population Council offices in Nigeria and Ethiopia, as well as mobilized resources to expand activities in Kenya and Ethiopia.

Erulkar has authored over 60 reports and journal articles related to adolescence in sub-Saharan Africa, including schooling, livelihoods, gender-based violence, early marriage, sexual behavior, reproductive health, and "youth-friendly" services. Prior to joining the Council in 1995, she was responsible for research and management information systems at Family Planning Association of Kenya, the largest nongovernmental family planning organization in the country. As an expatriate American/Canadian, she has lived in Africa for over 20 years - in Kenya, Ghana, and Ethiopia-and coordinated large adolescent projects in Ethiopia, Ghana, Kenya, Nigeria, South Africa, Tanzania, Uganda and Zimbabwe.

Erulkar holds an M.Sc. in population sciences from Harvard University and a Ph.D. in social statistics from University of Southampton, United Kingdom. 


\section{Michael Gibbons}

Michael Gibbons has worked in basic education, community development and social justice since the mid 1970s in Asia, Africa, Latin America and lowincome areas of the USA. He specializes in basic and nonformal education, child development, adult learning processes, training of educators and organizational learning. He holds a Ph.D. from the Fielding Institute in human and organizational development, with a focus on organizational learning processes within educational programs. He is particularly interested in the role learning plays in personal development and social transformation.

Currently, Mr. Gibbons serves as Director of Children's Rights and Education Programs at Wellspring Advisors LLC, a donor advising company based in Washington DC. Mr. Gibbons teaches courses in international training, education and development at The American University and George Washington University. He has served as associate director at Banyan Tree Foundation, country director and education advisor for Save the Children.

\section{Margaret Greene}

Margaret Greene has worked for nearly twenty years on the social and cultural determinants of health, adolescent reproductive health, development policy and gender. She is widely known for her research and advocacy on the conditions faced by girls in poor countries and on engaging men and boys for gender equality.

She now heads up GreeneWorks, a consulting group working to promote social change for health and development. She is chair of the board of PromundoUS, and has served in leadership roles on the boards of Advocates for Youth, and the Willows Foundation, an NGO that provides reproductive health services in Turkey, Ghana and Pakistan. Dr. Greene received MA and $\mathrm{PhD}$ degrees in Demography from the University of Pennsylvania, and a BA in linguistics from Yale University.

\section{Véronique Hertrich}

Véronique Hertrich heads the methodological unit on developing countries (Pole Suds) at the French Institute for Population Studies (INED). Her main areas of research are related to population and family changes in sub-Saharan Africa from a gendered perspective: nuptiality transition, polygamy, conjugality and parenthood, transition to adulthood and youth migration in Africa. She is also interested in methodological issues, especially in terms of data quality and comparability, combination of qualitative and quantitative data, and dissemination projects. She is the scientific head of the longitudinal project Slam in rural Mali, based on a follow-up survey which has been running for 25 years. She is an elected member of the International Union for the Scientific Study of Population (IUSSP)

Council and was Coordinator of the 2005 International Population Conference (Tours, France).

Hertrich holds bachelor degrees in sociology and anthropology from the University of Strasbourg, France and a Ph.D. in demography from Pantheon-Sorbonne University in Paris.

\section{Michele Klein-Solomon}

Michele Klein-Solomon is the Permanent Observer to the UN for the International Organization for Migration. Ms. Klein-Solomon began her career at the International Organization for Migration (IOM) in 2000, and from 2006 - 2010 served as the Director of the Migration Policy and Research Department at the Geneva-based agency's headquarters. From 2002 to 2006, she was that Department's Deputy Director, and from 2001 to 2002, she served as the Senior Policy Adviser in the Migration Policy and Research Programme. 
Apart from her work with IOM, for two years beginning in 1998, she served as an Attorney-Adviser in the Office of the Legal Adviser at the U.S. Department of State from 1989 - 1999, and held several positions there. These include serving as the principal refugee and migration lawyer in the Office of the Assistant Legal Adviser for Management (1996 - 1998), and as one of the lawyers addressing U.S. contributions to the UN and peacekeeping activities (1998 - 1999). She received numerous awards and honors, including the Federal Bar Association's Younger Lawyer of the Year in 1994. In 1988, Ms. Klein-Solomon received her Juris Doctor from the Georgetown University Law Centre and a masters degree in international relations from the Georgetown University School of Foreign Service.

\section{Anju Malhotra}

Anju Malhotra is the Principal Advisor on Gender and Rights at UNICEF. She was formerly the Vice President of Research, Innovation and Impact at the International Center for Research on Women (ICRW). An intellectual leader in the field of population, gender and development, Dr. Malhotra has led research teams of demographers, economists, and health experts on a broad range of issues, including reproductive health, child marriage, migration, economic empowerment, and girls' education. She continues a long term research focus on the social and economic drivers of child marriage and early childbearing in South Asia and Africa.

Prior to joining ICRW, Dr. Malhotra was assistant professor at the University of Maryland, and an NICHD post-doctoral fellow at the University of North Carolina. She holds a Ph.D. and Masters in Sociology and Demography from the University of Michigan, and a B.A. from Cornell University. The author of numerous articles and an edited volume, Dr. Malhotra serves on a wide range of committees, panels, workshops, seminars, and review boards. She provides expert insight to a variety of media outlets, including USA Today, and the National Geographic.

\section{Véronique Mathieu}

Véronique Mathieu has been a member of European Parliament and the French delegation in the European People's Party since 1999. From 1999 to 2001 she served on the Committee on Petitions where she supported several proposed resolutions against female mutilation and forced marriages. She is currently a member of the Committees on Civil Liberties, Justice and Home Affairs and the Coordinator of Special Committee on Organized Crime, Corruption and Money Laundering. She is also a member of the delegation for relations with Southeast Asian countries and Vice-Chair of the Working Group on Population and Development (EPWG).

Mathieu initiated the Written Declaration on the establishment of an International Day for Girls, which the European Parliament adopted before the UN General Assembly in December 2011. On the occasion of the first International Day of the Girl Child on 11 October 2012, she launched a policy roundtable and hosted a series of initiatives including a photo exhibition on child brides to remind her peers and top EU-leaders that "too often, we forget about the painful realities that young girls, who are doubly vulnerable through their double status of children and of women, are going through."

\section{Ann Whitehead}

Ann Whitehead is emeritus professor of anthropology in the Department of Anthropology and School of Global Studies at the University of Sussex. Her research, writing, teaching and policy interventions have been mainly within the fields of gender, poverty, and development, particularly within rural Africa, although extending more widely. In the last decade Whitehead has been working extensively on migration issues, initially within the Migration, Globalisation and 
Poverty Development Research Center (DRC) at the University of Sussex. This work focuses on internal and regional (especially cross-border) migration in the majority world, on links between poverty, livelihoods and migration, on independent child migration (many of whom are adolescent girls), and on gender and generational issues in migration. Whitehead also specializes in the collection and interpretation of qualitative and life history data. She has also acted as adviser on gender, poverty and development for the World Bank, UNCTAD and UNRISD.

\section{Yu Zhu}

Yu Zhu is a Professor in the School of Geography and Director of the Center for Population and Development Research at Fujian Normal University in China. $\mathrm{He}$ is also Chair of the International Union for the Scientific Study of Population (IUSSP)'s Scientific Panel on the Impact of Internal Migration and Urbanization in Developing Countries, Chair of Asia and Pacific Migration Research Network, member of the International Advisory Board of UN Habitat's State of World's Cities Report (2012/2013, 2010/2011), Member of the Editorial Board of the International Migration Review (IMR), Council Member of China Population Association (CPA), Member of CPA's Committee on Migration and Urbanization, and Deputy Director of the Committee on Population Geography, the Geographical Society of China. He received his Ph.D. from Demography Program at the Australian National University, and his research interests straddle the two disciplines of demography and human geography, focusing on issues relating to migration and urbanization. 


\section{ABOUT THE AUTHORS}

\section{Miriam Temin}

Miriam Temin is a public health and social policy expert with 16 years of experience in Africa, the United States, and Europe.

Prior to leading the development of Girls on the Move, she was the co-author of another Girls Count report

Start with a Girl: A New Agenda for Global Health, produced by the Center for Global Development. She has worked with major international organizations on adolescent girls, HIV, sexual and reproductive health, and social protection.

Previously, Temin served as a Senior HIV Policy Advisor at UNICEF Headquarters and a Health Advisor at the UK's Department for International Development (DFID) in Zimbabwe and London. She has also worked with the World Health Organization and various NGOs on gender-based violence and sexual and reproductive health. Temin has a master's degree in population and international health from Harvard University and is author and co-author of several influential reports and peer-reviewed publications.

\section{Mark R. Montgomery}

Mark R. Montgomery is a Professor of Economics at Stony Brook University and a Senior Associate in the Poverty, Gender, and Youth Program at the Population Council in New York. His research centers on empirical models of urban population growth, poverty, and health, with particular attention to the implications of climate-related risks.

From 1999 to 2003, Montgomery served as co-chair of the U.S. National Academy of Sciences Panel on Urban Population Dynamics, and was lead editor of its 2003 report, Cities Transformed: Demographic Change and Its Implications in the Developing World, a comprehensive analysis of the economic, social, and political features of urbanization in poor countries. He has also served as chair of the Scientific Panel on Urbanization of the International Union for the Scientific Study of Population (IUSSP), and was a member of the Roundtable for Urban Living Environment Research (RULER) on urban health metrics and methods, supported by the Rockefeller Foundation.

Montgomery holds a Ph.D. in Economics from the University of Michigan. 


\section{Sarah Engebretsen}

Sarah Engebretsen is an Associate in the Poverty, Gender, and Youth Program at the Population Council. Engebretsen specializes in the development, implementation, and evaluation of targeted, evidence-based programs for marginalized and vulnerable adolescent girls in West Africa. She is responsible for managing adolescent interventions in Francophone and Anglophone West Africa. Engebretsen has served as a technical advisor to build the capacity of UN agencies, government, and grassroots organizations in developing demand-driven programs that are responsive to the empirical evidence on adolescent girls.

Prior to her work at the Population Council, Engebretsen worked on contraceptive research at the HIV Center for Clinical and Behavioral Studies and the Reproductive Health and HIV Research Unit. Engebretsen holds an MPH from Columbia University's Department of Population and Family Health, where she specialized in reproductive, adolescent, and child health and received the department award for academic excellence.

\section{Kathryn M. Barker}

Kathryn M. Barker serves as the Project Coordinator for Girls on the Move in the Poverty, Gender, and Youth program at the Population Council in New York. Prior to joining the Council, Barker worked at the US Agency for International Development (USAID) in India to manage the President's Emergency Plan for AIDS Relief (PEPFAR) program portfolio. Prior to that assignment, she worked at USAID headquarters in Washington, DC in the Bureau for Global Health on service delivery improvement of reproductive health programs. While in graduate school at the University of North Carolina at Chapel Hill, she implemented and evaluated a capacity building program for public health professionals in developing countries. She is the co-author of peer-reviewed publications and reports on public health interventions for international development.

Barker holds a master's degree in public health from the University of North Carolina at Chapel Hill, specializing in global health and capacity building. 



\section{THE GIRLS COUNT SERIES IS AN INITIATIVE OF THE COALITION FOR ADOLESCENT GIRLS.}

www.coalitionforadolescentgirls.org

\section{The Coalition for Adolescent Girls}

The Coalition for Adolescent Girls

(www.coalitionforadolescentgirls.org) includes over 40 leading organizations committed to driving new and improving existing programming, policies, and investments that will promote the rights and opportunities of adolescent girls. The Coalition envisions a world where adolescent girls are able to fully realize their rights, navigate challenges and access opportunities during the transition from childhood to adulthood and beyond. The Coalition for Adolescent Girls is supported by the Nike Foundation and

United Nations Foundation.

\section{UNITED NATIONS}

\section{The United Nations Foundation}

The United Nations Foundation

(www.unfoundation.org), a public charity, was created in 1998 with entrepreneur and philanthropist Ted Turner's historic $\$ 1$ billion gift to support United Nations causes and activities. The United Nations Foundation is an advocate for the United Nations and a platform for connecting people, ideas, and capital to help the United Nations solve global problems, including women's and girls' inequality.

\section{Nike Foundation}

\section{The Nike Foundation}

The Nike Foundation (www.nikefoundation.org) is a non-profit organization dedicated to investing in adolescent girls as the most powerful force for change in the developing world. The work of the Nike Foundation is supported by NIKE, Inc., and by significant investments from the NoVo Foundation. 


\section{The Girls Count Series}

The Girls Count series uses adolescent girl-specific data and analysis to drive meaningful action. Each work explores an uncharted dimension of adolescent girls' lives and sets out concrete tasks for the global community. Together, these actions can put 515 million adolescent girls in the developing world on a path of health, education, and economic powerfor their own well-being and the prosperity of their families, communities, and nations.

The Girls Count series is an initiative of the Coalition for Adolescent Girls. www.coalitionforadolescentgirls.org

\section{Girls on the Move: Adolescent Girls \& Migration in the Developing World}

In Girls on the Move: Adolescent Girls \& Migration in the Developing World, the authors illuminate girls' migration to urban areas in pursuit of work, education, and social opportunities unavailable to them in rural areas. Migrant girls who successfully connect to these opportunities can be powerful agents of change, making them an important group warranting greater policy and programmatic attention.

"This report is another triumph for the Population Council and the Girls Count series. It combines a strong demographic perspective (new analyses of sex- and age-disaggregated data on patterns of internal migration in the developing world) with rich contextual description and practical proposals for building girls' assets before, during, and following their migration to urban settings."

\section{Ruth Dixon-Mueller \\ Consultant in Population and \\ Reproductive Health}

"In our global world, the large proportion of girls who migrate in search of opportunity and not as victims of human trafficking should not surprise us, but it does. Girls on the Move describes their more hopeful story, making a valuable-and thought-provoking - addition to the emerging empirical evidence on adolescent girls."

\section{Mayra Buvinic}

Senior Fellow, United Nations Foundation
"The Girls Count series is a terrific reference and advocacy tool to secure the development and human rights of some of the most disadvantaged, at-risk people on the planet. The newest report, Girls on the Move, is a fine example of clear and strategic thinking based on strong evidence, including new or never-analyzed data. Quotations and stories from individual girls lend power to the analysis. Specialists, and activists in the many sectors that influence each girl's life-her learning, productivity, health, and safety-will find this a most useful and engaging resource."

\section{Adrienne Germain}

President Emerita, International Women's Health Coalition \& Recipient of the 2012 United Nations Population Award 